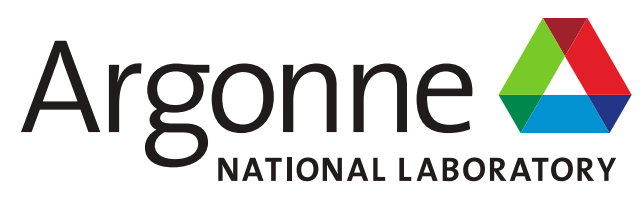

\title{
MITR Low-Enriched Uranium Conversion Fluid- Structure Interaction Preliminary Design Verification
}

Nuclear Science \& Engineering Division 


\section{About Argonne National Laboratory}

Argonne is a U.S. Department of Energy laboratory managed by UChicago Argonne, LLC under contract DE-AC02-06CH1 1357. The Laboratory's main facility is outside Chicago, at 9700 South Cass Avenue, Argonne, Illinois 60439. For information about Argonne and its pioneering science and technology programs, see www.anl.gov.

\section{DOCUMENT AVAILABILITY}

Online Access: U.S. Department of Energy (DOE) reports produced after 1991 and a growing number of pre-1991 documents are available free at OSTI.GOV (http://www.osti.gov/), a service of the U.S. Dept. of Energy's Office of Scientific and Technical Information.

\section{Reports not in digital format may be purchased by the public from the National Technical Information Service (NTIS):}

U.S. Department of Commerce

National Technical Information Service

5301 Shawnee Rd

Alexandria, VA 22312

www.ntis.gov

Phone: (800) 553-NTIS (6847) or (703)

605-6000 Fax: (703) 605-6900

Email: orders@ntis.gov

\section{Reports not in digital format are available to DOE and DOE contractors from the Office of Scientific and Technical Information (OSTI):}

U.S. Department of Energy

Office of Scientific and Technical Information

P.O. Box 62

Oak Ridge, TN 37831-0062

www.osti.gov

Phone: (865) 576-8401

Fax: (865) 576-5728

Email: reports@osti.gov

Disclaimer

\section{Disclaimer}

This report was prepared as an account of work sponsored by an agency of the United States Government. Neither the United States Government nor any agency thereof, nor UChicago Argonne, LLC, nor any of their employees or officers, makes any warranty, express or implied, or assumes any legal liability or responsibility for the accuracy, completeness, or usefulness of any information, apparatus, product, or process disclosed, or represents that its use would not infringe privately owned rights. Reference herein to any specific commercial product, process, or service by trade name, trademark, manufacturer, or otherwise, does not necessarily constitute or imply its endorsement, recommendation, or favoring by the United States Government or any agency thereof. The views and opinions of document authors expressed herein do not necessarily state or reflect those of the United States Government or any agency thereof, Argonne National Laboratory, or UChicago Argonne, LLC. 


\section{MITR Low-Enriched Uranium Conversion Fluid-Structure Interaction Preliminary Design Verification}

prepared by

Guanyi Wang, Cezary Bojanowski, Akshay Dave, David Jaluvka, Erik Wilson Nuclear Science \& Engineering Division, Argonne National Laboratory

Lin-wen $\mathrm{Hu}$

Nuclear Reactor Laboratory, Massachusetts Institute of Technology

July 2021 
(This page left intentionally blank) 


\section{Acronyms and Abbreviations}

CFD

CSM

DOE

FSI

GTPA

HEU

HFIR

HIP

LCO

LEU

LSSS

$\mathrm{M}^{3}$

MIT

MITR

NNSA

U-10Mo

USHPRR computational fluid dynamics

computational structural mechanics

U.S. Department of Energy

fluid-structure interaction

generic test plate assembly

highly enriched uranium with $\geq 20$ weight $\%$ enrichment

High Flux Isotope Reactor, ORNL

hot isostatic pressing

Limiting Conditions for Operation

low-enriched uranium with $<20$ weight $\%$ enrichment

limiting safety system setting

NNSA Office of Material Management and Minimization

Massachusetts Institute of Technology

Massachusetts Institute of Technology Research Reactor

U.S. National Nuclear Security Administration

uranium - 10 weight $\%$ molybdenum alloy fuel being developed as a monolithic metallic alloy fuel

U.S. high-performance research reactor 


\section{Definition of Terms}

\begin{tabular}{ll}
\hline Conservative & $\begin{array}{l}\text { Method, or resulting parameter value, that is not best estimate and } \\
\text { includes uncertainty or margin whether discretionary or due to } \\
\text { conservative assumptions. }\end{array}$ \\
\hline $\begin{array}{l}\text { Conservative } \\
\text { assumption }\end{array}$ & $\begin{array}{l}\text { Parameter value or other consideration technically determined to be } \\
\text { conservative as a consequence of intentional addition of margin or the } \\
\text { use of bounding data or other consideration. }\end{array}$ \\
\hline Fuel core & The uranium-bearing region of each fuel plate. \\
\hline Fission density & The number of nuclear fission events of all isotopes per volume of fuel. \\
\hline Fuel qualification & $\begin{array}{l}\text { The process of designing, conducting, and evaluating experiments to } \\
\text { ensure that the fuel is capable of performing without failure during } \\
\text { reactor operations up to reported performance limits. Fuel qualification } \\
\text { also includes measurements and reporting of fuel properties that can be } \\
\text { used in performance and safety modeling. }\end{array}$ \\
\hline $\begin{array}{l}\text { Irradiation } \\
\text { conditions }\end{array}$ & $\begin{array}{l}\text { Conditions occurring in a reactor during operation at power and that, in } \\
\text { the context of fuel design and qualification, refer to conditions } \\
\text { experienced in reactor driver fuel or fuel testing. }\end{array}$ \\
\hline Licensed power & $\begin{array}{l}\text { The power approved by the regulatory authority up to which the reactor } \\
\text { is licensed to operate. For a reactor without a defined licensed duration, } \\
\text { this term is taken to be the equivalent of approved operating power. }\end{array}$ \\
\hline $\begin{array}{l}\text { Limiting conditions } \\
\text { for operation }\end{array}$ & $\begin{array}{l}\text { Administratively established constraints on equipment and operational } \\
\text { characteristics that shall be adhered to during operation of the facility. } \\
\text { The limiting conditions for operation are the lowest functional capability } \\
\text { or performance level required for safe operation of the facility. }\end{array}$ \\
\hline Nominal & $\begin{array}{l}\text { Value of a parameter under normal operating conditions. } \\
\text { conditions that are reasonably expected to occur up to and including at } \\
\text { the reactor licensed power. These do not include calculation or } \\
\text { measurement uncertainties. }\end{array}$ \\
\hline
\end{tabular}




\section{Executive Summary}

The U.S. National Nuclear Security Administration (NNSA) Office of Material Management and Minimization $\left(\mathrm{M}^{3}\right)$ has developed and is pursuing an integrated approach to address the persistent threat posed by unintentional proliferation of nuclear materials. The NNSA $\mathrm{M}^{3}$ approach reduces the risk of highly enriched uranium (HEU) and plutonium falling into the hands of non-state actors by minimizing the use of and, when possible, eliminating weapons-usable nuclear material around the world. In this geopolitical context, most research and test reactors, both domestic and international, have completed or started a program of conversion from the use of HEU to low-enriched uranium (LEU) as fuel.

Conversion of civilian research reactors from HEU to LEU, and the return of the HEU to the country of origin, are important components of the NNSA non-proliferation program. Worldwide, 71 reactors have been converted to the use of LEU fuel, and an additional 32 have been confirmed to be permanently shut down. The U.S., with 20 reactor conversions, is among the 39 countries on six continents where conversions have occurred. With recent conversions in Ghana and Nigeria, an important milestone was reached in completing conversion of all reactors on the continent of Africa to LEU fuel. Africa thus becomes the third continent to have completed conversion of all HEU reactors to LEU, following Australia and South America.

As part of NNSA's HEU minimization mission, the NNSA M ${ }^{3}$ Conversion Program is collaborating with six U.S. High Performance Research Reactors (USHPRR, including one critical facility, to convert from the use of HEU to LEU fuel. The $\mathrm{M}^{3}$ conversion objectives for the USHPRR are to develop LEU fuelelement designs that will ensure safe reactor operations, as well as maintain the existing experimental performance of each facility. The work is being conducted through many interrelated activities that are being completed by stakeholders across organizations.

A new type of LEU fuel based on an alloy of uranium-10 weight $\%$ molybdenum (U-10Mo) is expected to allow the conversion of those USHPRR requiring higher-density fuels. This very-high-density monolithic fuel is currently undergoing irradiation and post-irradiation testing under a planned and documented fuel qualification program. The Fuel Qualification (FQ) Pillar of the USHPRR Project will document fuel properties and fuel performance data and qualify the fuel for use. The Fuel Fabrication (FF) Pillar is fabricating fuel for ongoing and future irradiation tests, as well as conducting fabrication demonstrations to validate or update preliminary fabrication assumptions. The FF Pillar is also working to develop and install manufacturing capacity for the U-10Mo monolithic fuel.

Within the Reactor Conversion Pillar of the USHPRR Project, four of the USHPRR, including the Massachusetts Institute of Technology Reactor (MITR-II, also referred to as MITR), have progressed through preliminary element design using the proposed monolithic alloy of U-10Mo. Preliminary fuel-element design and safety analyses have been completed for MITR. This work has relied on preliminary data for properties, performance, and fabrication tolerances for the fuel systems that have been produced by the FQ and FF Pillars.

The hydro-mechanical performance of existing MITR HEU fuel elements has proven over the years to be very robust. No structural failures or permanent deformations of the plates have been recorded throughout the decades of operation of MITR-II since 1975. MITR LEU fuel elements have been redesigned (design 19B25) to include 19 fuel plates (four more than in the HEU element). The proposed design of MITR LEU fuel plates has no fins on their surface, and their thickness is reduced from 60 mil ( 80 mil with fins) for HEU plates to 49 mil. Three different fuel-core thicknesses were

MITR Low-Enriched Uranium Conversion Fluid-Structure Interaction Preliminary Design Verification 
designed (F-full, Y-intermediate, T-thin) within the same overall plate thickness. The power of the proposed LEU core is $7 \mathrm{MW}$, which is $1 \mathrm{MW}$ higher than that of the HEU core to maintain equivalent performance for the reactor facility. The primary coolant flow rate has been increased by $20 \%$ as compared to the HEU operating core, from 2,000 gpm to 2,400 gpm.

Fuel plate deflection can be induced during reactor operation by the hydrodynamic pressure differential caused by differences in the gap thickness of surrounding coolant channels, turbulent fluctuations in the flow, or both. In this work, the fluid-structure interaction (FSI) effects have been separated from structural effects induced by irradiation (fuel swelling, creep, thermal expansion, material property change due to irradiation). The pressure-differential-induced deflections have been analyzed for the most limiting fuel plate under the most limiting flow conditions encountered during the use of the first full LEU core with 22 fresh LEU fuel elements and five solid aluminum dummy elements. The most limiting plate within the element, from the FSI perspective, is one of the outermost plates (plates 1 and 19 of "T" type) in the configuration where the end channel faces another end channel of a neighboring fuel element. In this case, the dimension disparity between the nominal channel on one side of the plate of interest and the (combined) two facing each other end channels is the largest, leading to the largest deflections of the plates.

Numerical simulations coupling computational fluid dynamics and computational structural mechanics were performed using STAR-CCM+ (version 14.02) commercial software to predict deflections of the MITR fuel plates due to channel pressure differentials. The numerical models were limited to a single plate and the two surrounding channels. Further full-element FSI analyses considering the influence of the other plates, end fittings, and resulting flow disturbances would be planned at a later stage of the conversion project if the need is confirmed in the future. Nominal as well as conservative flow conditions were used for cases with varying channel dimensions as well as imperfect plate shapes within the fabrication and assembling tolerances.

The analysis shows that the coolant velocity in the two facing end channels (thicker channel) is almost two times higher than that in the nominal-size internal channel. These velocities are below $20 \%$ of Miller's critical velocity calculated for MITR LEU fuel element, and in this flow rate regime, large-scale oscillations of the plates are not expected. Consequently, the pressure differential is expected to be a primary driver of plate deflections.

The deflections predicted for all cases analyzed here are very small, up to $1.10 \%$ of the channel gap thickness for stripe-averaged quantities. For pressure-differential-driven deflections, the plates tend to deflect into the thicker channel, which for the outermost plates (1 and 19), based on the assumed configuration of two elements facing each other with the outer channels, is outward. Thus, the thickness of the inner channels for these two plates is not reduced, and these deflections pose no threat to the cooling of the plates. For the inner plates, maximum deflections were predicted to be up to $0.24 \%$ (in stripe-averaged terms) of the channel gap thickness for the case of a slanted plate between two channels with the highest channel gap thickness disparity allowed by assembly tolerances.

Additional non-uniformity imposed on the plate's shape did not contribute significantly to the increase in the deflections. Various shapes of these non-uniformities with an amplitude that stayed within the tolerances of fabrication (plate flatness) and assembly had a similar effect on these deflections, increasing the maximum deflections by up to $8 \%$. Flow disparities in the core as well as uncertainties in the coolant-system performance account for a possibly $12.35 \%$ higher-than-nominal flow rate. This may lead to a $26 \%$ increase in both stripe-averaged deflection and the local maximum plate deflections.

MITR Low-Enriched Uranium Conversion Fluid-Structure Interaction Preliminary Design Verification 
Although the plate is assumed to be homogeneous and made only of aluminum alloy (AA6061) for most cases, layered cases with separate properties for the fuel core and cladding are also studied. Both the simulation and analytical results indicate that variations in Young's modulus of the fuel core do not significantly affect the plate's deflection, and the error introduced by the homogeneous allaluminum plate assumption is minimal. The expected reduction in Young's modulus of the fuel core due to irradiation is $24.6 \%$ during the first cycle with $22 \mathrm{LEU}$ elements in the core. This reduction is found to have minimal impact on the plate's FSI performance, causing only a $0.6 \%$ decrease in the overall stiffness of the plate.

The highest stresses are expected near the side boundaries at the leading edge. The solid elements in STAR-CCM+ and other solvers may not be able to predict these stresses, owing to the stress singularity. However, shell elements provide converged stresses at these locations. Also, for the flat MITR plates, these stresses can be approximated by doubling the stresses predicted in the middle of the span. For all analyzed cases, the von Mises stresses are predicted to be well below the yield strength of the AA6061.

In summary, all analyzed deflections remain small compared to fabrication tolerances ( 6 mil of plate flatness), and for all cases analyzed, deflection occurs towards the larger channel. Thus, flow-induced plate deflection is not a factor that would be expected to reduce flows in the limiting (i.e., narrow) channels in thermal hydraulics analyses of MITR. 


\section{Table of Contents}

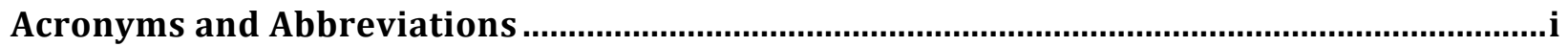

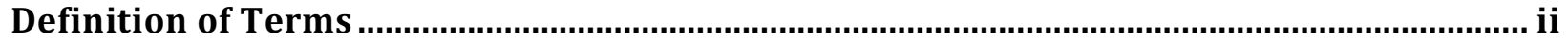

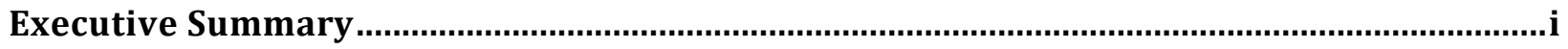

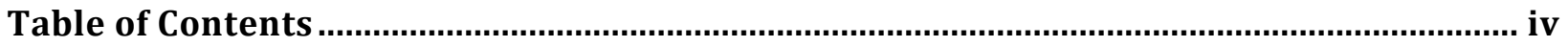

List of Figures

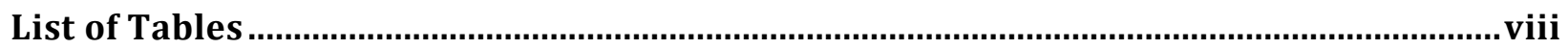

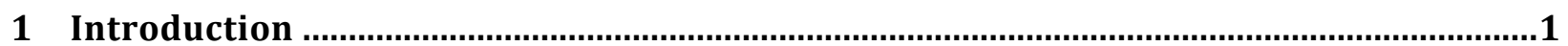

1.1 Massachusetts Institute of Technology Reactor and Fuel Element ............................................ 1

1.2 Literature Review on Fluid-Structure Interaction (FSI) for Thin Fuel Plates ........................... 3

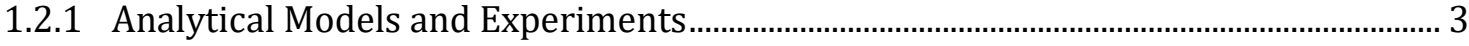

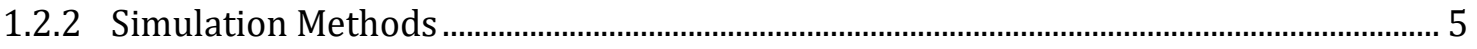

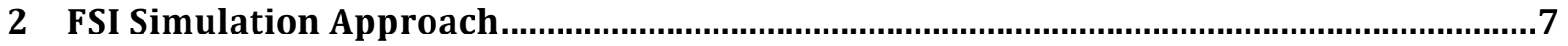

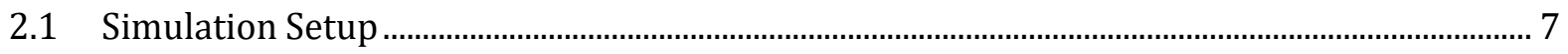

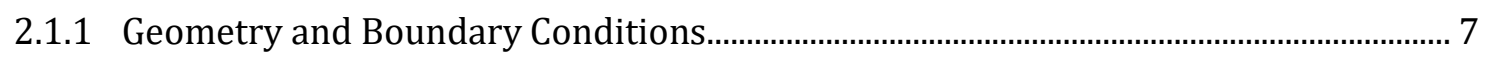

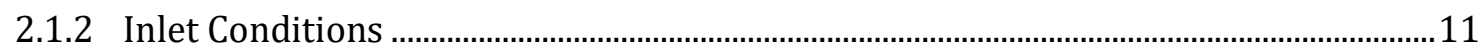

2.1.3 Turbulence Model Selection ......................................................................................................

2.1.4 Fluid Physical Properties....................................................................................................

2.1.5 Solid Properties and Model..................................................................................................17

2.2 Simulation Matrix .......................................................................................................................

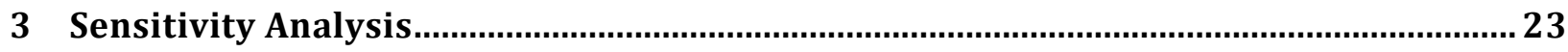

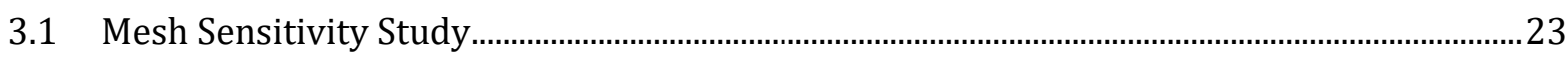

3.2 Time Step and Run Time Sensitivity …….................................................................................25

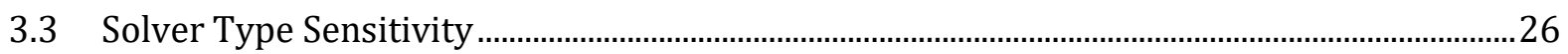

3.4 Sensitivity of the Model to Boundary Condition Type.......................................................................28

3.5 Turbulence Model Effect......................................................................................................................... 30

3.6 Sensitivity of FSI results to Coolant Properties ................................................................................. 30

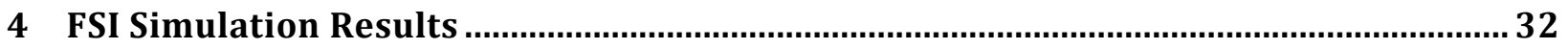

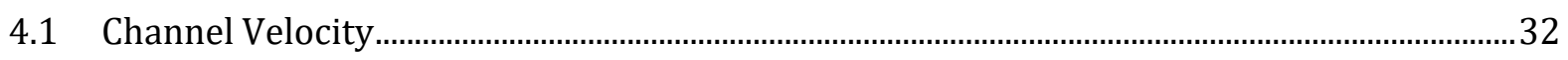

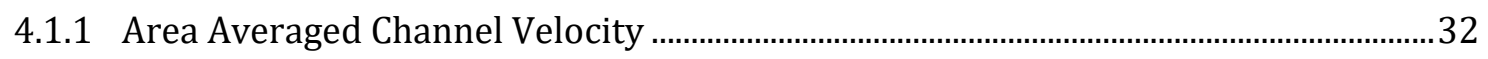

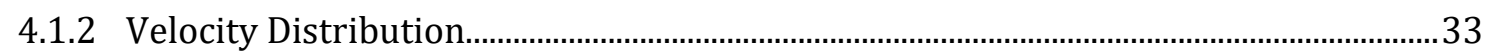

4.2 Pressure Distribution................................................................................................................. 34

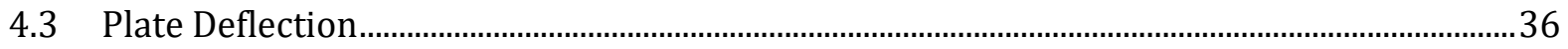

4.4 Stripe-Averaged Plate Deflection ...................................................................................................

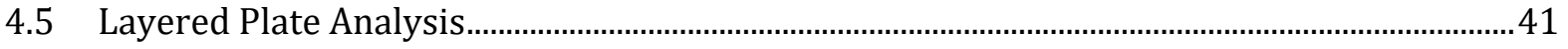




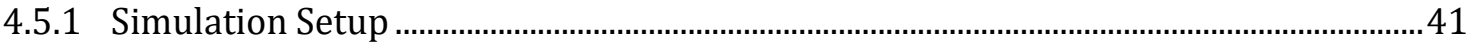

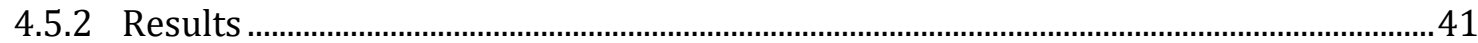

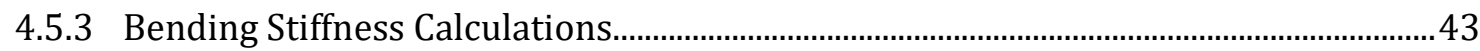

4.5.4 Effect of Fuel Swelling and Its Young's Modulus Reduction on Plate Stiffness ..........44

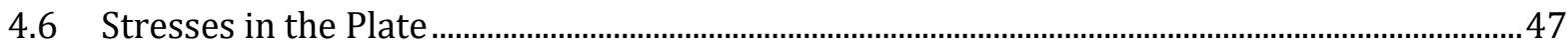

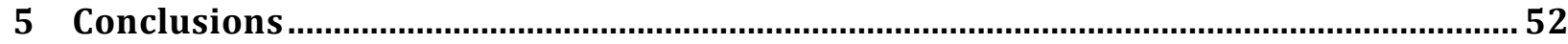

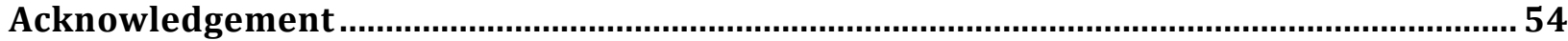

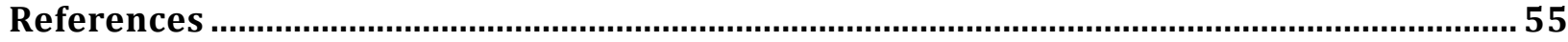

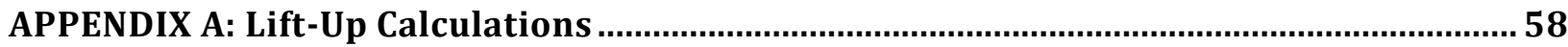

APPENDIX B: Results of Modal Analysis for the MITR Plate ...............................................59 


\section{List of Figures}

Figure 1.1. MITR reactor vessel cross-sectional view [1] …...................................................................... 1

Figure 1.2. Isometric view of MITR LEU fuel element (left); cross-sectional view (right)...................... 2

Figure 2.1. Cross-sectional view of MITR reactor vessel with various types of channels indicated..... 7

Figure 2.2. Most limiting configuration of MITR elements with highlighted two limiting plates .......... 8

Figure 2.3. FSI simulation geometry: front view (a); side view on the plate leading edge (b); top view (c) 9

Figure 2.4. Schematic of calculating combined coolant channel gap thickness: (a) nominal (side view), (b) conservative without lift (side view), (c) conservative with lift (top view). All dimensions in inches. Not in scale. 10

Figure 2.5. Schematic of the MITR LEU element on the lower grid plate..................................................11

Figure 2.6. Schematic side view of Case 6 slanted plate.............................................................................2

Figure 2.7. Side view of Case 7 deformed plate, $10^{\text {th }}$ mode (plate deformation magnitude scaled up by $500)$

Figure 2.8. Deformation contour in Y-direction of Case 7 deformed plate, $10^{\text {th }}$ mode. 21

Figure 2.9. 3-D view of Case 8 deformed plate, $2^{\text {nd }}$ mode (plate deformation magnitude scaled up by $500)$

Figure 2.10. Deformation contour in Y-direction of Case 8 deformed plate, $2^{\text {nd }}$ mode .22

Figure 3.1. Mesh sensitivity analysis results .24

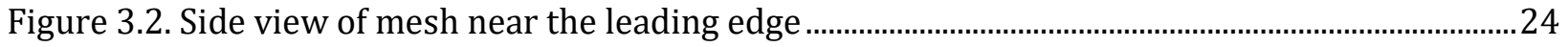

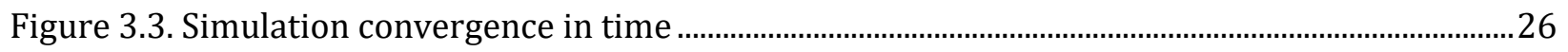

Figure 3.4. Mesh sensitivity study in LS-DYNA structural simulations........................................................22

Figure 3.5. Side view of velocity vector field at channel center of Case 2:................................................28

Figure 3.6. Side view of velocity vector of Case 2 (Wall boundary conditions for plenums)................29

Figure 3.7. Side view of velocity vector of Case 2 (Periodic boundary conditions for plenums) .........29

Figure 4.1. Velocity contour for Case 2 near the plate trailing edge ..............................................................33

Figure 4.2. Velocity profile in width direction (a) and in channel gap thickness direction (b) for Case 2 .

Figure 4.3. Pressure in the middle of channels ((a) to (c)) and the pressure difference between

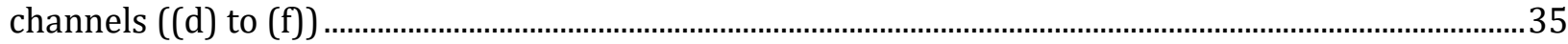

Figure 4.4. Pressure near the plate ((a) to (c)) and the pressure difference between the two sides ((d) to (f))

Figure 4.5. Pressure distribution on the plate surface for Case 1: thick-channel side (a), thin-channel

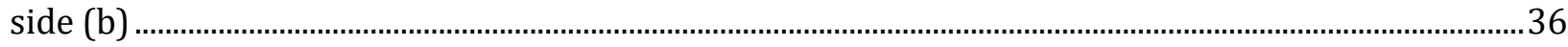

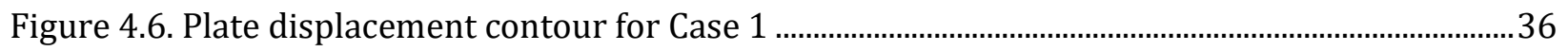

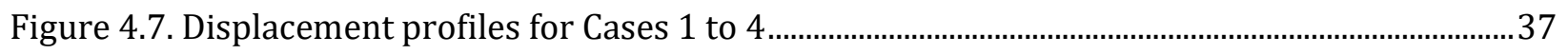

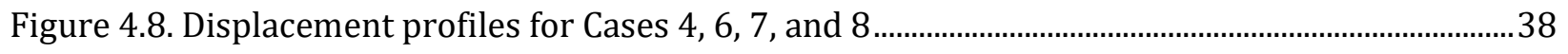

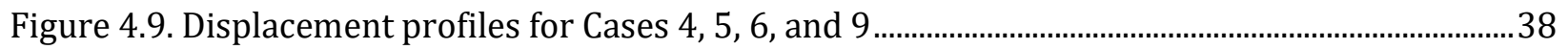




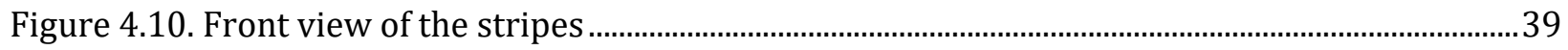

Figure 4.11. 3-D view of the stripes ...................................................................................................... 40

Figure 4.12. Top view of the simulation domain with fuel and cladding modeled separately..............41

Figure 4.13. Front view of the simulation domain with fuel and cladding modeled separately ..........41

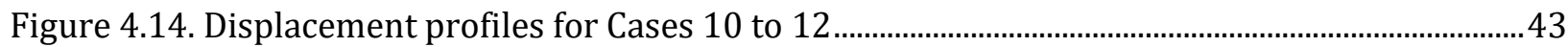

Figure 4.15. Typical temperature profile in plate 1 of ML-136 ..................................................................46

Figure 4.16. Stress (von Mises) contour of Case 1 (units in Pa) in solid (left) and shell (right) element-

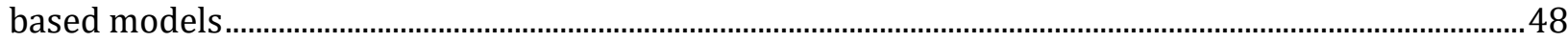

Figure 4.17. Maximum displacement as a function of elements on the leading edge ..............................48

Figure 4.18. Maximum stresses in the midspan as a function of elements number on the leading edge 49

Figure 4.19. Maximum stresses near the long edges as a function of elements number on the leading edge

Figure 4.20. von Mises stresses in the cross section of STAR-CCM+ models with 50 (top) and 400 (bottom) elements across the span of the plate. 


\section{List of Tables}

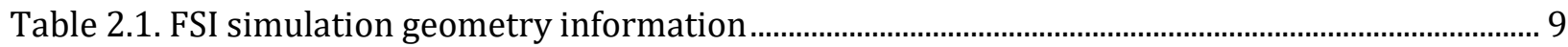

Table 2.2. Channel types and quantities for the MITR full LEU core at the start-up phase...................12

Table 2.3. Flow velocity calculated by pressure-drop balance....................................................................13

Table 2.4. Comparison of normalized results using different friction factor correlations ....................14

Table 2.5 Channel size and plate properties used in Miller's critical velocity calculations....................15

Table 2.6. Miller's critical velocity calculations for MITR LEU plate .............................................................16

Table 2.7. Assumed material properties of all-aluminum plate..................................................................18

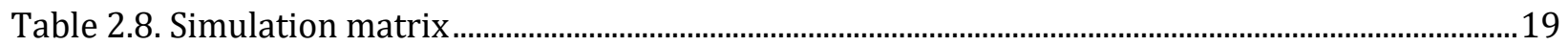

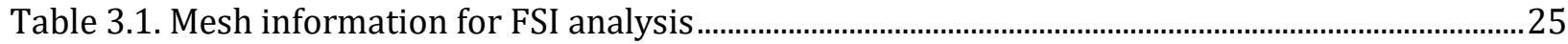

Table 3.2. Comparison of maximum displacement using different time steps and inner iterations..25

Table 3.3. Comparison of maximum deflections in Case 1 analyzed with various solvers.....................27

Table 3.4. Comparison of maximum displacement predicted using various turbulence models ........30

Table 3.5. Effect of coolant property change on maximum displacement and pressure drop..............31

Table 3.6. Effect of coolant property change on velocity and mass flow rate ............................................31

Table 4.1. Area-averaged velocity, mass flow rate, and pressure drop .......................................................32

Table 4.2. Comparison of simulation results with pressure drop balance results ....................................33

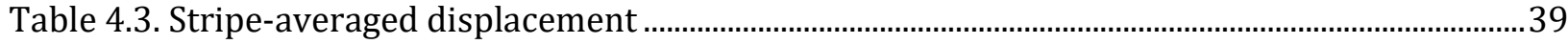

Table 4.4. Stripe-averaged displacement normalized by nominal channel gap thickness (74.6 mil)

Table 4.5. Stripe-averaged displacements for three new cases .....................................................................42

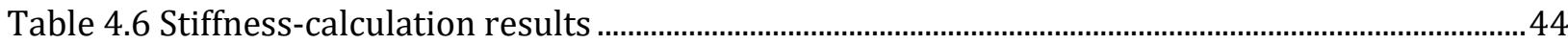

Table 4.7 Fission density for plate 1 in Element ML-136 after its 2nd depletion cycle ..........................45

Table 4.8 Fission density for plate 19 in Element ML-136 after its 2nd depletion cycle .......................45

Table 4.9. Von Mises stress at the plate center near the leading edge ........................................................51 


\section{Introduction}

\subsection{Massachusetts Institute of Technology Reactor and Fuel Element}

The Massachusetts Institute of Technology Reactor (MITR-II, also referred to as MITR) is a research reactor located in Cambridge, Massachusetts, designed primarily for experiments using neutronbeam and in-core irradiation facilities. Upgraded from MITR-I and relicensed as MITR-II, the MITR reactor has been in operation since 1975. It delivers neutron flux comparable to current LWR power reactors in a compact core with 6-MW licensed power using highly enriched uranium (HEU) dispersion fuel enriched at 93 weight $\%{ }^{235} \mathrm{U}$.

MITR is a light-water-cooled reactor. The water flows upward from the bottom to the top of the core. The Limiting Safety System Setting (LSSS) core flow rate is 1800 gpm. The core is surrounded by a heavy-water $\left(\mathrm{D}_{2} \mathrm{O}\right)$ reflector. All the fuel elements are of identical construction and have a rhomboid shape with internal angles of $60^{\circ}$ and $120^{\circ}$. As shown in Figure 1.1, the rhomboid elements are arranged in three concentric rings with three element positions in the innermost ring, nine in the middle ring, and 15 in the outermost ring, for a total of 27 positions. These 27 positions are arranged so that the core has a hexagonal shape. There are boron-impregnated stainless steel control blades along the hexagonal sides of the core. In the HEU core, typically 24 of the 27 positions are occupied by fuel elements during normal operating conditions and the other three are occupied by an in-core experimental facility or solid aluminum dummies.

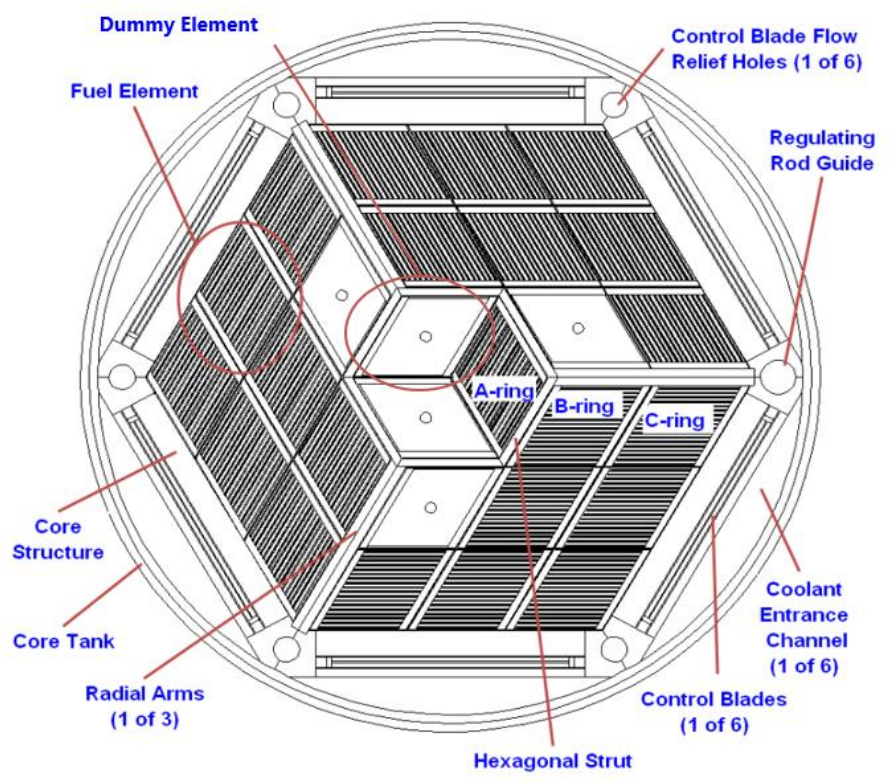

Figure 1.1. MITR reactor vessel cross-sectional view [1]

Each HEU element has 15 fuel plates that are 23 inches long. The fuel meat in each fuel plate is 22.375 inches long, 2.082 inches wide, and 30 mil thick ( 1 mil $=0.001$ inch). The aluminum cladding on each side of the meat has a thickness of 15 mil. In addition, there are 110 external vertical 
aluminum fins extruded on the cladding of each fuel plate to enhance heat transfer. The fins are $10 \mathrm{mil}$ apart, and each is 10 mil high and 10 mil wide. Thus, the distance from the fuel meat surface to a fin root is $15 \mathrm{mil}$ and to a fin tip is $25 \mathrm{mil}$. The plate-to-plate pitch is $158 \mathrm{mil}$, which implies that the fintip-to-fin-tip distance across the water channel between adjacent parallel fuel plates is 78 mil.

The isometric view of the proposed MITR low-enriched uranium (LEU) element and its cross-section schematic is shown in Figure 1.2. The proposed LEU element (design 19B25) [2] has 19 49-mil-thick finless fuel plates. The fuel core height and the plate height and width are the same as in the HEU design. Reduction in the thickness of the plates reduces their bending rigidity. Three different fuelmeat thicknesses were designed (F-full, Y-intermediate, T-thin) within the same overall plate thickness. To minimize power peaking on the ends of the element, the fuel core thicknesses of the first three fuel plates from either end of the element have been made thinner than the 25-mil thickness of the central 13 plates ("F" type). The fuel plate ("T" type) at either end has a fuel core thickness of 13 mil. The next two plates ("Y" type) from either end have core thicknesses of $17 \mathrm{mil}$. The water channel between interior plates is 74.6 mil thick.
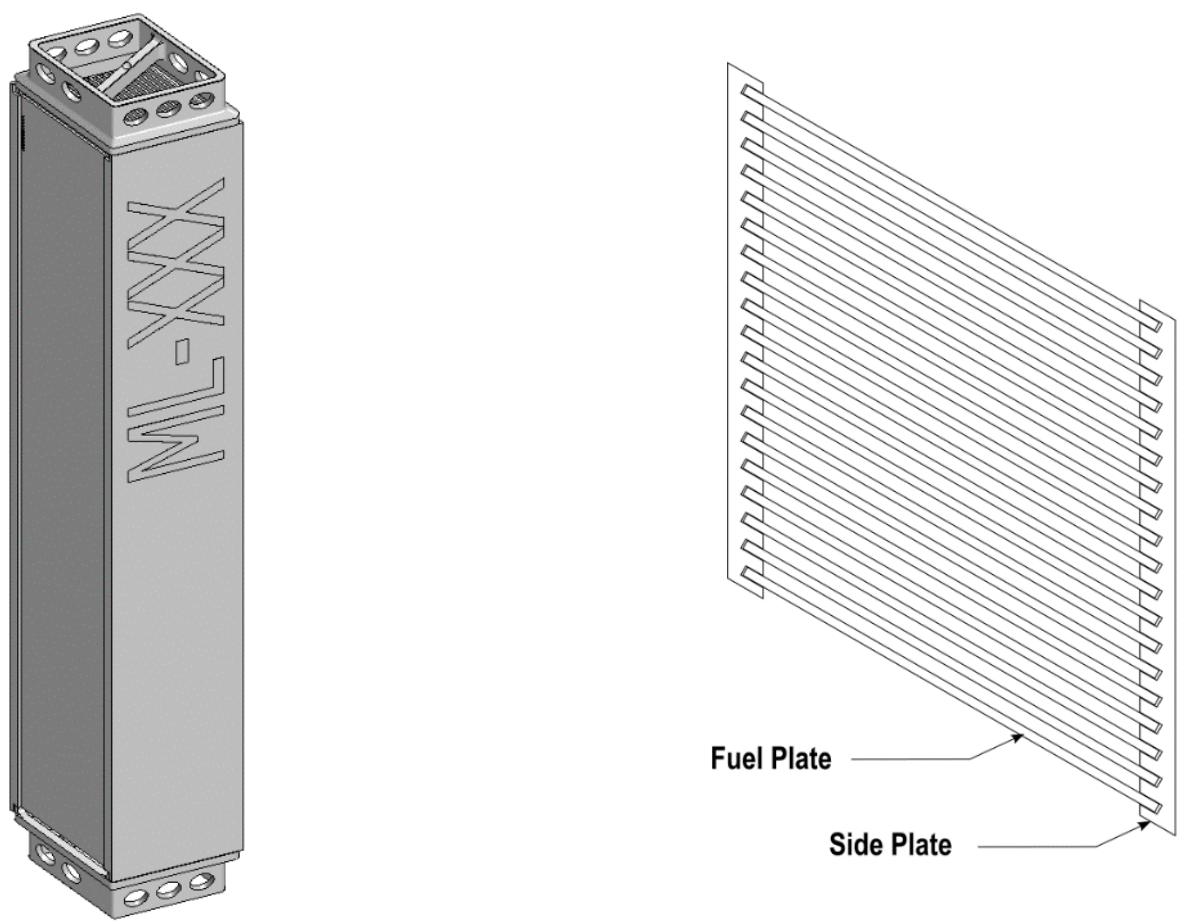

Figure 1.2. Isometric view of MITR LEU fuel element (left); cross-sectional view (right)

The power of the proposed LEU core is $7 \mathrm{MW}$, which is $1 \mathrm{MW}$ higher than that of the HEU core to maintain equivalent performance for the reactor facility. The primary coolant flow rate for the LEU cores has been increased by $20 \%$ as compared to the HEU core, from 2,000 gpm to 2,400 gpm. (The LSSS flow rate for the proposed LEU core is $2200 \mathrm{gpm}$, which is $400 \mathrm{gpm}$ greater than that for the HEU core). Further details on the LEU element design and comparison with the HEU fuel element can be found in [3] and [2].

Fuel-plate deflection can be induced during reactor operation by the hydrodynamic pressure differential caused by differences in the thicknesses of surrounding coolant channel gaps, turbulent 
fluctuations in the flow, or both. Higher coolant velocity in the core usually means that a larger velocity disparity between adjacent channel gaps can be expected, inducing larger deflections.

Fluid-structure interaction (FSI) analysis and the resulting estimation of flow-induced deflections of the fuel plates were not included in the previous safety analysis [4]. Thus, the present analysis will provide a preliminary assessment of these deflections.

According to the proposed LEU transition core plan [5], the MITR will start with 22 fresh LEU fuel elements and gradually change to 24 fuel elements arranged in an equilibrium configuration, while the remaining five or three fuel element positions will be occupied by solid aluminum dummy elements. Given that almost no coolant flows through the dummy elements, the start-up phase of the LEU core is expected to have the highest coolant velocity owing to its minimum cross-sectional flow area. Therefore, the start-up phase of the LEU core with 22 LEU elements will be studied in the present work. The detailed fuel orientation and channel structure of this core setup will be discussed in Section 2.1.2.

\subsection{Literature Review on Fluid-Structure Interaction (FSI) for Thin Fuel Plates}

\subsubsection{Analytical Models and Experiments}

The original design work on U.S. research reactors was conducted from the late 1940s through the 1960s. The early experiments conducted at Oak Ridge National Laboratory (ORNL) in 1948 by Stromquist and Sisman indicated that at sufficiently high flow velocities, mockup flat plates were deformed plastically, and curved plates experienced a reversal of curvature (i.e., the plates were buckling) [6]. These deformations were caused by pressure differentials on the two sides of the plate caused by the imbalance of the flow. As a result, one or more channels in the assembly were completely closed. This phenomenon raised a concern and triggered a series of experiments conducted in later years by many researchers. Of these, the most often cited is Miller, who in 1958 derived formulas for the critical coolant velocity at which elastic plates can lose their stability and collapse [7]. Miller derived his equations for both initially flat and curved plates with a multitude of boundary conditions, including built-in (fixed), hinged (simply supported), and periodically supported plates. However, these formulas were derived for ideally shaped plates surrounded by equal-size channels. A procedure to include effects of additional pressure differentials (like the one coming from channel-size disparities) was proposed, but it was limited to small deviations only.

Many researchers have continued the work begun by Miller. Some of the results, especially those coming from theoretical derivations, were supportive of Miller's findings. However, a substantial group of experimental studies did not confirm the presence of a critical velocity that would mark an onset of instabilities or collapse. Instead, they reported gradually increasing deflections of the plates or vibrations, depending on the flow conditions.

Refinements of Miller's theory came from, among others, Johansson [8]. One of Miller's original assumptions was that all channels have an equal thickness. He also assumed that the length of the plate was significantly larger than the length of the deflected region. In Miller's derivation, the friction pressure drop in the deflected region is small and inertia effects in the fluid are ignored. Miller also used wide-beam theory to describe the deflection of the plates, neglecting some of the threedimensional (3-D) characteristics of the plate deflections. In his work, Johansson made corrections 
to some of these assumptions. He accounted for flow redistribution between adjacent channels due to the plate's deflection. He also included the effects of longitudinal bending in his derivations and assumed that the length (in the flow direction) of the deflected region is equal to two widths of the plate. Depending on the geometrical characteristics of the plates, this assumption caused the predicted critical coolant velocity to be between 0.9 and 1.7 times that of Miller. Rosenberg and Youngdahl (1962) [9] formulated a dynamic model of the plate stability in the coolant flow. Their model confirmed Miller's findings of the presence of divergence (deflections increasing with time) at higher velocities and stable oscillations at lower velocities. Further improvements of Miller's theory were made by, among others, Scavuzzo (1965), who coupled the hydraulic equations with the plate deflection equations to obtain non-linear integral equations describing the plate's behavior even more accurately [10].

Groninger and Kane (1963) tested three 5-plate assemblies to examine their deflections due to the parallel flow [11]. The experiments introduced specially designed strain sensors installed in holes made in the plate edges to measure the deflections. Flow velocities up to $190 \%$ of Miller's critical velocity were considered in these tests. The primary conclusion of this work was that the critical velocity deflection is a magnification of the initial perturbations in the plate geometry. The authors did not notice catastrophic or sudden deformations of the plates. They noticed that the adjacent plates always deformed in opposite directions, either opening or closing the channels. Highfrequency vibrations (flutter) were noticed for the highest flow velocities. A comb installed on the leading edge suppressed this phenomenon, but large deformations were still present away from the leading edge. Further theoretical analysis performed by Kane [12] also focused on the influence of initial imperfections in the plate geometry near the leading edge on the increase in the flow-induced deflections. A formula for the pressure difference and resulting deflection was derived in that study.

Smissaert (1968) conducted a set of experiments on plate assemblies made of PVC to characterize the static and dynamic behavior of the plates at different flow velocities [13]. Five-, nine-, and fifteenplate assemblies were investigated. Strain gauges were embedded along the center plate's length in the middle of the span to capture the entire profile of the deflected plate. Owing to the minimum thickness needed for installation of the pressure taps, only the assembly with the largest channels (five-plate assembly) was instrumented with them. Smissaert identified several instabilities in the plate: static deflection of the leading edge, static deflection in the plate array, small-amplitude traveling waves, and large-amplitude flutter. He noticed that for low flow velocities, the plates deformed as a result of a static pressure differential in the channels. The flutter, consisting of traveling waves, originated at the leading edge of the plate and ran down the plate in the direction of coolant flow. The wavelength of the deformation was a function of the coolant velocity. For velocities close to two times Miller's critical velocity, high-frequency flutter instabilities without sudden collapse were reported. These tests also showed that any disturbance of flow entering the channels surrounding the fuel plates has a significant effect on plate deflections. Smissaert also noticed that installing a support comb on the leading edge suppressed the high-frequency flutter.

In the early 1990s, Swinson et al. conducted flow tests on involute plate assemblies in support of the Advanced Neutron Source reactor design [14], [15], [16], [17]. To lower the flow velocity and pressure required for the anticipated collapse conditions, the test assemblies were made from epoxy. Five-plate assemblies were the subject of the experiments. The inner three plates in the assembly were instrumented with five strain gauges for each plate along its center axis. The gauges were located at the entrance, the quarter point, the half point, the three-quarter point, and the exit point with respect to the plate length. Five static pressure taps in each channel were positioned in the same cross-sectional plane as the strain gauges. The maximum deflections were measured either at the leading edge or at the three-quarter length of the plate. The author formulated an analytical solution

MITR Low-Enriched Uranium Conversion Fluid-Structure Interaction Preliminary Design Verification 
for the maximum involute plate deflection due to a pressure load using Castigliano's energy theorems for deformation. The deflections calculated through this approach were compared with the deflections measured experimentally with the strain gauges. The calculated values were a reasonable approximation of the measured values.

Ho et al. (2004) performed a series of experiments on two-plate assemblies to support the design of the Replacement Research Reactor for the Australian Science and Technology Organisation [18]. The plates were instrumented with strain gauges at three positions: the leading edge, the middle of the plate, and the trailing edge. At each position, two strain gauges were installed on either side of the plate. To avoid influence by the strain gauges on the flow in thin channels, the gauges were epoxied into a $0.4-\mathrm{mm}$ groove milled on the plate's surface. The results showed plate collapse occurring at an average velocity of 78\% of Miller's critical velocity. During the plate collapse, cavitation was observed on the leading edge of the deformed plate. The mode of collapse in these experiments appeared to be random, with both plates either collapsing onto each other or deflecting away from each other.

Liu et al. (2011) [19] and Li et al. (2012) [20] performed a study on FSI for single- and double-plate assemblies in water flow. In their experiments, Liu et al. imposed constraints only on the four corners of the plates, which significantly increased the deflection of the plates as compared to the plates constrained along two longer edges. The testing section was enclosed with Plexiglas, which allowed for the utilization of a laser for measurement of the plates' deflection. Li et al. found several regimes of flow rates that resulted in different characteristic responses. At the lowest velocities, the thickness of the channel between the plates was reduced and no vibrations were present. At higher velocities, large vibrations occurred and caused both plates to oscillate in the same or opposite phases, depending on the flow-rate regime.

In 2017, Castro et al. [21] performed experiments on two-plate assemblies with dimensions similar to those in the fuel element of the Brazilian Multipurpose Reactor. The aluminum plates were enclosed in a testing section made of Plexiglas. Strain gauges were installed near the inlet, the middle, and the trailing edge of the plates to measure the deflections. Pressure-drop measurements were used as a secondary method for detecting the collapse of the plates. Collapse and plastic deformations of the plates were reported at a flow velocity close to $85.5 \%$ of Miller's critical velocity. Up to that flow velocity, the maximum deflection on the leading edge was proportional to the squared velocity.

\subsubsection{Simulation Methods}

As described above, since the early 1960s, multiple analytical models have been developed and experiments have been performed to quantify the deflection of the plates that bound coolant channel gaps. Over the years, the theoretical description of the phenomenon was expanded from the Miller's wide-beam theory to plate theory with included inertial effects as modeled by Rosenberg and Youngdahl [9]. Eventually, coupled hydraulic equations with plate equations were solved iteratively by Scavuzzo [10]. However, owing to the complexity of the coupling (with two-way feedback) between the flow distribution in the channels and the deflection of the plate, analytical models can only cover idealized cases of the fuel element flow performance analysis. Practical cases can only be solved using numerical methods, i.e., Computational Fluid Dynamics (CFD) or Computational Structural Mechanics (CSM), or a coupling between them.

In 1988, Gwaltney and Luttrell [22] developed a somewhat limited model of the elastic finite element of the plates coupled with Bernoulli's equation for the fluid. The authors analyzed flat, cylindrical, 
and involute plates, confirming much higher stiffness of the curved plates relatively to the flat ones. The numerical results were close to the predictions obtained from Miller's equations.

In 1993, Sartory [23] at ORNL performed a nonlinear analysis of hydraulic bucking instability of Advanced Neutron Source involute fuel plates based on Swinson's experiments [14]. Fuel plate assemblies were analyzed using the commercial ABAQUS finite-element (FE) code with the userimplemented element for the two-dimensional fluid flow in the coolant channels. That work marked one of the first FSI analyses for the purpose of reactor fuel element design.

More recent work has focused on the use of commercial FE or finite-volume (FV) codes to perform full 3-D FSI analysis of the single plates in turbulent flows. Elzawawy et al. (2015) used the COMSOL FE code to analyze ideal HFIR plates [24]. Tentner et al. (2017) [25] reported results of a series of flow loop experiments on both flat and curved plates. In parallel, FSI simulations of the plates were performed using STAR-CCM+ and the co-simulation approach of STAR-CCM+ and ABAQUS, as well as COMSOL software to model the experiments. Both ideal and as-built flat and curved plates were simulated. The authors concluded that the tested commercial codes could replicate the experimental results for the as-built cases, as long as the initial geometry of the plate was accurately represented in the model.

Mantecon and Neto (2018) [26] used Ansys CFX to study the deflections of two ideal flat plates with three constant-thickness coolant channel gaps (one channel separating the plates and one channel on the outer sides of each plate). Flow velocities between 0.5 and 1.2 times the Miller critical velocity were considered. The plates deflected in opposite directions, widening the channel gap between them without sudden collapse, for flow velocities near Miller's critical velocity. The maximum deflection registered at the leading edge of the plates was observed to grow linearly with the square of the ratio of current coolant velocity to Miller's critical velocity.

In addition to the CFD-CSM coupled simulations, Howard et al. [27] proposed a 1-D, semi-analytical model to solve FSI problems and predict the plate deflection. The plate deflection field was obtained by solving the wide-beam theory-based equations for each axial solid node and the coupling adjacent solid nodes by solving for the force between them. The obtained plate deflection field was comparable to the numerical solution and experimental data, and the computational cost was significantly reduced due to the simplicity of the model.

Modeling of full fuel elements with multiple coolant channels and all deformable plates is still difficult and, in many cases, prohibitively expensive. However, simulating single or a limited number of the fuel plates has proven to be a viable approach in predicting their structural response to pressure induced deflections, especially at velocities significantly lower than Miller's critical velocity. The current work will use that approach following simulation methodology developed and validated in $[25]$. 


\section{FSI Simulation Approach}

The commercial software STAR-CCM+(14.02) [28] was used to perform the FSI analysis presented in this report. Details of the simulation approach, including simulation setup (Section 2.1) and test matrix (Section 2.2), are discussed below.

\subsection{Simulation Setup}

\subsubsection{Geometry and Boundary Conditions}

As mentioned in the introduction, the deflection of the fuel plate occurs because of the pressure difference on the two sides of the plate, which usually results from the velocity disparity between two adjacent coolant channels of the plate. The velocity disparity is usually caused by the size difference between the two channels. The frictional pressure drop for a larger channel is lower, so the velocity is higher in that channel. Therefore, the most limiting plate of a MITR fuel element can be identified by comparing the size difference between adjacent channels. Figure 2.1 shows the cross section of the MITR core, with various types of channels indicated. The end channel gap of each element may face the core structure or another fuel element. In the case where the end channels of two neighboring elements face each other (case (a) or (b) in Figure 2.1), they form a combined coolant channel gap with a thickness about twice the thickness of an internal channel gap. This type of fuel element orientation results in the largest coolant channel gap thickness disparity in the MITR core. The most limiting plates resulting from that configuration of elements in the core are shown in yellow color in Figure 2.2.

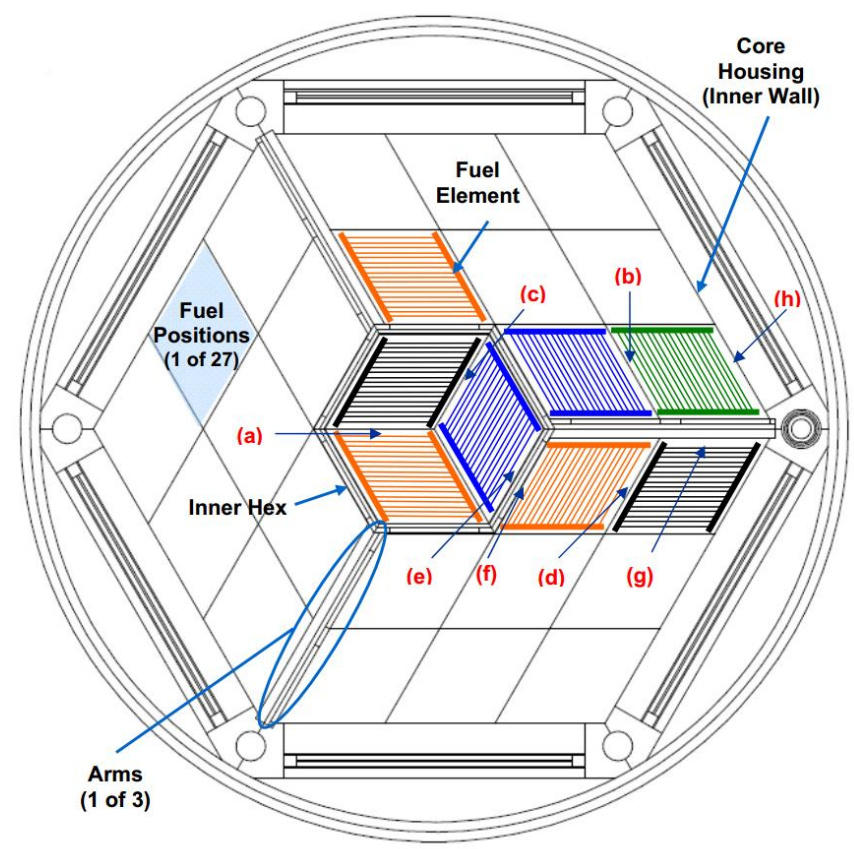

Figure 2.1. Cross-sectional view of MITR reactor vessel with various types of channels indicated 


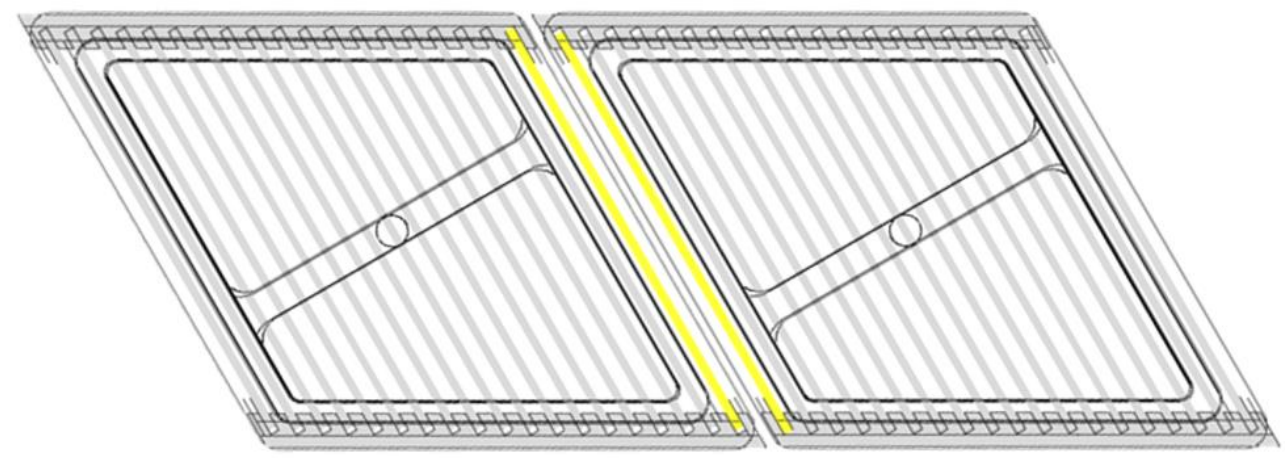

Figure 2.2. Most limiting configuration of MITR elements with highlighted two limiting plates

In the current analysis, the simulation domain has been simplified to a single plate and two surrounding channel gaps to reduce the computational cost of the analysis significantly. In this approach, the influence of the deformation of the neighboring plates, as well as the presence of the end fitting, on the flow redistribution is not considered. Further full-element FSI analyses considering the influence of the other plates, end fittings, and resulting flow disturbances may be planned at a later stage of the conversion project. Also, a flow test of a prototypic MITR LEU element is currently being designed to demonstrate geometric stability of the element under coolant flow conditions relevant to licensing. Plate deflections will be measured during the flow test.

The geometry of the FSI simulation domain is presented in Figure 2.3, in which one plate and two adjacent coolant channel gaps are included. The lower and upper plenums are added for the flow to develop before entering and after leaving the two coolant channel gaps. In Figure 2.3 (b) and (c), the boundary is specified as blue solid line, black dashed line, and red solid line for the wall, symmetry boundary, and inlet/outlet, respectively. The geometry size of the simulation domain is determined in accordance with the technical drawings [29] [30] [31] of the MITR LEU fuel element and is summarized in Table 2.1. Note that the nominal size for the combined end channel gap ((b) in Figure 2.1) is 141 mil, as shown in Figure 2.4 (a), but if the fabrication tolerances of the end fitting of the fuel element is considered, the largest possible channel gap thickness is 186 mil, as shown in Figure 2.4 (b). Furthermore, since the MITR fuel element is positioned in the lower grid plate without any mechanical constraint that would prevent movement of the element in the axial direction, as shown in Figure 2.5, the fuel element can be lifted because of the upward-flow configuration (refer to Appendix A for the lift-up force calculations). The magnitude of that motion is limited by the presence of the upper grid. Because of the chamfered design of the end fitting, axial motion can result in further increase of the outer channel gap thickness: it can reach 247 mil in the worst-case scenario, as shown in Figure 2.4 (c). Since a larger channel gap thickness disparity will result in larger velocity disparity and fuel-plate displacement, these large channel gap thicknesses should be considered as the conservative case. 
(a)

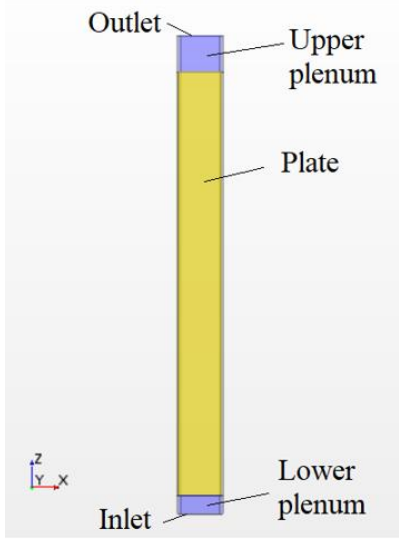

(b)

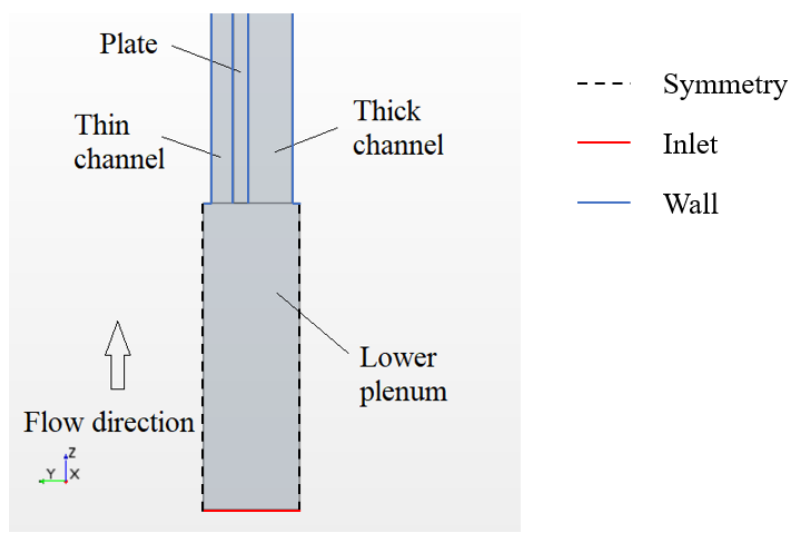

(c)

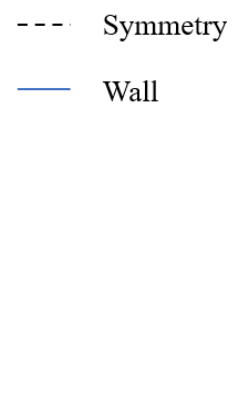

Thick channel

Y. $\mathrm{X}$

Thin channel

Plate

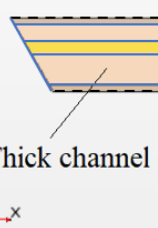

Figure 2.3. FSI simulation geometry: front view (a); side view on the plate leading edge (b); top view (c)

Table 2.1. FSI simulation geometry information

\begin{tabular}{|c|c|c|}
\hline Geometry category & Size (inches) & Note \\
\hline Plate thickness & 0.046 & $\begin{array}{c}\text { Thinnest within tolerances, } \\
\text { nominal size is 0.049 inch }\end{array}$ \\
\hline Thin channel gap thickness & 0.070 & $\begin{array}{c}\text { Thinnest within tolerances, } \\
\text { nominal size is 0.0746 inch }\end{array}$ \\
\hline Thick channel 1 gap thickness & 0.141 & Nominal \\
\hline Thick channel 2 gap thickness & 0.186 & Conservative without lift \\
\hline Thick channel 3 gap thickness & 0.247 & Conservative with lift \\
\hline Channel gap width (plate span) & 2.312 & Nominal \\
\hline Plate length & 23.00 & - \\
\hline Lower (Inlet) plenum length & 0.984 & - \\
\hline Upper (Outlet) plenum length & 1.967 & Nominal \\
\hline
\end{tabular}




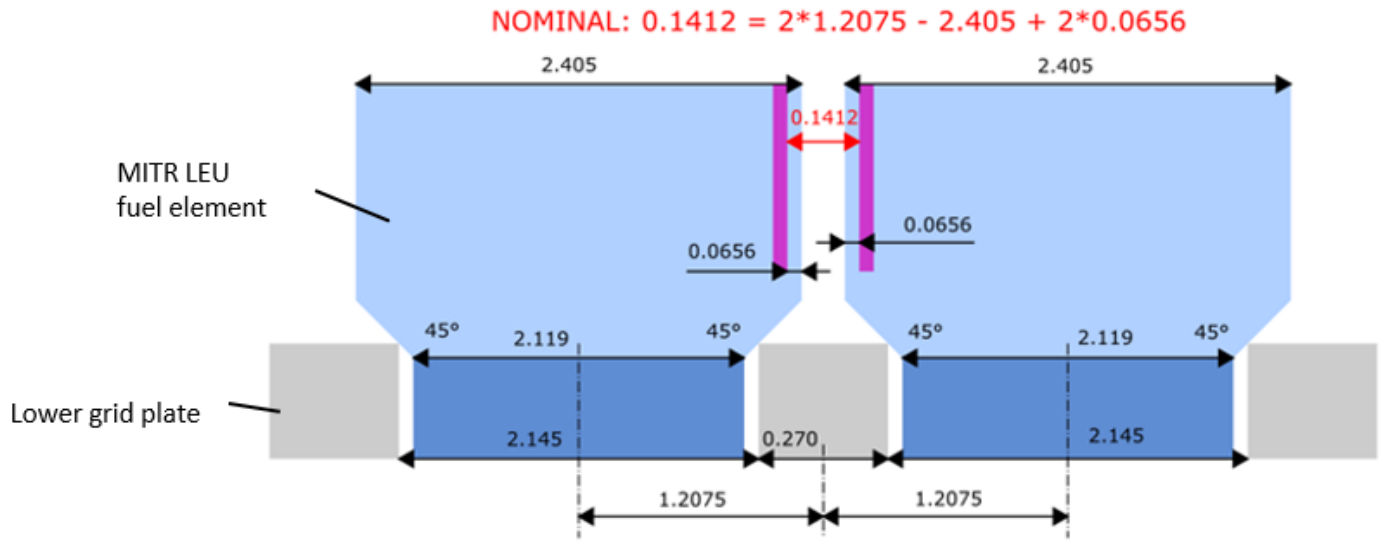

(a)

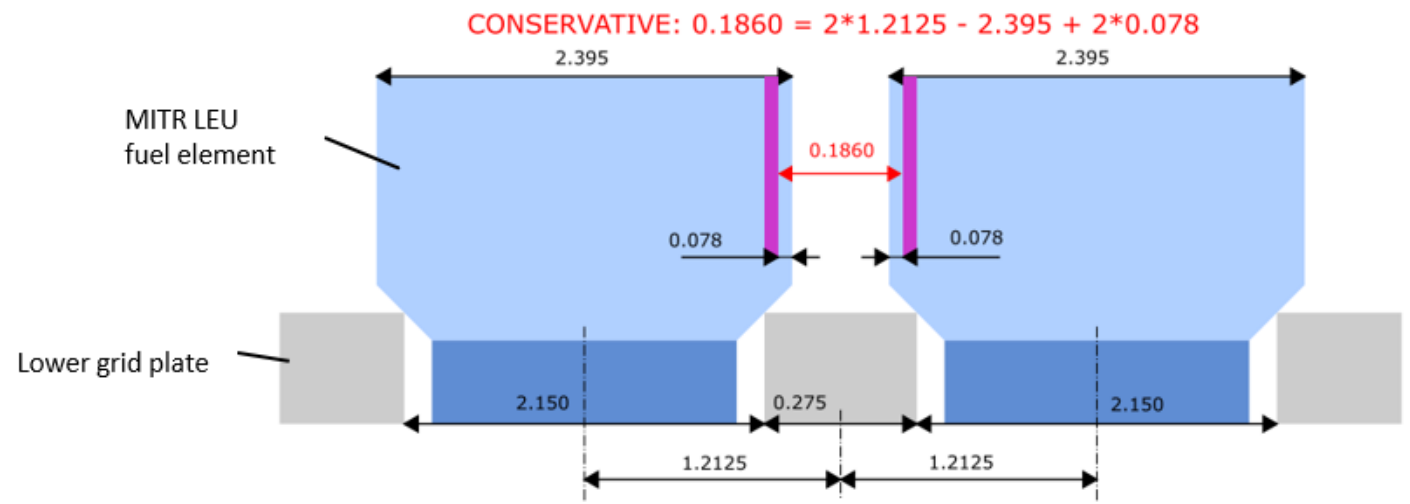

(b)

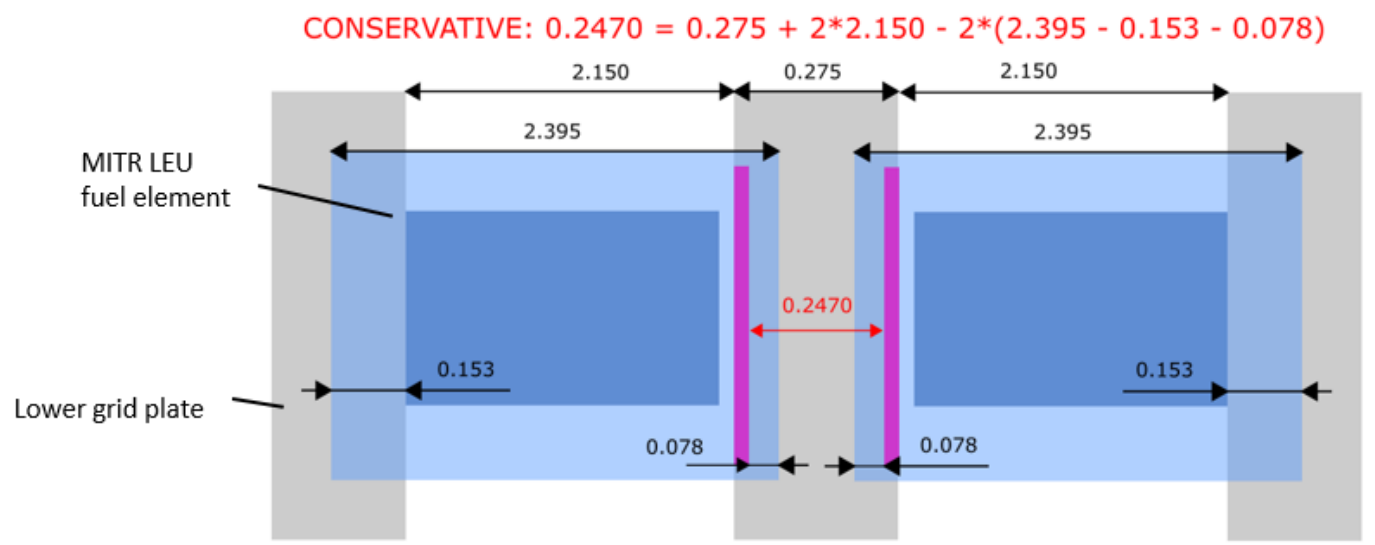

(c)

Figure 2.4. Schematic of calculating combined coolant channel gap thickness: (a) nominal (side view), (b) conservative without lift (side view), (c) conservative with lift (top view). All dimensions in inches. Not in scale. 


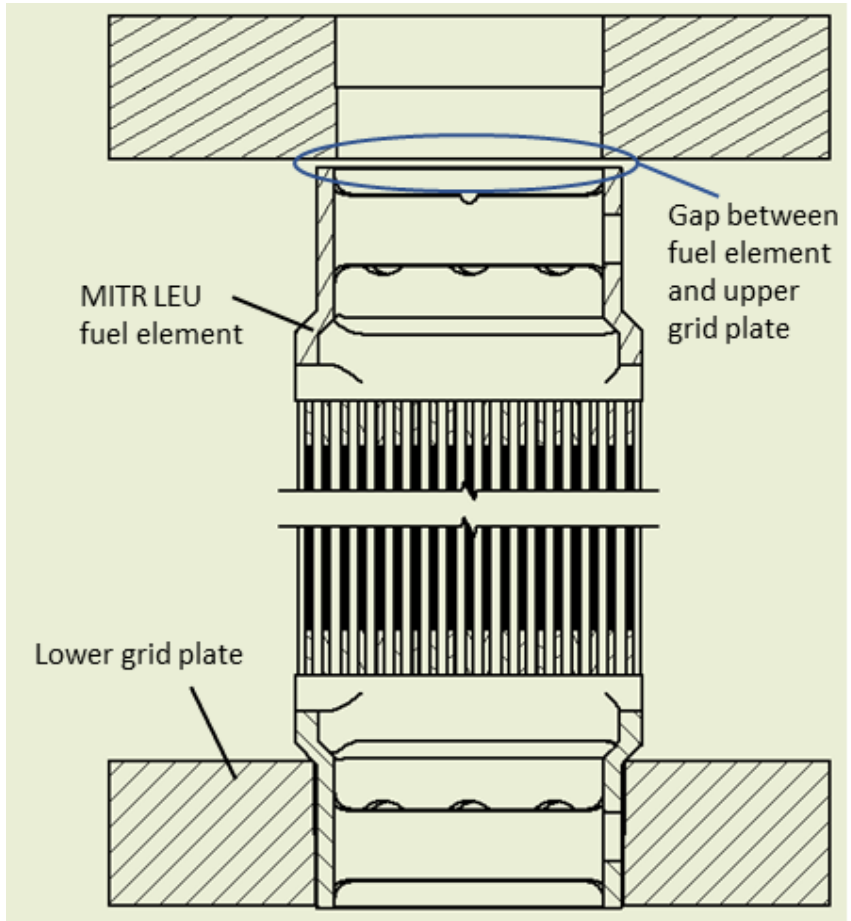

Figure 2.5. Schematic of the MITR LEU element on the lower grid plate

\subsubsection{Inlet Conditions}

It is important to set the proper inlet mass flow rate for the simulation to reflect the actual velocity in the adjacent channel gaps of interest in the core. The flow distribution of the 22-element LEU core is calculated using the pressure-drop balance method, which assumes that all coolant channel gaps have the same pressure drop. Therefore, the full core coolant channel gap setup is needed to estimate the flow rate for the target channel gap. The detailed fuel-element orientation of the MITR LEU core at the start-up phase is available in [5], from which the number of each type of channel can be obtained; these numbers are listed in Table 2.2. The channel configuration ID shown in this table corresponds to orientations shown in Figure 2.1. There are a total of 440 channels for the 22 fuel elements, as each element has 19 fuel plates and 20 flow channels. Note that the size shown in Table 2.2 for end channel gaps facing adjacent element end channel gap ( $(a)$ and $(b))$ is for the combined channel gap; namely, the total dimension of two facing end channel gaps (including the gap between the two elements) is $141 \mathrm{mil}$ (or 129 mil for A-ring). Table 2.2 shows that there are $12(24 / 2)$ combined end channel gaps with a thickness of about twice that of an internal channel gap. The thicknesses of the other types of end channel gaps ((c) to (h)) do not significantly differ from the nominal thickness of the internal channel gaps. 
Table 2.2. Channel types and quantities for the MITR full LEU core at the start-up phase

\begin{tabular}{|c|l|c|c|}
\hline \multicolumn{1}{|c|}{ ID } & \multicolumn{1}{|c|}{ Channel configuration } & Number & $\begin{array}{c}\text { Channel gap } \\
\text { thickness } \\
\text { (mil) }\end{array}$ \\
\hline (a) & End channel gap facing adjacent-element end channel, A-ring & 0 & 129 for 2 \\
\hline (b) & End channel gap facing adjacent-element end channel, B/C ring & 24 & 141 for 2 \\
\hline (c) & End channel gap facing adjacent-element side plate, A-ring & 1 & 78.0 \\
\hline (d) & End channel gap facing adjacent-element side plate, B/C-ring & 3 & 88.0 \\
\hline (e) & End channel gap facing inner hex (A-ring) & 1 & 82.5 \\
\hline (f) & End channel gap facing inner hex (B-ring) & 0 & 81.5 \\
\hline (g) & End channel gap facing arm & 6 & 69.5 \\
\hline (h) & End channel gap facing outer hex & 9 & 79.5 \\
\hline (i) & Internal channel gap & 396 & 74.6 \\
\hline
\end{tabular}

With the geometry information shown in Table 2.2, the flow distribution of various types of channel gaps can be solved using conservation of mass and pressure drop balance:

$$
m_{1}+m_{2}+\ldots+m_{9}=m_{t o t}
$$

where $m_{k}$ represents the sum volumetric flow rate of the channel type $k$ ( $k=1$ to 9 , corresponds channel ID a to i in Table 2.2), and $m_{\text {tot }}$ is the total volumetric flow rate of the core. The pressure drop balance can be expressed as:

$$
\Delta p_{1}=\Delta p_{2}=\ldots=\Delta p_{9}
$$

where $\Delta p_{k}$ is the pressure drop of the type $k$ channel, which can be calculated using:

$$
\Delta p_{k}=\frac{\rho v_{k}^{2}}{2}\left(K_{c}+K_{e}+\frac{f_{k} L}{D_{h, k}}\right)
$$

where $v_{k}$ is the coolant velocity and $K_{c}$ and $K_{e}$ are contraction and expansion pressure losses of the flow, which accounts for the pressure drop at the inlet and outlet of the channel gap. The values of $K_{c}$ and $K_{e}$ are 0.3 and 0.25 , which are estimated using the flow area ratio of one fuel element and reference [32]. $L$ and $D_{h, k}$ are the length and hydraulic diameter of the channel gap, respectively, and $f_{k}$ is the friction factor. In this study, three correlations are used to calculate the friction factor, and their effect on flow distribution calculation will be evaluated. The first one is the Colebrook-White (C-W) equation [33]:

$$
\frac{1}{\sqrt{f}}=-2 \log \left(\frac{\varepsilon}{3.7 D_{h}}+\frac{2.51}{R e \sqrt{f}}\right)
$$

The surface roughness of the cladding in the element $\varepsilon$ is assumed to be $0.001 \mathrm{~mm}$. One of the explicit forms of the $\mathrm{C}-\mathrm{W}$ equation [34] is also used: 


$$
\begin{aligned}
& f \\
& =\left\{-2 \log \left[\frac{\varepsilon}{3.7 D_{h}}\right.\right. \\
& \left.\left.+\frac{5.02}{R e} \log \left(\frac{\varepsilon}{3.7 D_{h}}+\frac{13}{R e}\right)\right]\right\}^{-2}
\end{aligned}
$$

The last correlation is the Blasius correlation [35] used in STAT7 [36], a one-dimensional code developed at Argonne National Laboratory for MITR steady-state thermal-hydraulics analysis:

$$
f=a_{f} R e^{b_{f}}
$$

Usually, $a_{f}=0.316$ and $b_{f}=-0.25$ if $R e$ is less than 20,000. For higher Re, $a_{f}=0.184$ and $b_{f}=-0.2$.

The flow distribution calculated using the explicit C-W equation (Eq. (2.5)) is shown in Table 2.3, where $v_{\text {thin }}$ and $v_{\text {thick }}$ represent the velocity in the thin and thick channel, respectively, and $\Delta \mathrm{P}$ represents the pressure drop between the inlet and outlet. Note that for the thick-channel types 2 and 3, only one of the 12 thick channels are assumed to be this size (186 mil or 247 mil), while the remaining 11 channels are still the nominal size ( $141 \mathrm{mil})$. Table 2.3 shows that the velocity disparity increases with the thick channel gap thickness, and the pressure drop reduces slightly. The total mass flow of the thick channel gap of interest and an internal channel gap will be used as the inlet mass flow rate for the subsequent FSI simulation.

Table 2.3. Flow velocity calculated by pressure-drop balance

\begin{tabular}{|c|c|c|c|c|c|}
\hline Thick channel type & $\begin{array}{c}\text { Channel gap } \\
\text { thickness (mil) }\end{array}$ & $\begin{array}{c}\text { Mass flow rate } \\
(\mathrm{kg} / \mathrm{s})\end{array}$ & $v_{\text {thin }}(\mathrm{m} / \mathrm{s})$ & $v_{\text {thick }}(\mathrm{m} / \mathrm{s})$ & $\Delta \mathrm{P}(\mathrm{Pa})$ \\
\hline 1. Nominal & 141 & 1.1302 & 2.792 & 3.954 & $1.88 \mathrm{E}+04$ \\
\hline 2. Conservative & 186 & 1.5357 & 2.784 & 4.478 & $1.87 \mathrm{E}+04$ \\
\hline $\begin{array}{c}\text { 3. Conservative with } \\
\text { lift }\end{array}$ & 247 & 2.1263 & 2.772 & 4.996 & $1.86 \mathrm{E}+04$ \\
\hline
\end{tabular}

The comparison of results using different friction factor correlations is shown in Table 2.4, in which $f_{\text {thick }}$ and $f_{\text {thin }}$ represent the friction factor of the thick and thin channels, respectively. The results obtained with the explicit C-W equation (Eq. (2.5)) are used to normalize the results obtained with the other two correlations. The mass flow rate comparison is of interest and is highlighted, because this parameter will be used as the simulation inlet condition and its change may affect the further FSI analysis. Table 2.4 shows that the mass flow rates calculated using these three correlations are close to each other and the deviation is less than $1 \%$. Thus, any of these correlations can be used in the calculations of the mass flow rate, and the explicit $\mathrm{C}-\mathrm{W}$ equation is selected because of the simplicity to implement. 
Table 2.4. Comparison of normalized results using different friction factor correlations

\begin{tabular}{|c|c|c|c|c|c|c|c|}
\hline $\begin{array}{c}\text { Thick } \\
\text { channel } \\
\text { size }\end{array}$ & $\begin{array}{c}\text { Friction- } \\
\text { factor } \\
\text { correlation }\end{array}$ & $\begin{array}{c}\text { Mass } \\
\text { flow }\end{array}$ & $v_{\text {thin }}$ & $v_{\text {thick }}$ & $f_{\text {thin }}$ & $f_{\text {thick }}$ & $\Delta \mathrm{P}$ \\
\hline \multirow{1}{*}{141 mil } & $\begin{array}{c}\text { Explicit } \\
\text { C-W }\end{array}$ & 1 & 1 & 1 & 1 & 1 & 1 \\
\cline { 2 - 8 } & $\begin{array}{c}\text { Implicit } \\
\text { C-W }\end{array}$ & 1.000 & 1.000 & 1.000 & 0.995 & 0.993 & 0.995 \\
\cline { 2 - 8 } & $\begin{array}{c}\text { Blasius } \\
\text { (STAT7) }\end{array}$ & 1.006 & 0.999 & 1.009 & 1.002 & 0.977 & 1.000 \\
\hline & $\begin{array}{c}\text { Explicit } \\
\text { C-W }\end{array}$ & 1 & 1 & 1 & 1 & 1 & 1 \\
\cline { 2 - 8 } & $\begin{array}{c}\text { Implicit } \\
\text { C-W }\end{array}$ & 1.000 & 1.000 & 1.000 & 0.995 & 0.993 & 0.995 \\
\cline { 2 - 8 } & $\begin{array}{c}\text { Blasius } \\
\text { (STAT7) }\end{array}$ & 1.004 & 0.999 & 1.005 & 1.002 & 0.985 & 1.000 \\
\hline \multirow{2}{*}{247 mil } & $\begin{array}{c}\text { Explicit } \\
\text { C-W }\end{array}$ & 1 & 1 & 1 & 1 & 1 & 1 \\
\cline { 2 - 8 } & $\begin{array}{c}\text { Implicit } \\
\text { C-W }\end{array}$ & 1.000 & 1.000 & 1.000 & 0.995 & 0.993 & 0.995 \\
\cline { 2 - 8 } & $\begin{array}{c}\text { Blasius } \\
\text { (STAT7) }\end{array}$ & 1.003 & 0.999 & 1.003 & 1.002 & 0.990 & 1.000 \\
\hline
\end{tabular}

\subsubsection{Turbulence Model Selection}

One of the critical aspects of FSI analysis is the expected type of behavior of the structure under a hydrodynamic load. Deformations of a fuel plate due to its interaction with the flowing coolant can be categorized as steady-state deflections or transient oscillations. Steady-state deflections are primarily induced by a pressure differential between the two sides of the plate. A pressure differential develops when the channel gaps on the two sides of the plate have dissimilar thicknesses. These differences usually come from the manufacturing tolerances. The pressure-induced deflections are further exacerbated by non-uniformities in the shape of the plate or its tilt in the side plate grooves. To solve for pressure-induced deflections, a solution of Reynolds Averaged NavierStokes (RANS) equations is frequently sufficient. RANS equations are time-averaged equations of motion for fluid flow, and thus by definition provide a steady-state solution. Vibrations of a plate cannot be predicted using this approach. On the other hand, the solution to unsteady RANS (URANS) equations provides a time-dependent field able to capture some oscillations of the plate in the flow. The frequency of the flow fluctuations predicted by this approach is limited by the quantity called turbulent time scale. Thus, this approach limits the range of frequencies of plate oscillations that can be detected.

Oscillations of the plate may be induced by fluctuations in the coolant flow that originate from the vortex shedding from reactor structure components, fuel element end fittings, or the plate edges exposed to the flow. For oscillatory behavior, the analysis must be able to resolve all the flow fluctuations leading to cyclic loading exerted on the plate and subsequently must be able to resolve the motion of the plate at the time discretization level associated with the frequencies of the oscillating loads. If resolution on smaller time and length scales is required (owing to the expected 
large oscillations), the solution of Large Eddy Simulation (LES) may be needed. LES requires significantly denser spatial and temporal discretization than the URANS simulations.

MITR HEU fuel plates have been operating within the MIT reactor for several decades without any failures. Experiments conducted during the design and original start-up stages did not indicate any visible oscillations of the plates [37]. However, the proposed MITR LEU fuel plates are thinner than the HEU plates and do not have fins. Thus, their bending stiffness is reduced as compared to the HEU plates.

To judge which type of analysis is required for this study, the estimation of Miller's critical velocity and comparison of the expected velocities in the coolant channels of the proposed LEU element were performed. As pointed out earlier, if the expected velocity in the coolant channels is well below Miller's critical velocity, the pressure differential is expected to be a primary driver of plate deflections, and large-scale oscillations of the plates are not expected. The following equation has been used for the critical velocity estimation for a flat plate with fixed boundary conditions [7]:

$$
V_{c}=\left[\frac{15 E a^{3} h}{\rho b^{4}\left(1-v^{2}\right)}\right]^{1 / 2}
$$

where $V_{c}$ is the critical velocity beyond which the plate could collapse, $E$ is Young's modulus of the plate, $a$ is the plate thickness, $h$ is the channel gap thickness, $\rho$ is coolant density, $b$ is the channel width, and $v$ is Poisson's ratio. The Miller's velocity for the MITR LEU core was calculated to be $16.65 \mathrm{~m} / \mathrm{s}$ using the inputs shown in Table 2.5. In this evaluation, the plate aluminum properties were used for the plate. Note that here the thin channel gap size $(70 \mathrm{mil})$ and the plate thickness (46 mil) are the minimum within the tolerance, which makes the calculated Miller velocity more conservative. The Miller velocity calculated using the nominal thicknesses for plate and channels is $18.90 \mathrm{~m} / \mathrm{s}$.

Table 2.5 Channel size and plate properties used in Miller's critical velocity calculations

\begin{tabular}{|l|l|c|}
\hline Plate/channel width & $b(\mathrm{inch})$ & 2.308 \\
\hline Plate thickness & $a(\mathrm{mil})$ & 46 \\
\hline Channel gap thickness & $h(\mathrm{mil})$ & 70 \\
\hline Young's modulus & $E(\mathrm{GPa})$ & 68.1 \\
\hline Poisson's ratio & $v(-)$ & 0.33 \\
\hline Density & $\rho\left(\mathrm{kg} / \mathrm{m}^{3}\right)$ & 991 \\
\hline
\end{tabular}

The ratios of the predicted flow velocities from Section 2.1.2 to Miller's critical velocity have been calculated for the conservative scenario with lift and are listed in Table 2.6. The basic Miller's formula has been developed for channels with identical thickness on both sides of the plate. In the worst case analyzed here, there is a large disparity in the channel gap thicknesses ( $70 \mathrm{vs} 247 \mathrm{mil}$ ). The maximum velocities in these two channels are estimated at 2.79 and $4.99 \mathrm{~m} / \mathrm{s}$, respectively. It is expected that Miller's formula is less reliable for cases with such large disparities. Thus, the actual threshold velocity around which vibrations can be noticed may be different. Nonetheless, this estimation should provide the first check of the nature of the plate's behavior. 
Table 2.6. Miller's critical velocity calculations for MITR LEU plate

\begin{tabular}{|c|c|c|c|}
\hline Channel type & $\begin{array}{c}\text { Velocity in } \\
\text { channel v }(\mathrm{m} / \mathrm{s})\end{array}$ & $\begin{array}{c}\text { Critical velocity } \\
\mathrm{V}_{\mathrm{c}}(\mathrm{m} / \mathrm{s})\end{array}$ & $\begin{array}{c}\text { Ratio } \\
\mathrm{v} / \mathrm{v}_{\mathrm{c}}\end{array}$ \\
\hline Thin & 2.79 & 16.65 & 0.168 \\
\hline Thick & 4.99 & 31.28 & 0.160 \\
\hline
\end{tabular}

If the Miller's velocity is estimated separately for the thin and thick channel gaps and then actual coolant velocities are compared to these values, the ratios are 0.17 and 0.16 for the thin and thick channel gaps, respectively. These ratios are far away from Miller's critical velocity, and vibrations of the plate at significant magnitudes are not expected.

For the reason described above, pressure differential induced deflections are expected to be the primary mode of the plate's response to the hydrodynamic loading expected during the operation of MITR with LEU fuel. Thus, the URANS methodology is sufficient for further analysis.

The turbulence models provide closure relations for the RANS equations, which govern the transport of the mean flow quantities. The RANS momentum equation can be written as [28]

$$
\frac{\partial \rho}{\partial t}(\rho \bar{v})+\nabla \cdot(\rho \bar{v} \otimes \bar{v})=-\nabla \cdot \bar{p} \mathbf{I}+\nabla \cdot\left(\mathbf{T}+\mathbf{T}_{\mathbf{R A N S}}\right)+\mathbf{f}_{\mathbf{b}}
$$

where $\rho$ is density, and $\bar{v}$ and $\bar{p}$ are the mean velocity and pressure, respectively. I and $\mathbf{T}$ are the identity tensor and the viscous stress tensor; $\mathbf{f}_{\mathbf{b}}$ represents the body force effect. $\mathbf{T}_{\text {RANS }}$ is the additional turbulent stress tensor compared to the original form of the Navier-Stokes equations and is defined as follows:

$$
\mathbf{T}_{\mathbf{R A N S}}=-\rho\left(\begin{array}{lll}
\overline{u^{\prime} u^{\prime}} & \overline{u^{\prime} v^{\prime}} & \overline{u^{\prime} w^{\prime}} \\
\overline{u^{\prime} v^{\prime}} & \overline{v^{\prime} v^{\prime}} & \overline{v^{\prime} w^{\prime}} \\
\overline{u^{\prime} w^{\prime}} & \overline{v^{\prime} w^{\prime}} & \overline{w^{\prime} w^{\prime}}
\end{array}\right)+\frac{2}{3} \rho k \mathbf{I}
$$

where $k$ is the turbulent kinetic energy and the terms in the brackets are the Reynolds stress tensor components. The eddy (turbulent) viscosity concept is widely used to model the turbulent stress tensor, and most used turbulence models are based on the Boussinesq approximation:

$$
\mathbf{T}_{\mathbf{R A N S}}=-2 \mu_{t} \mathbf{S}+\frac{2}{3}\left(\mu_{t} \nabla \cdot \bar{v}\right) \mathbf{I}
$$

where $\mathbf{S}$ is the mean strain tensor which can be calculated using the mean velocity, and $\mu_{t}$ is the effective or eddy viscosity, which is determined by turbulence closure models. The eddy viscosity for the $\mathrm{k}-\varepsilon$ model, used in this study, is calculated using the following formula [38] [28]:

$$
\mu_{t}=\rho C_{\mu} f_{\mu} k \frac{k}{\varepsilon}
$$


Where $\varepsilon$ is the dissipation rate of turbulent kinetic energy $k$, and the ratio $k / \varepsilon$ is the turbulent time scale. $C_{\mu}$ and $f_{\mu}$ are the model coefficient and damping function, respectively. The transport equations for turbulent kinetic energy $k$ and the dissipation rate $\varepsilon$ are given as

$$
\begin{gathered}
\frac{\partial(\rho k)}{\partial t}+\nabla \cdot(\rho k \bar{v})=\nabla \cdot\left[\left(\mu+\frac{\mu_{t}}{\sigma_{k}}\right) \nabla k\right]+P_{k}-\rho\left(\varepsilon-\varepsilon_{0}\right)+S_{k} \\
\frac{\partial(\rho \varepsilon)}{\partial t}+\nabla \cdot(\rho \varepsilon \bar{v})=\nabla \cdot\left[\left(\mu+\frac{\mu_{t}}{\sigma_{\varepsilon}}\right) \varepsilon k\right]+\frac{1}{T_{e}} C_{\varepsilon 1} P_{\varepsilon}-C_{\varepsilon 2} f_{2} \rho\left(\frac{\varepsilon}{T_{e}}-\frac{\varepsilon_{0}}{T_{0}}\right)+S_{\varepsilon}
\end{gathered}
$$

Detailed descriptions of the coefficients in these two equations are available in the STAR-CCM+ user guide [28]. Various forms of the k- $\varepsilon$ model are incorporated in STAR-CCM+, and the default option of the realizable $\mathrm{k}-\varepsilon$ two-layer model with the two-layer all $\mathrm{y}+$ (a non-dimensional distance from the wall to the first element's center) wall function is used in this work, detailed description of two-layer all $y+$ wall function is available in the reference [28] . The effects of turbulence model selection on the FSI analysis have been evaluated and will be discussed in Section 3.5.

Tentner et al. [25] used the k- $\varepsilon$ turbulence model in the STAR-CCM+ simulations to replicate FSI experiments for flat and curved aluminum plates. Since good agreement between the experimental and simulated results have been obtained, that approach was adopted in the current work.

\subsubsection{Fluid Physical Properties}

MITR uses light water as the coolant. The nominal inlet coolant temperature of MITR is around $44{ }^{\circ} \mathrm{C}$ [39], and the nominal outlet temperature is $55^{\circ} \mathrm{C}$ [40]. In addition, the coolant temperature varies for different channels, and Reference [39] mentioned that the bulk coolant temperature is in the range of $45^{\circ} \mathrm{C}-65^{\circ} \mathrm{C}$. In this work, the coolant properties (density and dynamic viscosity) at $55^{\circ} \mathrm{C}$ are used for FSI simulation: the coolant density is $985.71 \mathrm{~kg} / \mathrm{m}^{3}$, and the coolant dynamic viscosity is $0.5036 \mathrm{mPa} \cdot \mathrm{s}$. Sensitivity analysis of the coolant properties effect on the FSI simulation result is presented in Section 3.6

\subsubsection{Solid Properties and Model}

In this analysis, the FSI has been decoupled from the other structural effects caused by irradiation (swelling, creep, material property change, thermal expansion). Assessment of combined effects may be planned for a later stage of this project if deemed necessary. The primary property governing the structural response of a material in the elastic range is its Young's modulus. Since the modulus of the fuel core in the fresh state is higher than the modulus of the aluminum, a conservative magnitude of displacement is computed in this work assuming aluminum properties throughout the entire thickness of the plate. This assumption has also been confirmed by the experimental results of the Generic Test Plate Assembly (GTPA) campaign [41]. In a three-point bending test, it has been shown that the bending stiffnesses of four plates, including two tempers of 6061 aluminum plates (T0 and T6) as well as two composite plates, one with stainless steel surrogate dispersed fuel and one with depleted U-10Mo foil cores, are nearly identical. Nonetheless, FSI analysis with the separate model

MITR Low-Enriched Uranium Conversion Fluid-Structure Interaction Preliminary Design Verification 
of fuel and cladding was also performed to evaluate the differences in predicted deflections without this simplification. The results from that analysis are presented in Section 4.5.

The isotropic linear elasticity model is assumed for the material law in the simulation. The solidstress model and the fluid-structure two-way coupling model are used for the FSI analysis. A detailed description of these models is available in the STAR-CCM+14.02 user guide [28]. The assumed material properties of aluminum are listed in Table 2.7. The basis for these properties was Reference [42]. While Young's modulus decreases with the temperature, the irradiation effects are not considered in this analysis. A constant value of the modulus has been assumed for the maximum fuel plate temperature of $93.8{ }^{\circ} \mathrm{C}$ [39]. As stated earlier, this analysis is not considering to the full extent the effects of irradiation. Thus, no detailed thermal analyses are performed here. However, based on the available analysis from STAT7 [39], it can be concluded that during the reactor operation, the temperature experienced by the fuel plate will be within the approximate range of $65^{\circ} \mathrm{C}$ to $93.8{ }^{\circ} \mathrm{C}$. In that range, Young's modulus will vary between 67.9 and $66.8 \mathrm{GPa}$ [42]. Since no plastic deformations due to FSI are expected (as confirmed later in this work), linear dependency of deflection on the Young's modulus can be assumed. That narrow range of Young's modulus variation within expected temperatures will result in a $<1.6 \%$ variation of predicted deflections.

Table 2.7. Assumed material properties of all-aluminum plate

\begin{tabular}{|c|c|c|}
\hline Density & Young's modulus & Poisson's ratio \\
\hline $2686.5 \mathrm{~kg} / \mathrm{m}^{3}$ & $66.8 \mathrm{GPa}$ & 0.33 \\
\hline
\end{tabular}

Assuming that the fuel-plate swaging in the side plates is a controlled process creating a continuous connection between them with a high resistance to pull, perfect fixed structural-boundary conditions were used on the longer edges of the plates. Shorter edges (leading and trailing edges) were free to move.

The yield strength of AA6061 cladding after a fuel plate has been processed by hot isostatic pressing (HIP) was reported in the Preliminary U-10Mo Report [43]. Using the properties of O-temper AA6061 is comparable in this case, which at room temperature is listed in Reference [43] as $55 \mathrm{MPa}$. This is a reasonable (and conservative) approximation for AA6061 yield strength [42].

As mentioned above, although a homogenous aluminum plate was assumed for most simulation cases to represent the whole fuel plate and its behavior due to FSI, several simulations (in Section 4.5) were performed with a more complex model containing separate layers of the fuel core and cladding. Thus, the properties of U-10Mo fuel core are introduced here. The Young's modulus of U-10Mo alloy varies with temperature, heat-treatment approach, aging, irradiation effect, etc. [43]. Therefore, three values of Young's modulus are used in the FSI simulation to envelop the possible values of Young's modulus of U-10Mo. Young's modulus of 88.4 GPa represents the nominal value at $20^{\circ} \mathrm{C}$ based on Table C-13 of Reference [43], while 30.6 GPa and 125.5 GPa represent the lower and upper limits, respectively. The Young's modulus value of $125.5 \mathrm{GPa}$ was reported in reference [44] for gammaquenched and aged U-10Mo alloys at $21^{\circ} \mathrm{C}$, and the value of $30.6 \mathrm{GPa}$ is for U-10Mo irradiated at $8.0 \times 10^{21}$ fissions $/ \mathrm{cm}^{3}$ at $20^{\circ} \mathrm{C}$ [43]. All these numbers were obtained from the Preliminary Report on U-Mo Monolithic Fuel for Research Reactor [43]. The Poisson's ratio of 0.41 from the same reference [43] is used for U-10Mo fuel. 


\subsection{Simulation Matrix}

Three factors that could affect the plate deflection are considered in this work: 1) thickness disparity of adjacent coolant channel gaps, 2) non-uniformities in the shape of the plate within the design tolerances, and 3) coolant velocity uncertainty. Table 2.8 shows the details of the 14 FSI simulation cases performed in this work. Case 1 adopts all nominal geometry (thicknesses of the plate as well as the thick and thin coolant channel gaps), while Cases 2 through 9 assume conservative (thinnest possible within the manufacturing tolerance) sizes for the internal (thin) channel gaps and the plate thicknesses. Details of these sizes and tolerances are available in references [29] and [30]. Cases 2, 3, and 4 have different outer (thick) channel sizes, and different inlet mass flow rates, which are determined by full-core pressure-drop balance analysis and have been discussed in Section 2.1.2. The outer channel could reach 247 mil if one considers the fuel element lift-up and the end fitting geometric fabrication tolerances, compared to the nominal size of $141 \mathrm{mil}$. If one does not consider the lift-up and only accounts for the end fitting fabrication tolerances, the maximum outer channel gap is 186 mil. Case 4, with the largest channel gap thickness disparity, is expected to have the maximum plate displacement among Cases 1 to 4, as will be shown in Section 3.3.

Table 2.8. Simulation matrix

\begin{tabular}{|c|c|c|c|c|c|}
\hline $\begin{array}{c}\text { Case } \\
\#\end{array}$ & $\begin{array}{c}\text { Thick- } \\
\text { channel size } \\
\text { (mil) }\end{array}$ & $\begin{array}{c}\text { Thin- } \\
\text { channel } \\
\text { size } \\
\text { (mil) }\end{array}$ & $\begin{array}{c}\text { Plate } \\
\text { thickness } \\
\text { (mil) }\end{array}$ & $\begin{array}{l}\text { Inlet } \\
\text { flow } \\
\text { rate } \\
(\mathrm{kg} / \mathrm{s})\end{array}$ & Notes \\
\hline 1 & 141 & 74.6 & 49 & 1.13 & All geometry size is nominal \\
\hline 2 & 141 & 70 & 46 & 1.13 & $\begin{array}{l}\text { Nominal outer channel, thinnest inner } \\
\text { channel and plate }\end{array}$ \\
\hline 3 & 186 & 70 & 46 & 1.54 & Conservative outer channel \\
\hline 4 & 247 & 70 & 46 & 2.13 & $\begin{array}{l}\text { Conservative outer channel with fuel lift } \\
\text { considered }\end{array}$ \\
\hline 5 & 247 & 70 & 46 & 2.34 & $12.35 \%$ higher inlet velocity than Case 4 \\
\hline 6 & $242.5-251.5$ & $70-79$ & 46 & 2.13 & Plate slanted (see Figure 2.6) \\
\hline 7 & 247 & 70 & 46 & 2.13 & Plate deformed 10th mode (see Figure 2.8) \\
\hline 8 & 247 & 70 & 46 & 2.13 & Plate deformed $2^{\text {nd }}$ mode (see Figure 2.10 ) \\
\hline 9 & $242.5-251.5$ & $70-79$ & 46 & 2.34 & $12.35 \%$ higher inlet velocity than Case 6 \\
\hline 10 & 141 & 74.6 & 49 & 1.13 & $\begin{array}{l}\text { Layered plate with separate core model } \\
\text { (Efuel }=88.4 \mathrm{GPa} \text { ) }\end{array}$ \\
\hline 11 & 141 & 74.6 & 49 & 1.13 & $\begin{array}{l}\text { Layered plate with separate core model } \\
\left(E_{\text {fuel }}=30.6 \mathrm{GPa}\right)\end{array}$ \\
\hline 12 & 141 & 74.6 & 49 & 1.13 & $\begin{array}{l}\text { Layered plate with separate core model } \\
\left(E_{\text {fuel }}=125.5 \mathrm{GPa}\right)\end{array}$ \\
\hline 13 & $70-79$ & $79-70$ & 46 & 0.61 & Inner channels with slanted plate \\
\hline 14 & 79 & 70 & 46 & 0.61 & $\begin{array}{l}\text { Inner channels with the largest size disparity } \\
\text { within the tolerance }\end{array}$ \\
\hline
\end{tabular}

To further explore the maximum possible displacement, the flow rate uncertainty and the range of allowable plate shape are considered, and Case 4 will be used as the base for further simulations. The MITR pump flow uncertainty is $5 \%$, and the flow disparity for the different elements within the core is estimated to be $7 \%$ [40]. Combining the pump uncertainty and the flow distribution uncertainty 
(by multiplying the two factors $1.07 \times 1.05$ ), a total uncertainly level of $12.35 \%$ has been obtained, which is considered as limiting conditions for operation for coolant flow rate in FSI aspect. Therefore, the flow rate of Case 5 is $112.35 \%$ of the flow rate of Case 4.

In the case of coolant velocity significantly lower than Miller's critical velocity, the non-uniformity in the shape of the plate and channel boundaries may have an impact on the magnitude of the plate's deflection. Once the velocity approaches the critical threshold, the plate may start to vibrate, assuming one or a combination of its modal shapes. The amplitude of these vibrations will become significantly larger than the assembly tolerances, and at some high velocity (significantly higher than the nominal operating velocity) the plate will fail plastically, assuming one or a combination of these modal shapes. This behavior has been confirmed recently by GTPA experiments [41].

Since it is known that the imperfections influence the shape and the magnitude of the deflections [25], it is prudent to analyze other than ideal shapes of the plates. The fuel elements with LEU plates have not been manufactured yet and their as-built shape cannot be predetermined. For the following cases, various shapes of pre-deformed plates have been assumed within the manufacturing and assembly tolerances to maximize the predicted deflections of the plate (i.e., create the most adverse geometrical conditions).

Cases 6 through 9 consider range of allowable shapes of the plate and channel thicknesses. In Case 6, the plate is slanted within the tolerance of the internal channel gap thickness. Figure 2.6 contains a schematic showing a side view of the geometry used in that case. The assembly tolerance range for the internal channel is from 70 mil to 79 mil, which is based on the fuel element drawings [29]. As an additional adverse condition, the thin channel gap thickness is 79 mil at the inlet and 70 mil at the outlet. The thick-channel size varies correspondingly to ensure a constant total channel gap thickness along the flow direction. As a result, there will be extra pressure acting on the plate, deforming it towards the thick channel, and larger displacement is expected compared to Case 4 (with plate parallel to the flow direction).

In Cases 7 and 8, the plate was pre-deformed, with the shapes determined on the basis of modal analysis. Results of that analysis are briefly presented in APPENDIX B. The modal analysis, by definition, only provides the shapes but not the magnitude, which was scaled to stay within the fuel plate flatness tolerance of 6 mil [30]. Previous GTPA experimental study [41] on flat plates indicated that plastic deformation failures occurred at velocities far higher than are of interest for MITR, and observed in most failures wavy, higher-order (between $7^{\text {th }}$ and $10^{\text {th }}$ ) modal shapes. In this analysis, $2^{\text {nd }}$ and $10^{\text {th }}$ modes were considered, though only in the expected elastic range of deformation. The $2^{\text {nd }}$ mode is similar to the shape of the deformed ideal plate (see Case 1 for an example). Thus, assuming a pre-deformed shape using the $2^{\text {nd }}$ mode could amplify that preferred deformation shape. The higher-order modes that were identified in failed-GTPA studies (between $7^{\text {th }}$ and $10^{\text {th }}$ ) have their modal frequencies very close to each other. This means that when the plate vibrates, each of these is equally possible. The $10^{\text {th }}$ mode was used for Case 7 as a representative one from that group. The side view of the $10^{\text {th }}$ mode deformed plate of Case 7 is shown in Figure 2.7. The plate is deformed with a peak-to-peak amplitude of $6 \mathrm{mil}$, which ensures that the plate with such deformation is still satisfying the design specification and could be used in the fuel element. Note that the plate deformation magnitude shown in Figure 2.7 is scaled up by a factor of 500 for illustration purposes only; the deformation shape is hardly visible if plotted to true scale.

MITR Low-Enriched Uranium Conversion Fluid-Structure Interaction Preliminary Design Verification 


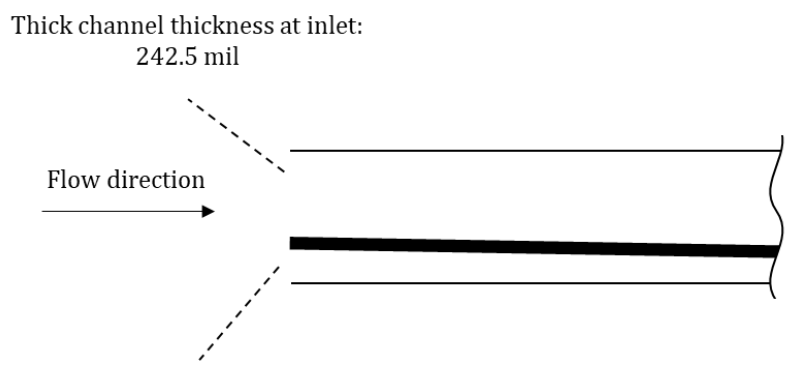

Thin channel thickness at inlet: 79 mil

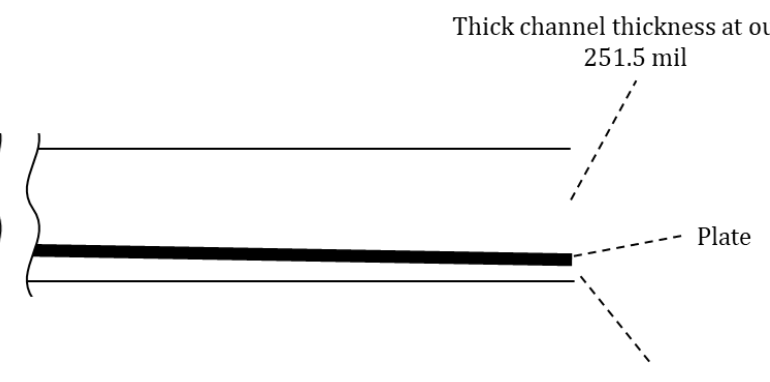

Thin channel thickness at outlet 70 mil

Figure 2.6. Schematic side view of Case 6 slanted plate

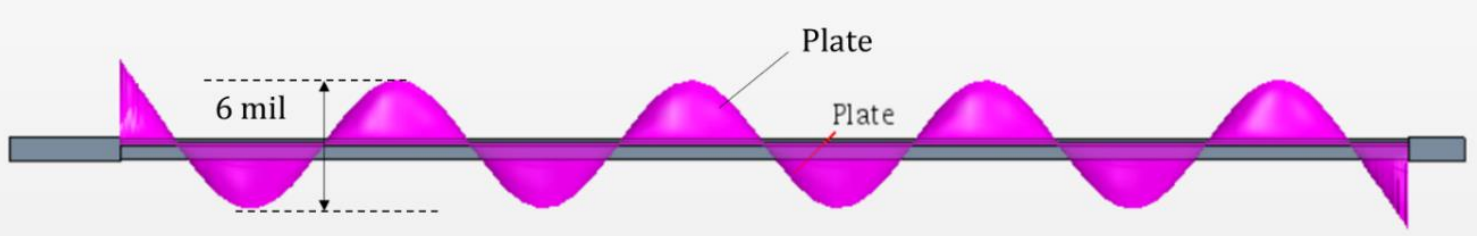

$z \stackrel{Y}{X}$

Figure 2.7. Side view of Case 7 deformed plate, $10^{\text {th }}$ mode (plate deformation magnitude scaled up by 500)

$\longleftarrow$ Flow direction

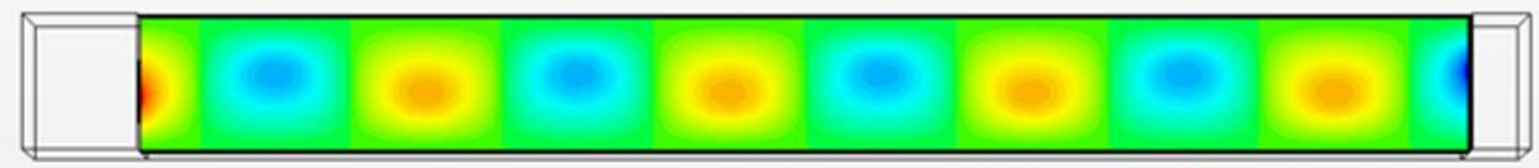

Magnitude of fuel plate non-uniformity [inch]

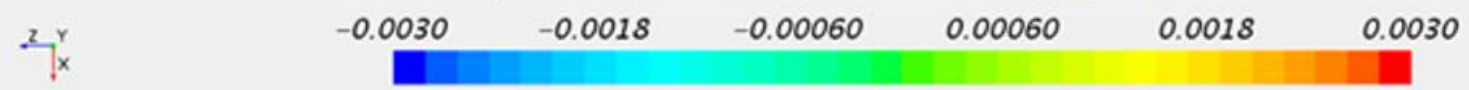

Figure 2.8. Deformation contour in Y-direction of Case 7 deformed plate, $\mathbf{1 0}^{\text {th }}$ mode

For Case 8 , the plate was pre-deformed using the $2^{\text {nd }}$ modal shape. Figure 2.9 is a 3 -D view of the geometry used in that case. Note that the deformation magnitude is also scaled up here, for illustration purposes only. Figure 2.10 presents the initial deformation contour plot on the plate for Case 8. 


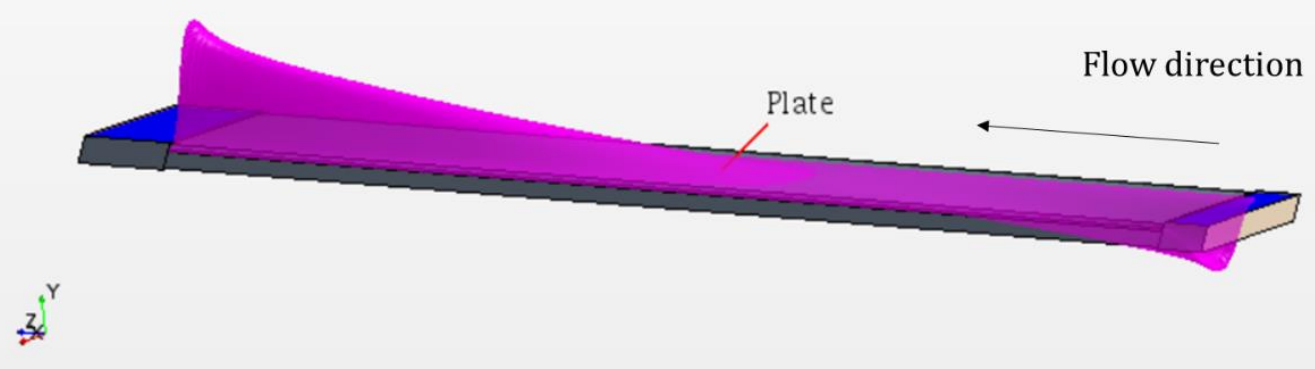

Figure 2.9. 3-D view of Case 8 deformed plate, $2^{\text {nd }}$ mode (plate deformation magnitude scaled up by 500)

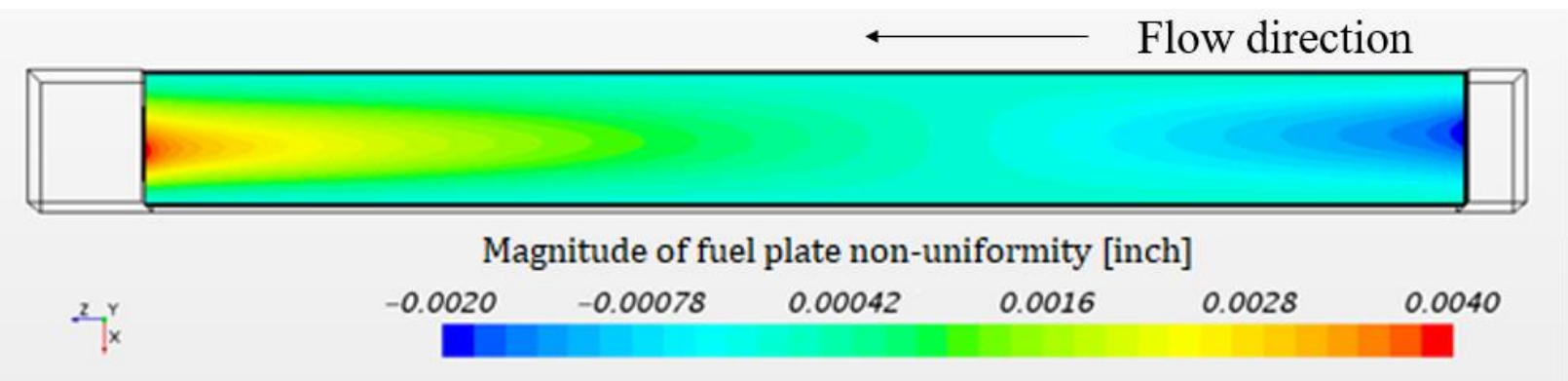

Figure 2.10. Deformation contour in Y-direction of Case 8 deformed plate, $2^{\text {nd }}$ mode

The Case 6 geometry was used as a base for Case 9. Among the cases with pre-deformed geometry (Cases 6 to 8), the largest displacement was predicted for Case 6. In Case 9, the flow rate was increased by $12.35 \%$ to account for the uncertainties of the flow rate.

In Cases 10 to 12, the same channel gap geometry and flow rate as in Case 1 was used. However, in this case the plate was built of two external layers of cladding, and the core had a Young's modulus of U-10Mo fuel. These cases were built to verify the accuracy of the assumption that an all-aluminum plate yields conservative results for the FSI type of analysis. A detailed explanation of these three cases along with the layered plate model is given in Section 4.5.

Since the limiting thermal hydraulic locations in MITR are the "F" plates (or the internal ones), FSI analysis was performed by modeling the " $F$ " plate of interest and surrounding coolant channel gaps in Case 13 and 14. In Case 13, a slanted flat plate was modeled (equivalent to Case 6), with both channel gaps varying only within the range from 70 to 79 mil, while in Case 14 the thick-channel gap thickness is 79 mil and the thin-channel gap thickness is 70 mil. The inlet flow rate for these two conditions is the sum of the mass flow rate of two internal channels with nominal channel gap thickness. 


\section{Sensitivity Analysis}

\subsection{Mesh Sensitivity Study}

The results of the mesh sensitivity analysis are shown in Figure 3.1. The maximum displacement of the plate is the parameter of interest and is used to evaluate mesh sensitivity. The mesh refinement is performed separately in the channel gap thickness, length, and width directions, and the results are shown as subplots in Figure 3.1. The meshes in the fluid and solid region are refined simultaneously. In these subplots, the y axis is the maximum plate displacement normalized by the value from the finest mesh, and the $\mathrm{x}$-axis is the nominal element size, which is the geometry size divided by the element number in that direction. Note that the actual element size usually varies, as the finer mesh is needed in the channel direction near the wall to keep y+ below 5 , as well as in the length direction near the plate leading/trailing edge to resolve the flow separation. The number beside the symbol is the corresponding element quantity, and the solid symbol represents the mesh that is selected to perform the FSI analysis. Figure 3.1 shows that the maximum displacement will not change by more than $0.5 \%$ as a result of further refining the selected mesh, and the selected mesh result is in the asymptotic region.

In addition to the element quantity in each direction, the sensitivity of the element size in the length direction near the leading edge was also evaluated. Figure 3.2 is the side view of the mesh, which shows that the mesh size in the length direction is smallest at the leading edge and increases in both directions with the hyperbolic distribution. Since the pressure difference peak and maximum displacement usually happen at the leading edge, the element size at this position requires extra attention. The selected leading-edge element size is $0.05 \mathrm{~mm}$, and Figure 3.1 shows that further reducing this size has a negligible effect on maximum-displacement prediction. Detailed information about the selected mesh is shown in Table 3.1. For nominal thick channel gap thickness (Case 2), the total element number is 2,920,000 and 400,000 for the fluid and solid region, respectively. For the largest thick channel gap thickness (Cases 4-9), the fluid-region element number increases to $4,160,000$, while the solid-region element number stays unchanged.

It is worth mentioning that sensitivity analyses performed in this section, excepting the coolant properties sensitivity (Section 3.6), are performed using fluid properties at $25^{\circ} \mathrm{C}$. However, the results presented and discussed in Section 4 are based on coolant properties evaluated at $55^{\circ} \mathrm{C}$ (MITR nominal outlet temperature). See Section 3.6 for discussion of the relative insensitivity to the coolant properties. 

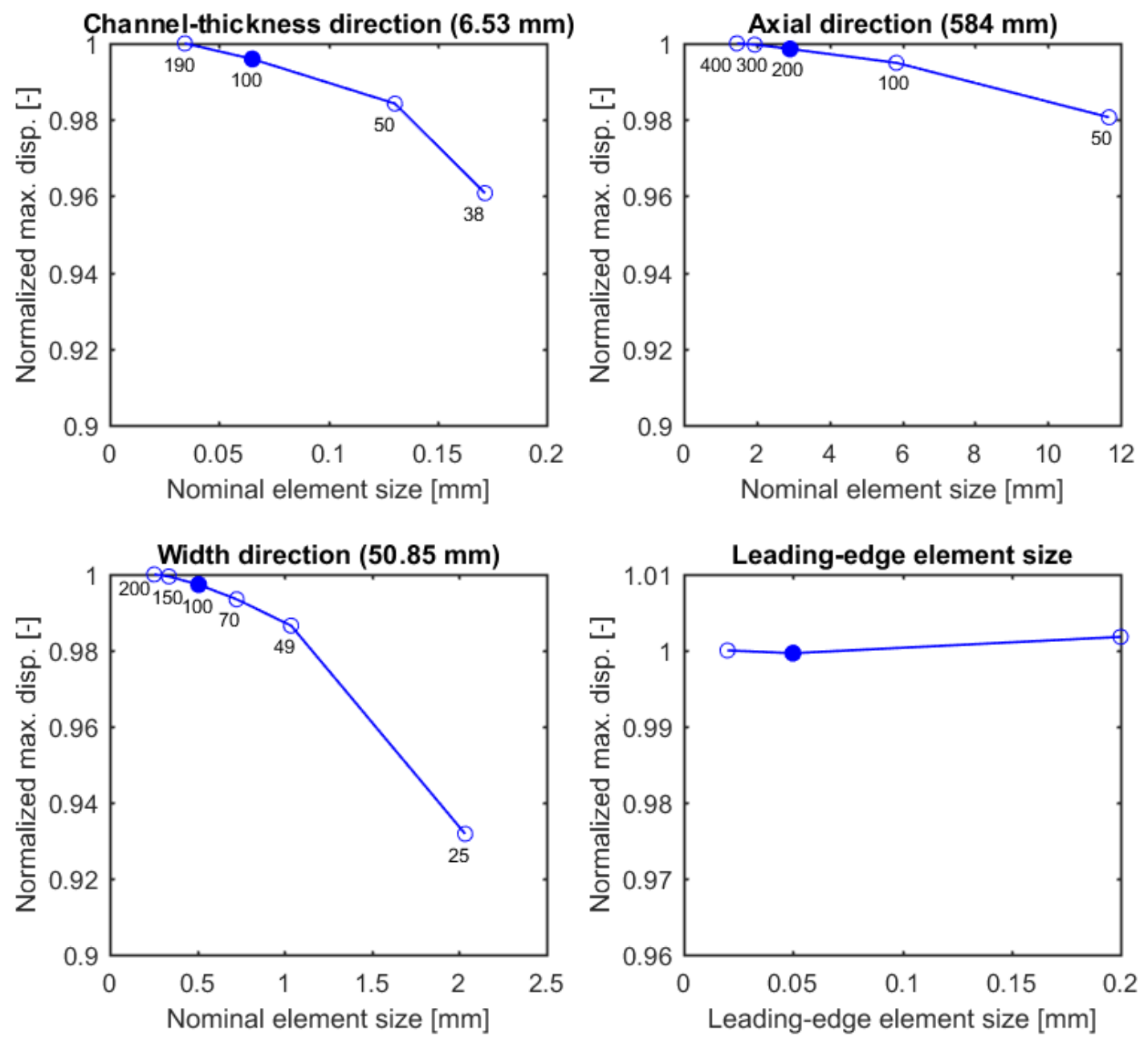

Figure 3.1. Mesh sensitivity analysis results

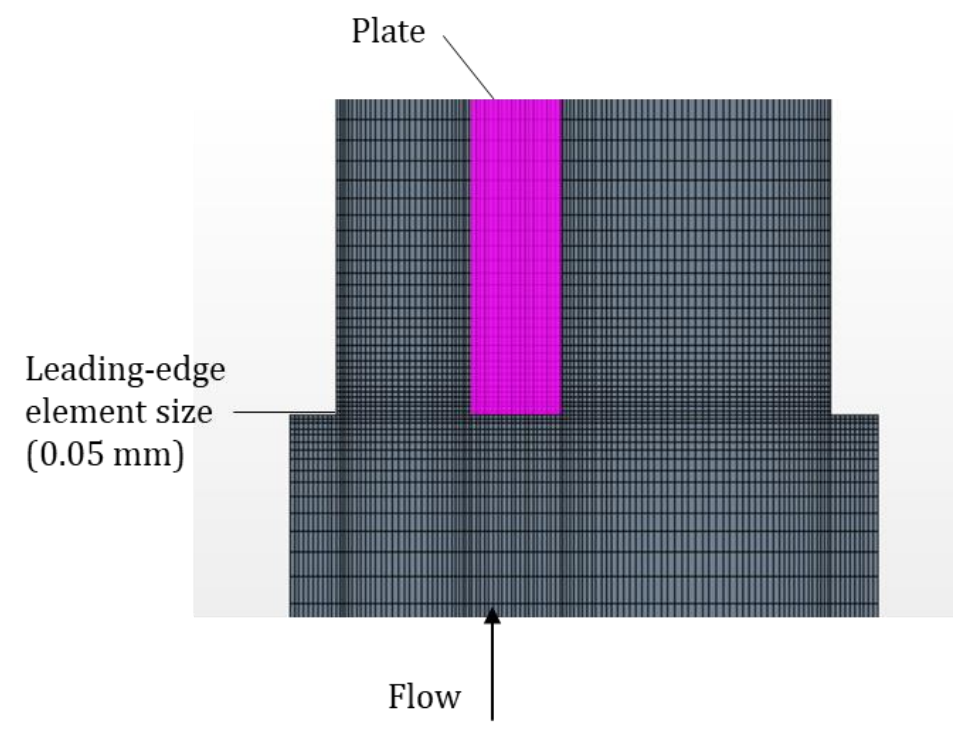

Figure 3.2. Side view of mesh near the leading edge 
Table 3.1. Mesh information for FSI analysis

\begin{tabular}{|c|c|c|c|}
\hline Number of elements in the direction of: & $\begin{array}{c}\text { Element } \\
\#\end{array}$ & Type & $\begin{array}{c}\text { Side } \\
\text { element } \\
\text { size (mm) }\end{array}$ \\
\hline Thin channel gap thickness & 30 & Two side Hyperbolic & 0.02 \\
\hline Plate thickness & 20 & Constant & - \\
\hline $\begin{array}{c}\text { Thick channel gap thickness } \\
\text { (Nominal/Conservative/Conservative with Lift) }\end{array}$ & $50 / 70 / 90$ & Two side Hyperbolic & 0.025 \\
\hline Upper plenum length & 50 & Two side Hyperbolic & $0.2 / 0.05$ \\
\hline Plate length & 200 & Two side Hyperbolic & $0.05 / 0.1$ \\
\hline Lower plenum length & 60 & One side Hyperbolic & 0.1 \\
\hline Width of fluid & 100 & Two side Hyperbolic & 0.05 \\
\hline Width of plate & 100 & Constant & - \\
\hline
\end{tabular}

\subsection{Time Step and Run Time Sensitivity}

The time step used in this study was $0.001 \mathrm{~s}$, and within each time step the inner iteration step was 30. The total FSI simulation time was more than $0.4 \mathrm{~s}$, compared to the flow-through time of $0.21 \mathrm{~s}$. The sensitivity of these parameters was evaluated, and the results are presented in Table 3.2 and Figure 3.3. Table 3.2 is the comparison of maximum displacement using different time steps and inner iteration step numbers, where the selected value is highlighted in blue and used for normalization. The comparison indicates that further reducing the time step or increasing the inner iteration number does not noticeably affect the maximum displacement result. Figure 3.3 shows the iteration/time history of the plate maximum displacement. During the first $0.15 \mathrm{~s}$, the FSI-related solvers (solid stress, fluid-structure coupling) are frozen so that STAR-CCM+ only solves for the fluid field. After the fluid flow is converged (no more changes in the flow rate on the outlet), the FSI-related solvers are enabled, and the displacement of the plate is tracked. The FSI simulation runs for more than $1 \mathrm{~s}$, and the maximum displacement is almost converged after $0.3 \mathrm{~s}$; as shown in Figure 3.3, the maximum deviation from $0.4 \mathrm{~s}$ to around $1.15 \mathrm{~s}$ is $0.0031 \%$. Therefore, the first $0.4 \mathrm{~s}$ of FSI simulation time used in this study is enough to get a converged result.

Table 3.2. Comparison of maximum displacement using different time steps and inner iterations

\begin{tabular}{|c|c|c|}
\hline \multirow{4}{*}{$\begin{array}{c}\text { Time step } \\
\text { sensitivity }\end{array}$} & $\begin{array}{c}\text { Time step } \\
\text { (ms) }\end{array}$ & $\begin{array}{c}\text { Normalized } \\
\text { Max. Displ. }\end{array}$ \\
\cline { 2 - 3 } & 0.5 & $99.9 \%$ \\
\cline { 2 - 3 } & 1 & $100.0 \%$ \\
\hline \multirow{2}{*}{$\begin{array}{c}\text { Inner } \\
\text { iteration } \\
\text { step } \\
\text { sensitivity }\end{array}$} & $\begin{array}{c}\text { Inner } \\
\text { iteration step }\end{array}$ & $\begin{array}{c}\text { Normalized } \\
\text { Max. Displ. }\end{array}$ \\
\cline { 2 - 3 } & 30 & $100.0 \%$ \\
\hline
\end{tabular}




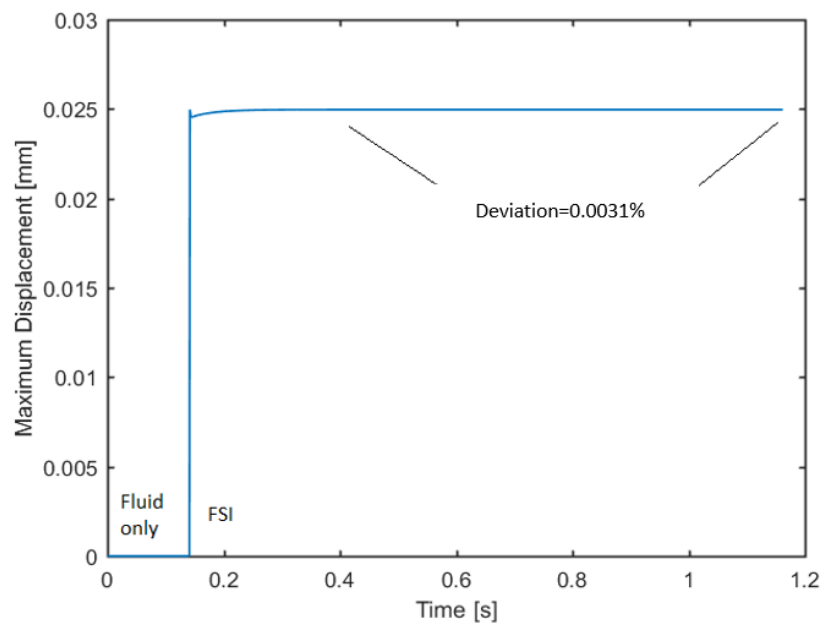

Figure 3.3. Simulation convergence in time

\subsection{Solver Type Sensitivity}

The past FSI analysis performed for another USHPRR [25] used primarily an FV solver within STAR$\mathrm{CCM}+$ to solve both the fluid and the solid domains. The FE solver was just being developed in STAR$\mathrm{CCM}+$ at the time, and only a few verification cases had been run. For both cases, the FV solver was used for the fluid as the only option. The analysis has shown that for very thin curved plates (16 mil thick), the combination of FE solver for the solid and FV solver for the fluid may underestimate maximum deflections by up to $20 \%$ for high flow rates. Such verification had not been performed at the time for thicker ( $\geq 40$ mil) flat plates. Currently, the FV solver is no longer being developed in STAR-CCM+ (although it is still available). It has many limitations and requires significantly denser meshes than the equivalent FE solver. For example, the FV solid model tested in this work requires 400 cells in the width direction and 800 cells in the axial direction to get a mesh independent result, while these values for the FE solid model are 100 and 200, respectively. Thus, the FV solver is not recommended if FE can be used instead. The FE solver has become the primary solver for the structural mechanics in STAR-CCM+ and is used in this work for most of the simulations. To check that predictions made by FE solver for solid and FV solver for fluid are not underestimating the deflections, several verification cases have been run using the FV solver for both solid and fluid domains. Also, additional cases have been simulated in LS-DYNA commercial software in order to perform code-to-code verification. This comparison was made for the geometry and flow conditions of Case 1.

The pressure on the plate was obtained from STAR-CCM+ and only the deflections were calculated in LS-DYNA. That way, for all performed simulations, the pressure distribution on the plates was calculated with the use of FV solver, regardless of the solver used for the solution of the solids (fuel plates). In the LS-DYNA solver, solid (brick) as well as shell elements have been used to model the plate. Both approaches to modeling fuel plates have their advantages and disadvantages. Currently, STAR-CCM+ does not offer shell elements. While, in general, solid elements allow for more precise through-thickness behavior modeling by explicitly modeling all the layers of a plate, they require significantly more elements for converged results than the shell elements. The shape of solid elements should be as close to a cube as possible to obtain a correct solution. The shell elements are perfectly suited for modeling the bending behavior of slender structures like fuel plates, but throughthickness behavior modeling with the use of shell elements is not straightforward, and layered 
composite theory needs to be utilized. For the current FSI purposes, only bending characteristics of the fuel and the cladding are of interest, and no complex through-thickness effects are considered.

Figure 3.4 shows results of a limited mesh sensitivity study using one-way coupling simulations between STAR-CCM+ and structural models in LS-DYNA. Since this was treated only as a verification run, a more detailed mesh convergence study was not performed. The largest deflection predicted by the model with solid elements was $0.0174 \mathrm{~mm}$ for the element size on the edge of $0.2 \mathrm{~mm}$. The shell model predicts larger deflections, at $0.0187 \mathrm{~mm}$, and appears to be converged even for the mesh with $3 \mathrm{~mm}$-long elements (in the axial direction). Reducing the size of the smallest elements from $3 \mathrm{~mm}$ to $1.5 \mathrm{~mm}$ did not influence the predicted maximum displacement.

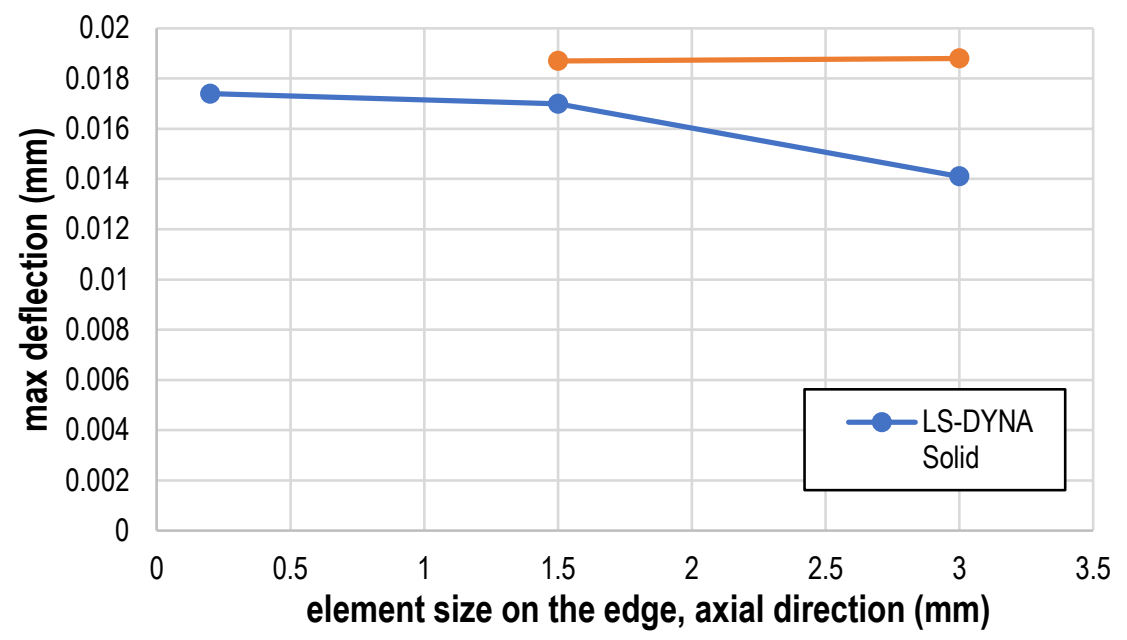

Figure 3.4. Mesh sensitivity study in LS-DYNA structural simulations

In Table 3.3, the maximum deflections obtained with LS-DYNA are compared with the maximum deflections obtained with the use of the FV and FE solvers for structure in STAR-CCM+. The deflection predicted by the solver within STAR-CCM+ assumed for this study, the FE solver for the solid domain in combination with the FV solver for the fluid solution, predicts the most conservative deflection of the solid models. It is $6.0 \%$ higher than the solution obtained by the FV solver in STAR-CCM+ and 4.9\% higher than the solution obtained by solid elements in LS-DYNA. The shell model in LS-DYNA predicted $2.2 \%$ higher deflection than the FE model in STAR-CCM+. It can be concluded that the current approach of modeling fluid with the FV solver and structure with the FE solver is a conservative approach as compared to the FV solver for structure. The added conservatism over the previously validated FV solver, is not overly high and is bounded by predictions made with shell elements in LS-DYNA solver.

Table 3.3. Comparison of maximum deflections in Case 1 analyzed with various solvers

\begin{tabular}{|c|c|c|c|}
\hline Fluid solver & Structure solver & Max. deflection* (mm) & $\begin{array}{c}\text { Deviation from } \\
\text { STAR-CCM+ FE }\end{array}$ \\
\hline STAR-CCM+ FV & STAR-CCM+ FE & 0.0183 & $0.0 \%$ \\
\hline STAR-CCM+ FV & STAR-CCM+ FV & 0.0172 & $-6.0 \%$ \\
\hline STAR-CCM+ FV & LS-DYNA FE solid & 0.0174 & $-4.9 \%$ \\
\hline STAR-CCM+ FV & LS-DYNA FE shell & 0.0187 & $2.2 \%$ \\
\hline
\end{tabular}

${ }^{*}$ The solver type sensitivity analysis is performed using fluid properties at $25^{\circ} \mathrm{C}$ and the results presented and discussed in Section 4 uses fluid properties at $55^{\circ} \mathrm{C}$ (MITR nominal outlet temperature). See Section 3.6 for discussion of the relative insensitivity to the coolant properties. 


\subsection{Sensitivity of the Model to Boundary Condition Type}

In this section, the velocity distribution in the coolant channel gaps is presented. The case with the nominal outer coolant channel gap thickness (Case 2) is selected as a representative example. Figure 3.5 shows the side view of the velocity vector field in the channel center. Expected flow contraction is observed due to the separation of the flow from the edges of the channel boundaries and the plate's leading edge. Note that symmetric boundary conditions are used for the faces of the upper and lower plenum in the width direction, which is in the center plane of the two neighboring plates. The separation layer is asymmetric in both the thin and the thick channels. For the thin channel, the asymmetric velocity field is expected in the real element as the two channel gaps adjacent to it are different (one is the thick channel gap and the other is an internal, nominal-size channel gap), affecting the flow distribution. However, for the thick channel gap, the flow is expected to be more symmetric, as its adjacent channels are the same (nominal-size internal channel gaps). The lack of symmetry in the simulations is caused by the reduced size of the modeled domain and the boundary condition types used. The most realistic model should include two full fuel elements with end fittings to properly resolve the flow. However, this would create a prohibitively large numerical model.

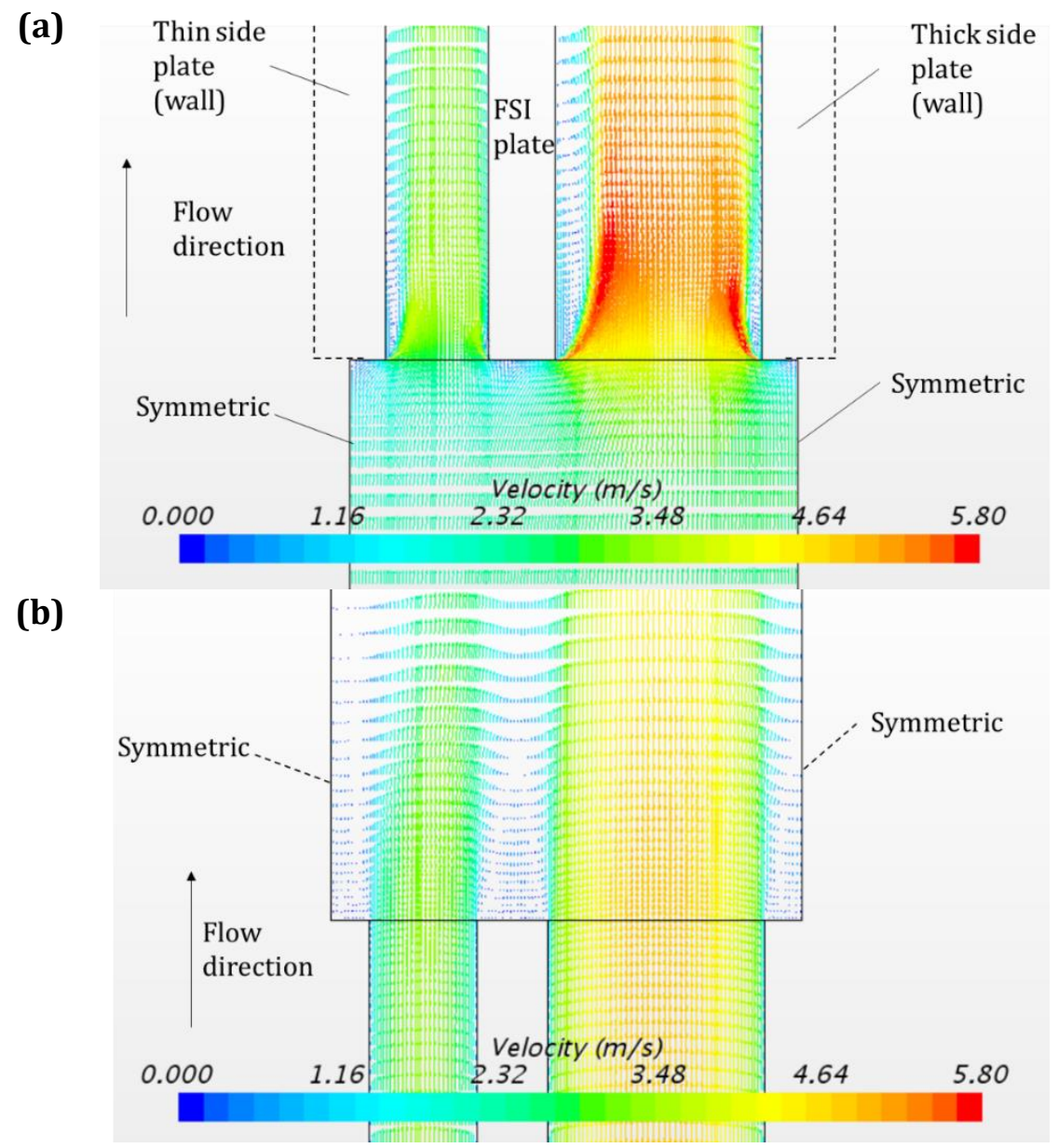

Figure 3.5. Side view of velocity vector field at channel center of Case 2: (a) plate leading edge, (b) plate trailing edge

Two other boundary condition types, wall and periodic, were also tested to investigate how various flow patterns influence the deflection of the plate. The results are presented in Figure 3.6 and Figure 
3.7. Using the wall boundary for the upper and lower plenum in the width direction does not improve the symmetry of the flow in the thick channel. Periodic boundaries are specified in pairs so the flow exiting from one periodic boundary will enter from the other. In this case, it means the thick and thin channels are arranged in alternate permutation, which also does not explicitly represent the real situation. While more symmetric flow in the thick channel gap is observed using the periodic boundary, the thin channel gap also becomes symmetric because of the alternate permutation, which is unexpected for the real case. At last, when the predicted maximum displacements using these three types of boundary condition are compared, the values for symmetric, wall, and periodic boundary are $0.98 \mathrm{mil}, 0.97 \mathrm{mil}$, and $0.95 \mathrm{mil}$, respectively. Given that among these three choices the symmetric boundary is closer to the practical situation and predicts larger displacement, it is kept for the rest of the analyses.

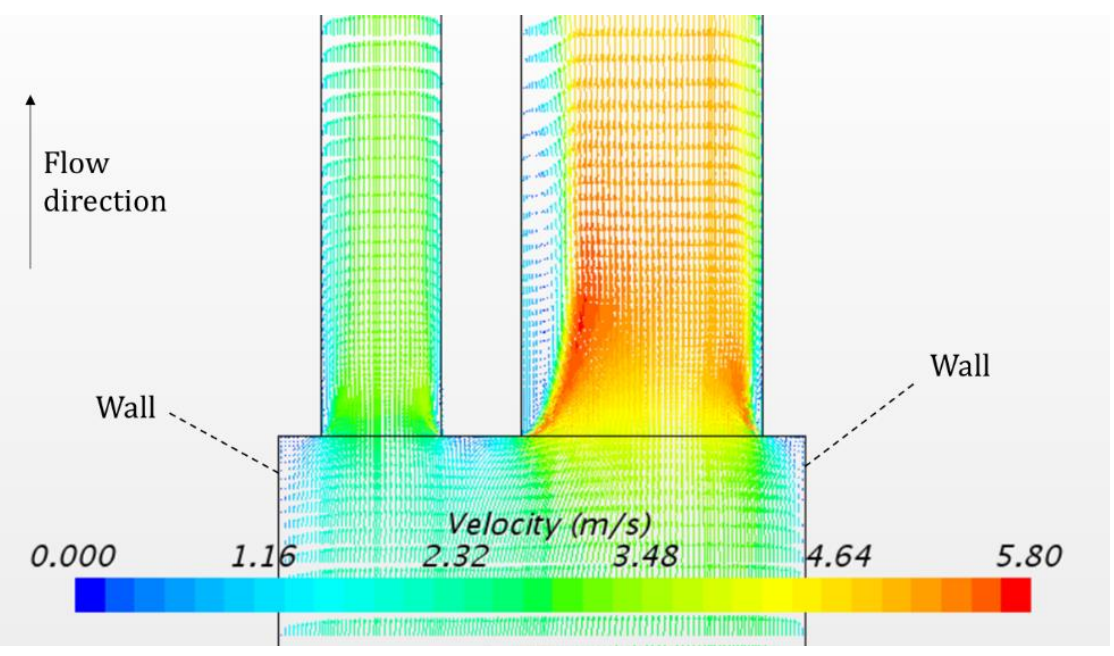

Figure 3.6. Side view of velocity vector of Case 2 (Wall boundary conditions for plenums)

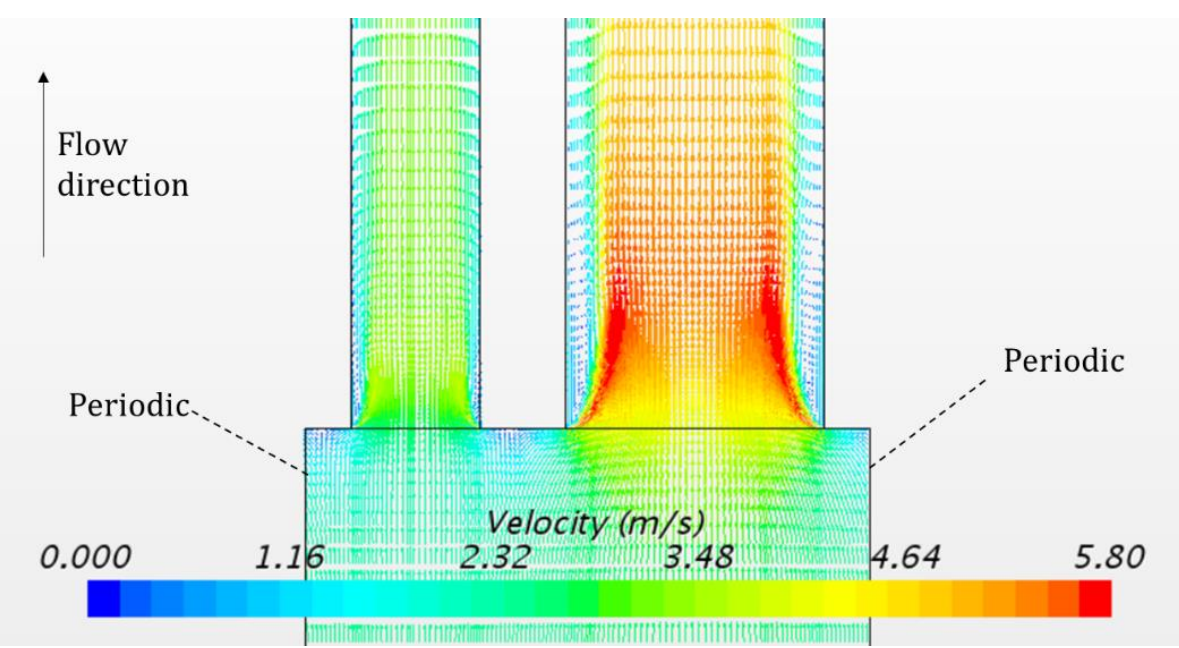

Figure 3.7. Side view of velocity vector of Case 2 (Periodic boundary conditions for plenums) 


\subsection{Turbulence Model Effect}

In addition to the URANS k- $\varepsilon$ turbulence model used for the base runs, several other turbulence models (k- $\omega$ SST, and Detached Eddy Simulation [DES]) were tested for several cases, and the maximum plate displacement predicted with these models is compared with the URANS k- $\varepsilon$ model in Table 3.4. For the four cases tested, the RANS k- $\omega$ shear stress transport (SST) model predicts less displacement than the URANS k- $\varepsilon$ model. DES is a simulation approach based on the RANS model that switches to the LES model in the regions with sufficiently fine mesh. Usually, the turbulent length scale near the wall is small and the RANS is used. The DES $\mathrm{k}-\varepsilon$ model predicts similar maximum displacement to the RANS k- $\varepsilon$ model, with a deviation of less than $3 \%$ for the cases studied. The DES $\mathrm{k}-\omega$ SST model predicts much larger displacements compared to the URANS k- $\omega$ SST model for Cases 4, 6, and 9, and a slightly larger displacement for Case 1. The time trace of the plate displacement is almost constant for both RANS and DES, which indicates no flow induced oscillation and supports that RANS is sufficient for this study. Note that the same mesh is used for both URANS and DES, and the convergence performance for the DES model is not satisfying. The residual for DES is around two orders of magnitude higher than that of URANS. Preliminary mesh sensitivity study for the DES shows that isotropically refining the mesh with $70 \%$ more elements results in $1.2 \%$ decrease of maximum displacement. The DES results presented here should be considered as a rough estimate as these results may not be mesh independent. No extensive mesh sensitivity study has been performed for DES because the URANS is sufficient for this work, as discussed in Section 2.1.3, also the cost (computational power, time) for extensive mesh sensitivity study for DES was not planned in the scope of this work. Further investigation is needed to better quantify the uncertainty from the use of various turbulence models. In this work, the URANS k- $\varepsilon$ model is used because of its universal applicability and accuracy for channel flow, as well as its robustness and good convergence performance, have been verified over a wide range of engineering problems.

Table 3.4. Comparison of maximum displacement predicted using various turbulence models

\begin{tabular}{|c|c|c|c|c|c|c|c|c|}
\hline \multirow{2}{*}{ Case \# } & \multicolumn{7}{|c|}{$\begin{array}{c}\text { Maximum Displacement*, mil (deviation from the base model } \\
\text { with the URANS k- } \text { turbulence model) }\end{array}$} \\
\cline { 2 - 9 } & \multicolumn{7}{|c|}{ URANS } & \multicolumn{3}{c|}{ DES } \\
\cline { 2 - 9 } & \multicolumn{2}{|c|}{$\mathrm{k}-\varepsilon$} & \multicolumn{2}{c|}{$\mathrm{k}-\omega \mathrm{SST}$} & \multicolumn{2}{c|}{$\mathrm{k}-\varepsilon$} & \multicolumn{2}{c|}{$\mathrm{k}-\omega \mathrm{SST}$} \\
\hline 2 & 0.98 & $(0.0 \%)$ & 0.74 & $(-24.7 \%)$ & 0.96 & $(-2.2 \%)$ & 0.77 & $(-21.8 \%)$ \\
\hline 4 & 2.00 & $(0.0 \%)$ & 1.80 & $(-9.9 \%)$ & - & - & 2.11 & $(5.9 \%)$ \\
\hline 6 & 2.14 & $(0.0 \%)$ & 1.96 & $(-8.4 \%)$ & 2.16 & $(1.0 \%)$ & 2.31 & $(8.2 \%)$ \\
\hline 9 & 2.58 & $(0.0 \%)$ & 2.44 & $(-5.6 \%)$ & - & - & 2.86 & $(10.8 \%)$ \\
\hline
\end{tabular}

* The turbulence model sensitivity analysis is performed using fluid properties at $25{ }^{\circ} \mathrm{C}$ and the results presented and discussed in Section 4 uses fluid properties at $55^{\circ} \mathrm{C}$ (MITR nominal outlet temperature). See Section 3.6for discussion of the relative insensitivity to the coolant properties.

\subsection{Sensitivity of FSI results to Coolant Properties}

As mentioned in Section 2.1.4, the coolant properties (density and dynamic viscosity) are assumed to be constant and the physical property values at MITR nominal outlet temperature $\left(55^{\circ} \mathrm{C}\right)$ are used for FSI simulation. The coolant density is $985.71 \mathrm{~kg} / \mathrm{m}^{3}$ and viscosity is $0.5036 \mathrm{mPa} \cdot \mathrm{s}$. In the MITR core the coolant is continuously heated along the flow direction and the coolant temperature also 
changes for different channels. The potential deviation introduced by the assumption of constant coolant properties should be evaluated. The nominal inlet coolant temperature of MITR is around $44^{\circ} \mathrm{C}$ [39], and the upper limit (not the plenum average) is $65^{\circ} \mathrm{C}$ [39]. Therefore, these two values of temperature are used as bounding for the sensitivity analyses. FSI simulation for Case 1 (nominal case) and Case 9 (limiting case with maximum displacement) is performed using the coolant properties at the bounding temperature values, and the results are presented in Table 3.5. The results using properties at $55^{\circ} \mathrm{C}$ are shaded gray and used as the base for a percentage deviation calculation, while the results using properties at $44^{\circ} \mathrm{C}$ and $65{ }^{\circ} \mathrm{C}$ are cases for sensitivity analysis. By changing the temperature from $55^{\circ} \mathrm{C}$ to the bounding values $\left(44^{\circ} \mathrm{C}\right.$ or $\left.65^{\circ} \mathrm{C}\right)$, there is a $\pm 0.5 \%$ difference in density, and around $+20 \% /-14 \%$ difference in viscosity. For the two cases analyzed here, the change of coolant density and viscosity leads to the deviation of maximum displacement up to $+2.2 \% /-0.7 \%$ and deviation in pressure drop up to $\pm 3 \%$. Note that the predicted maximum displacement decreases with the increasing temperature. The velocity and mass flow results are shown in Table 3.6. The ratio of thin channel mass flow to the total mass flow increases with the temperature. Thus, the thin channel velocity increases and the velocity disparity between channels reduces, which accounts for less displacement at higher temperature.

In summary, using the coolant temperature of $55^{\circ} \mathrm{C}$ (MITR nominal outlet temperature) to determine the coolant properties, and considering the bounding range of $44^{\circ} \mathrm{C}$ to $65^{\circ} \mathrm{C}$, the coolant density would vary $\pm 0.5 \%$, and viscosity would vary $+20 \% /-14 \%$. These deviations of coolant density and viscosity lead to a maximum displacement deviation up to $+2.2 \% /-0.7 \%$ and for pressure drop up to $\pm 3.0 \%$.

Table 3.5. Effect of coolant property change on maximum displacement and pressure drop

\begin{tabular}{|c|c|c|c|c|c|c|c|}
\hline \multirow{3}{*}{ Cases } & Temperature & Density & Viscosity & \multicolumn{2}{|c|}{ Maximum displacement } & \multicolumn{2}{|c|}{$\Delta$ P with gravity } \\
\cline { 2 - 8 } & ${ }^{\circ} \mathrm{C}$ & $\mathrm{kg} / \mathrm{m}^{3}$ & $\mathrm{mPa} \cdot \mathrm{s}$ & $\mathrm{mil}$ & $\begin{array}{c}\text { percentage } \\
\text { difference }\end{array}$ & $\mathrm{kPa}$ & $\begin{array}{c}\text { percentage } \\
\text { difference }\end{array}$ \\
\hline \multirow{3}{*}{1} & 44 & 990.64 & 0.6065 & 0.67 & $2.2 \%$ & 24.33 & $2.8 \%$ \\
\cline { 2 - 8 } & 55 & 985.71 & 0.5036 & 0.66 & $0.0 \%$ & 23.67 & $0.0 \%$ \\
\hline \multirow{3}{*}{9} & 65 & 980.57 & 0.4329 & 0.66 & $-0.6 \%$ & 23.16 & $-2.2 \%$ \\
\cline { 2 - 8 } & 44 & 990.64 & 0.6065 & 2.58 & $1.1 \%$ & 25.29 & $2.1 \%$ \\
\cline { 2 - 8 } & 55 & 985.71 & 0.5036 & 2.55 & $0.0 \%$ & 24.76 & $0.0 \%$ \\
\hline
\end{tabular}

Table 3.6. Effect of coolant property change on velocity and mass flow rate

\begin{tabular}{|c|c|c|c|c|c|c|}
\hline \multirow{3}{*}{ Cases } & Temperature & $\begin{array}{c}\text { Velocity in } \\
\text { thin channel } \\
\text { gap }\end{array}$ & $\begin{array}{c}\text { Velocity in } \\
\text { thick } \\
\text { channel gap }\end{array}$ & $\begin{array}{c}\text { Mass flow } \\
\text { rate in thin } \\
\text { channel gap }\end{array}$ & $\begin{array}{c}\text { Mass flow } \\
\text { rate in thick } \\
\text { channel gap }\end{array}$ & $\begin{array}{c}\text { Total } \\
\text { mass } \\
\text { flow rate }\end{array}$ \\
\cline { 2 - 7 } & ${ }^{\circ} \mathrm{C}$ & $\mathrm{m} / \mathrm{s}$ & $\mathrm{m} / \mathrm{s}$ & $\mathrm{kg} / \mathrm{s}$ & $\mathrm{kg} / \mathrm{s}$ & $\mathrm{kg} / \mathrm{s}$ \\
\cline { 2 - 7 } 1 & 44 & 2.84 & 3.92 & 0.313 & 0.817 & 1.130 \\
\cline { 2 - 7 } & 55 & 2.88 & 3.93 & 0.316 & 0.815 & 1.130 \\
\hline \multirow{3}{*}{9} & 65 & 2.90 & 3.95 & 0.317 & 0.814 & 1.130 \\
\cline { 2 - 7 } & 44 & 3.50 & 5.46 & 0.362 & 2.027 & 2.389 \\
\cline { 2 - 7 } & 55 & 3.56 & 5.47 & 0.367 & 2.022 & 2.389 \\
\hline
\end{tabular}




\section{FSI Simulation Results}

\subsection{Channel Velocity}

\subsubsection{Area Averaged Channel Velocity}

The cross-sectional averaged velocity, mass flow rate, and pressure-drop results are shown in Table 4.1 for all analyzed cases. The pressure drops listed here are the differences in pressures between the inlet and outlet boundaries of the simulation domain with the gravity pressure head included. The probing location for flow rate and velocity is $28 \mathrm{~mm}$ upstream from the plate's trailing edge.

Table 4.1. Area-averaged velocity, mass flow rate, and pressure drop

\begin{tabular}{|c|c|c|c|c|c|c|}
\hline Case & $\begin{array}{c}\text { Velocity in } \\
\text { thin channel } \\
\text { gap } \\
\text { (m/s) }\end{array}$ & $\begin{array}{c}\text { Velocity in } \\
\text { thick } \\
\text { channel } \\
\text { gap } \\
(\mathrm{m} / \mathrm{s})\end{array}$ & $\begin{array}{c}\Delta \text { P with } \\
\text { gravity } \\
(\mathrm{kPa})\end{array}$ & $\begin{array}{c}\text { Mass flow } \\
\text { rate in thin } \\
\text { channel } \\
\text { gap } \\
(\mathrm{kg} / \mathrm{s})\end{array}$ & $\begin{array}{c}\text { Mass flow } \\
\text { rate in } \\
\text { thick } \\
\text { channel } \\
\text { gap } \\
(\mathrm{kg} / \mathrm{s})\end{array}$ & $\begin{array}{c}\text { Total mass } \\
\text { flow rate } \\
\text { (kg/s) }\end{array}$ \\
\hline 1 & 2.88 & 3.93 & 23.67 & 0.32 & 0.81 & 1.13 \\
\hline 2 & 2.85 & 4.04 & 24.54 & 0.29 & 0.84 & 1.13 \\
\hline 3 & 2.89 & 4.53 & 23.16 & 0.30 & 1.24 & 1.54 \\
\hline 4 & 2.94 & 5.02 & 20.72 & 0.30 & 1.82 & 2.13 \\
\hline 5 & 3.31 & 5.64 & 23.78 & 0.34 & 2.05 & 2.39 \\
\hline 6 & 3.15 & 4.88 & 20.43 & 0.32 & 1.80 & 2.13 \\
\hline 7 & 2.89 & 5.02 & 21.67 & 0.30 & 1.82 & 2.13 \\
\hline 8 & 2.87 & 5.00 & 21.62 & 0.30 & 1.82 & 2.13 \\
\hline 9 & 3.56 & 5.47 & 24.76 & 0.37 & 2.02 & 2.39 \\
\hline 10 & 2.87 & 3.93 & 23.61 & 0.32 & 0.81 & 1.13 \\
\hline 11 & 2.87 & 3.93 & 23.61 & 0.32 & 0.81 & 1.13 \\
\hline 12 & 2.87 & 3.93 & 23.59 & 0.32 & 0.81 & 1.13 \\
\hline 13 & 2.67 & 2.96 & 25.52 & 0.31 & 0.31 & 0.61 \\
\hline 14 & 2.70 & 2.90 & 25.34 & 0.28 & 0.34 & 0.61 \\
\hline & & & & & & \\
\hline
\end{tabular}

Table 4.2 shows a comparison of the averaged velocity and pressure drop obtained in FSI simulations with the results from 0-D (lumped) pressure-drop balance calculations (refer to Section 2.1.2 for an explanation of the method). Cases 1 and 2 used nominal thick coolant channel gap thickness and are compared with the 0-D results for the nominal thick channel as well. Cases 3 and 4 adopt different thick-channel gap thickness and are compared with the equivalent 0-D results. The comparison shows that both velocity and pressure drop results agree well between the FSI simulations and the 0 -D calculations. Thus, the comparisons with Miller's critical velocity presented in Section 2.1 .3 are still valid. The actual velocity in the channels is below $20 \%$ of the Miller's critical velocity for a plate with fixed longer edges. 
Table 4.2. Comparison of simulation results with pressure drop balance results

\begin{tabular}{|l|c|c|c|}
\hline \multicolumn{1}{|c|}{ Case } & $\begin{array}{c}\text { Thin channel } \\
\text { velocity } \\
(\mathrm{m} / \mathrm{s})\end{array}$ & $\begin{array}{c}\text { Thick channel } \\
\text { velocity } \\
\text { (m/s) }\end{array}$ & $\begin{array}{c}\Delta \mathrm{P} \text { with } \\
\text { gravity head } \\
\text { included } \\
\text { (kPa) }\end{array}$ \\
\hline $\begin{array}{l}\text { Case 1 } \\
\text { (All nominal sizes) }\end{array}$ & 2.88 & 3.93 & 23.67 \\
\hline $\begin{array}{l}\text { Case 2 } \\
\text { (Nominal thick channel dimension) }\end{array}$ & 2.85 & 4.04 & 24.54 \\
\hline $\begin{array}{l}\text { 0-D Pressure drop balance result } \\
\text { (Nominal thick channel dimension) }\end{array}$ & 2.79 & 3.95 & 24.48 \\
\hline $\begin{array}{l}\text { Case 3 } \\
\text { (Conservative thick channel dimension) }\end{array}$ & 2.89 & 4.53 & 23.16 \\
\hline $\begin{array}{l}\text { 0-D Pressure drop balance result } \\
\text { (Conservative thick channel dimension) }\end{array}$ & 2.78 & 4.48 & 24.38 \\
\hline $\begin{array}{l}\text { Case 4 } \\
\text { (Conservative with lift thick channel dimension) }\end{array}$ & 2.94 & 5.02 & 20.72 \\
\hline $\begin{array}{l}\text { 0-D Pressure drop balance result } \\
\text { (Conservative with lift thick channel dimension) }\end{array}$ & 2.77 & 5.00 & 24.24 \\
\hline
\end{tabular}

\subsubsection{Velocity Distribution}

The cross-sectional velocity contour near the plate trailing edge for Case 2 is shown in Figure 4.1. It indicates that the mesh is fine enough to smoothly capture the velocity field, and the thick channel gap velocity is higher than that of the thin channel. The channel center velocity profile in the width direction and the channel gap thickness direction is shown in Figure 4.2. The inlet profile is obtained at $25 \mathrm{~mm}$ downstream from the leading edge, while the outlet profile is obtained at $28 \mathrm{~mm}$ upstream from the trailing edge. The middle profile is in the half-length of the plate. Figure 4.2 shows that the inlet velocity profile is slightly different between thin and thick channel, while the middle and outlet profile are close, indicating fully developed flow.

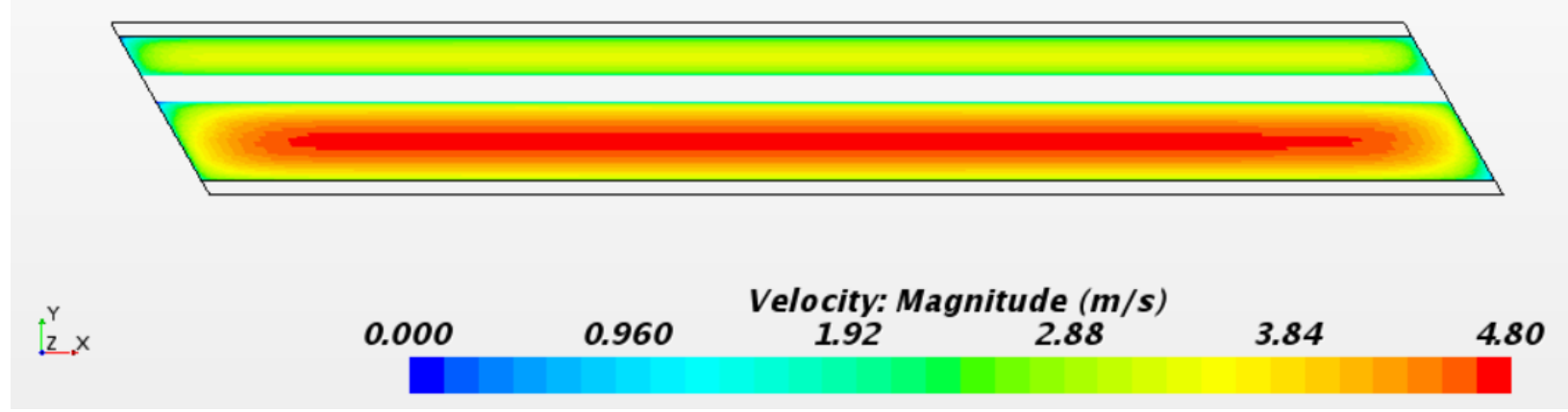

Figure 4.1. Velocity contour for Case 2 near the plate trailing edge 
(a)

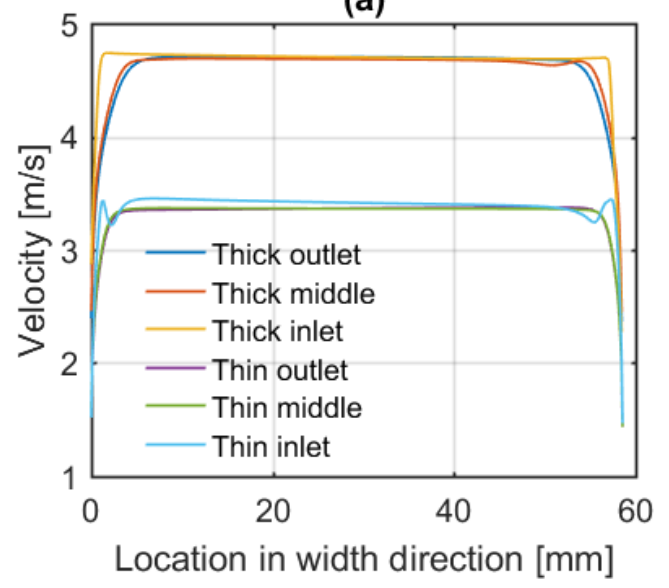

(b)

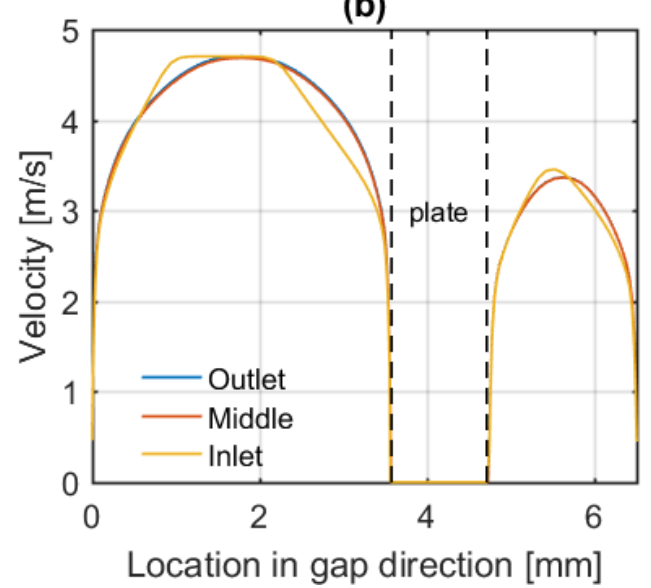

Figure 4.2. Velocity profile in width direction (a) and in channel gap thickness direction (b) for Case 2

\subsection{Pressure Distribution}

The pressure differential on the two sides of a fuel plate is the reason for plate's deflection. In this section, pressure in the individual channels as well as on the plate surface is analyzed.

Figure 4.3 (a) to (c) show pressure in the middle of the channel gaps for Cases 1, 2, and 9. Case 1 adopts all nominal sizes and can be considered as the best-estimate case for ideal geometry. Case 2 also uses nominal outer channel gap thickness and a perfectly flat plate, but the thin channel gap thickness and the plate thickness are lowered to the minimum of the manufacturing and assembly tolerance, so it can be used as a reference case for the remaining conservative cases with imperfect plate shape. Case 9 has the largest channel gap thickness disparity, highest inlet flow rate, and the slanted plate orientation, which together result in the largest plate displacement among all cases. Figure 4.3 (d) to (f) show the difference between the pressures in the thin and thick channels for these three cases. The maximum pressure differential occurs at the leading edge, which leads to the maximum plate displacement at that location. Since the pressure in the thin channel gap is higher than that in the thick channel gap, the plate usually deforms towards the thick channel. The pressure differentials magnitudes for Cases 1 and 2 are close; the magnitude is slightly higher for Case 2 because of the reduction in thin channel gap thickness (from the nominal value of 74.6 mil to 70 mil). The maximum pressure difference for Case 9 is more than twice that of Case 1 or 2, so a larger displacement is expected. The pressure differential plot has a significant spike near the leading edge. To capture that behavior, a very dense mesh in the fluid region needs to be established in that region.

In addition to the channel center pressure, the pressure near the plate in both channels is also presented (Figure 4.4 (a) to (c)). Although the pressure differential between the two sides of the plate near the leading edge is larger (Figure 4.4 (d) to f)) than the pressure differential between the center line of two channels, the trends are similar for plate surface pressure differential and channel center line pressure differential, which are characterized by a peak near the leading edge and then decreases along the flow. The pressure distribution on the plate surface is shown in Figure 4.5 for Case 1. 
(a) Case 1

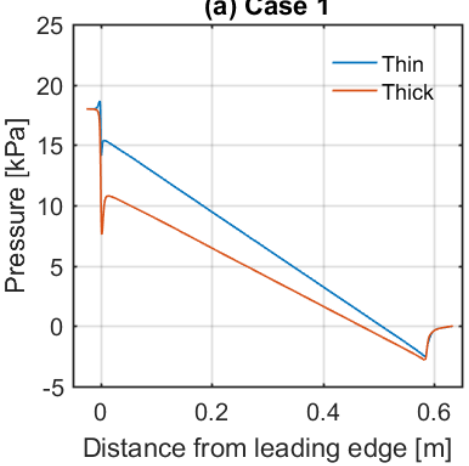

(d) Case 1

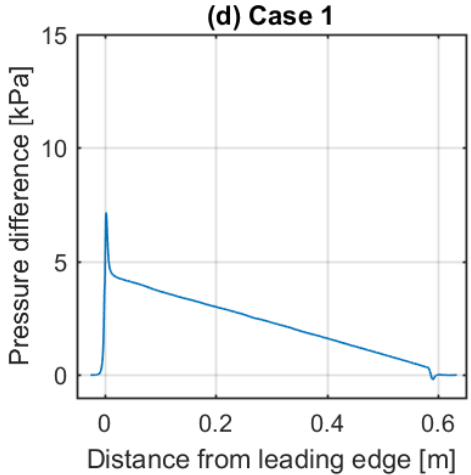

(b) Case 2

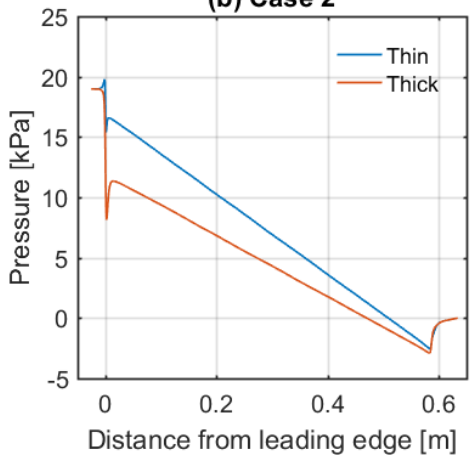

(e) Case 2

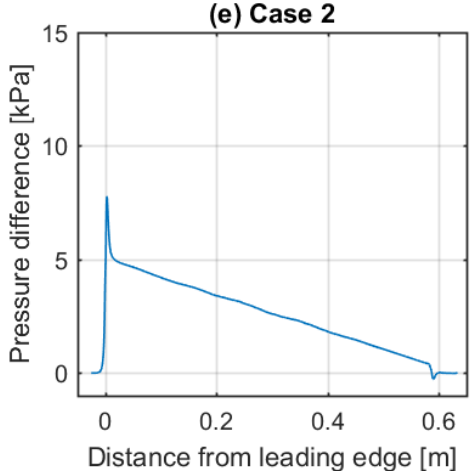

(c) Case 9

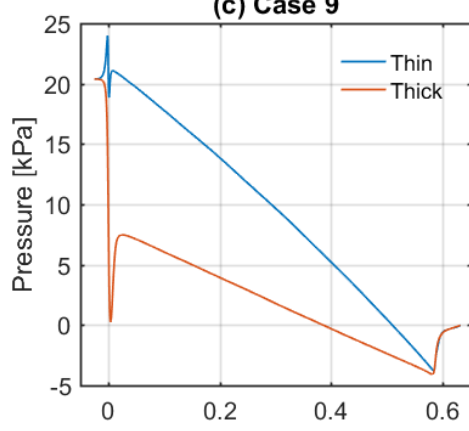

Distance from leading edge [m]

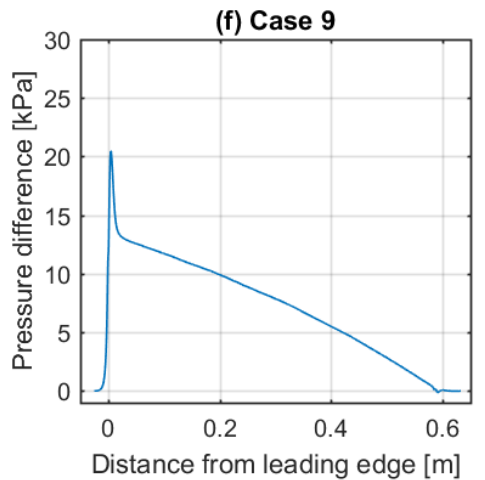

Figure 4.3. Pressure in the middle of channels ((a) to (c)) and the pressure difference between channels ( (d) to (f))

(a) Case 1

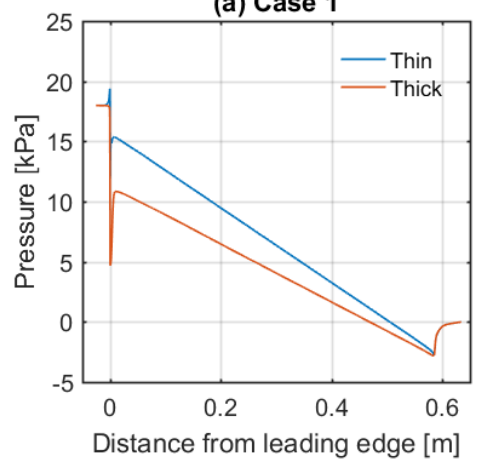

(d) Case 1

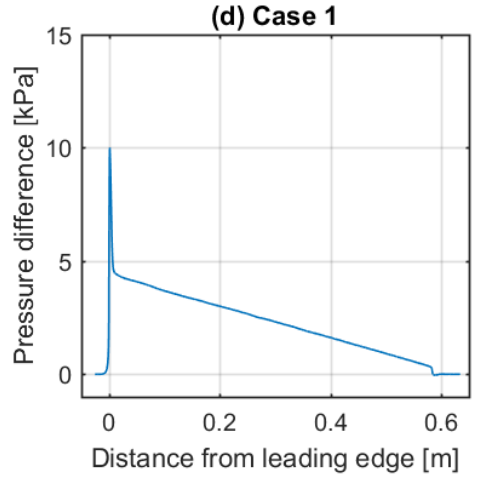

(b) Case 2

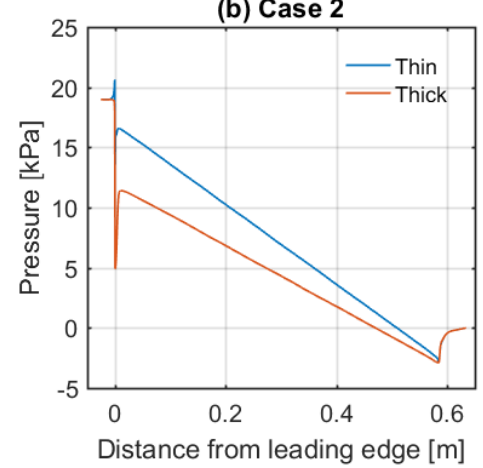

(e) Case 2

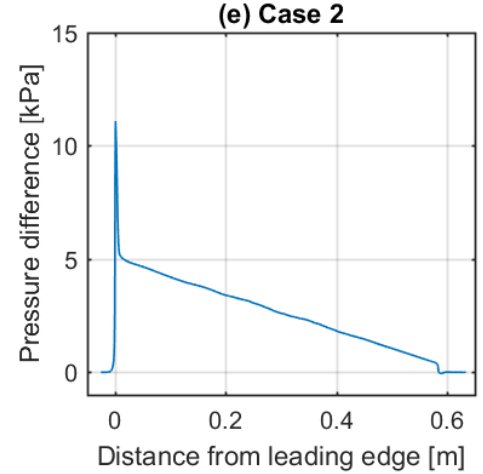

(c) Case 9

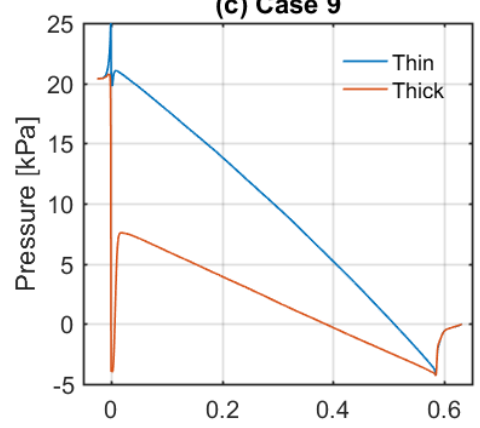

Distance from leading edge [m]

(f) Case 9

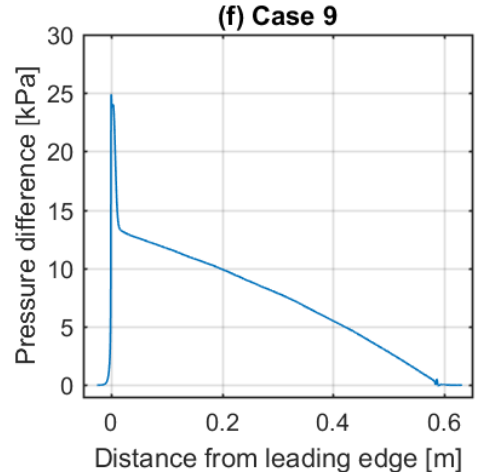

Figure 4.4. Pressure near the plate ((a) to (c)) and the pressure difference between the two sides ((d) to (f)) 


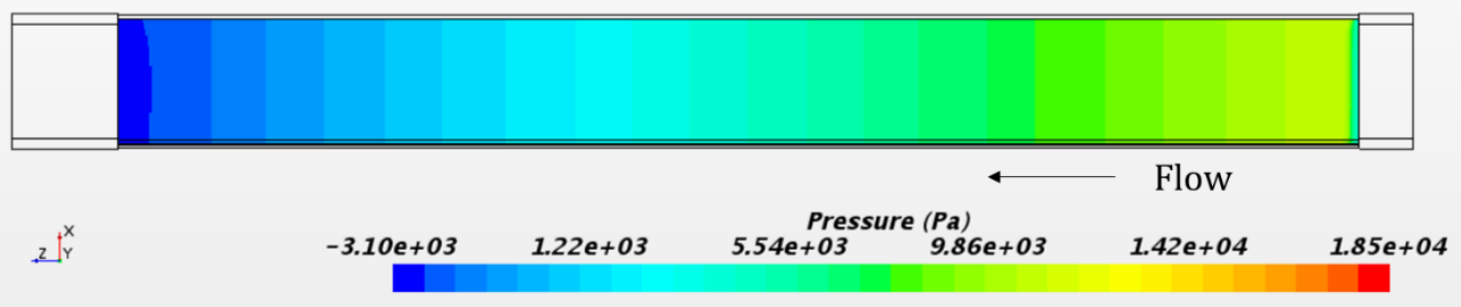

(a) Thick channel side

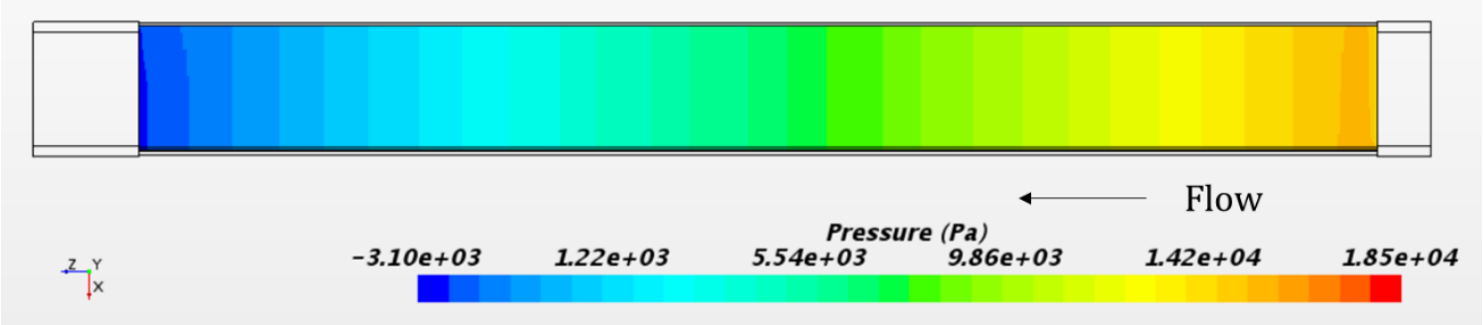

(b) Thin channel side

Figure 4.5. Pressure distribution on the plate surface for Case 1: thick-channel side (a), thin-channel side (b)

\subsection{Plate Deflection}

Figure 4.6 shows the plate displacement contour for the base Case 1. In the figure, the displacement towards the thick channel is defined as positive. The maximum displacement occurs at the center of the leading edge of the plate. The character of the displacement for all the other cases is similar to that of Case 1, with the displacement decreasing away from the leading edge.

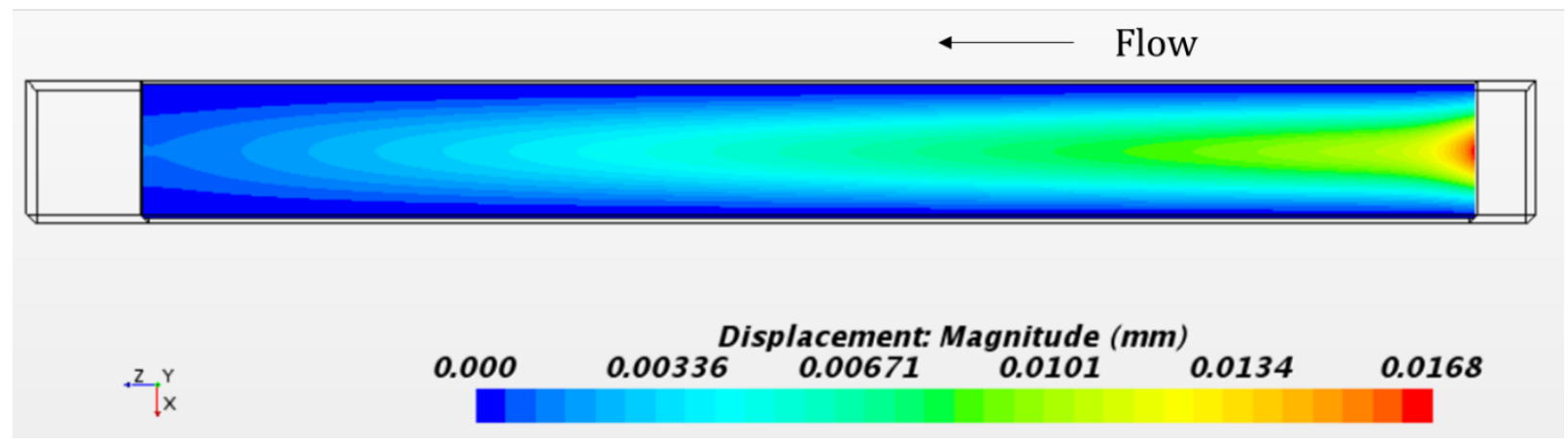

Figure 4.6. Plate displacement contour for Case 1

To illustrate the difference in plate displacement for various cases, the displacement profiles near the leading edge and across the plate in the axial direction are presented in Figure 4.7, Figure 4.8, and Figure 4.9. For these figures, the left subplot is the displacement profile near the leading edge $1 \mathrm{~mm}$ downstream from the leading edge), and the right subplot is the displacement profile in the axial direction at the center of the plate. The description of cases can be found in Table 2.8. Displacements 
from Cases 1 to 4 are compared in Figure 4.7 to highlight the outer channel gap thickness effect on the magnitude of the deflection. Cases 2 to 4 have the same thin channel gap thickness and plate thickness but varying thick channel gap thickness, and their inlet velocity varies depending on the full-core flow distribution analysis. Case 4 has the highest displacement among these four, as in this model the thick channel has the largest size, and the highest flow rate is applied at the inlet. Case 1 has a larger thin channel gap thickness and a larger plate thickness compared to Case 2. Therefore, its displacement is less than Case 2.
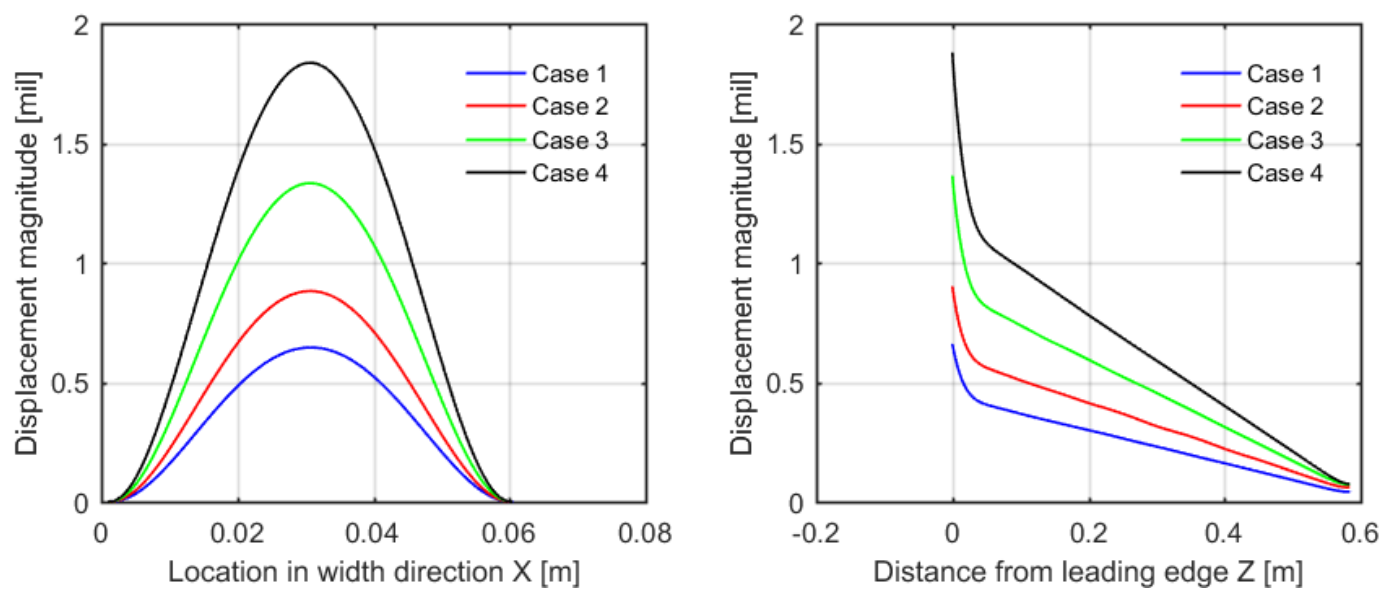

Figure 4.7. Displacement profiles for Cases 1 to 4

Displacements obtained in simulations for Cases 4, 6, 7, and 8 are plotted in Figure 4.8 to highlight the influence of plate-shape non-uniformity on the displacements. As discussed in Section 2.2, Cases 6 to 8 consider three shapes of deformed plate: plate tilt (Case 6), pre-deformed plate using the $10^{\text {th }}$ natural mode of vibration (Case 7), and pre-deformed plate using the $2^{\text {nd }}$ natural mode of vibration (Case 8), while the other flow conditions are identical to those in Case 4. Note that the amplitude of these initial deformations is lower than the fuel plate flatness tolerance. The non-uniformities in the plate amplify locally the magnitude of deflections. However, as shown in Figure 4.8, the shape of the pre-deformed plate is not dramatically influencing the maximum magnitude of the deflections. These four cases all predict a maximum deflection similar to the deflection obtained in Case 4 (with the perfect plate), for the following reasons: the channel gap thickness disparity is significant and drives the magnitude of deflections, the flow rates are well below the critical velocity, and the tolerances imposed on the fabrication and assembly are limiting these effects.

The largest deflections have been obtained for Case 6, with the slanted plate. The maximum displacements for that case increased $8.2 \%$ as compared to the ideal-plate case with large channel disparities (Case 4). It is interesting to note that for Case 7, the displacement profile in the flow direction preserved some of its initial shape (shown in Figure 2.7). 

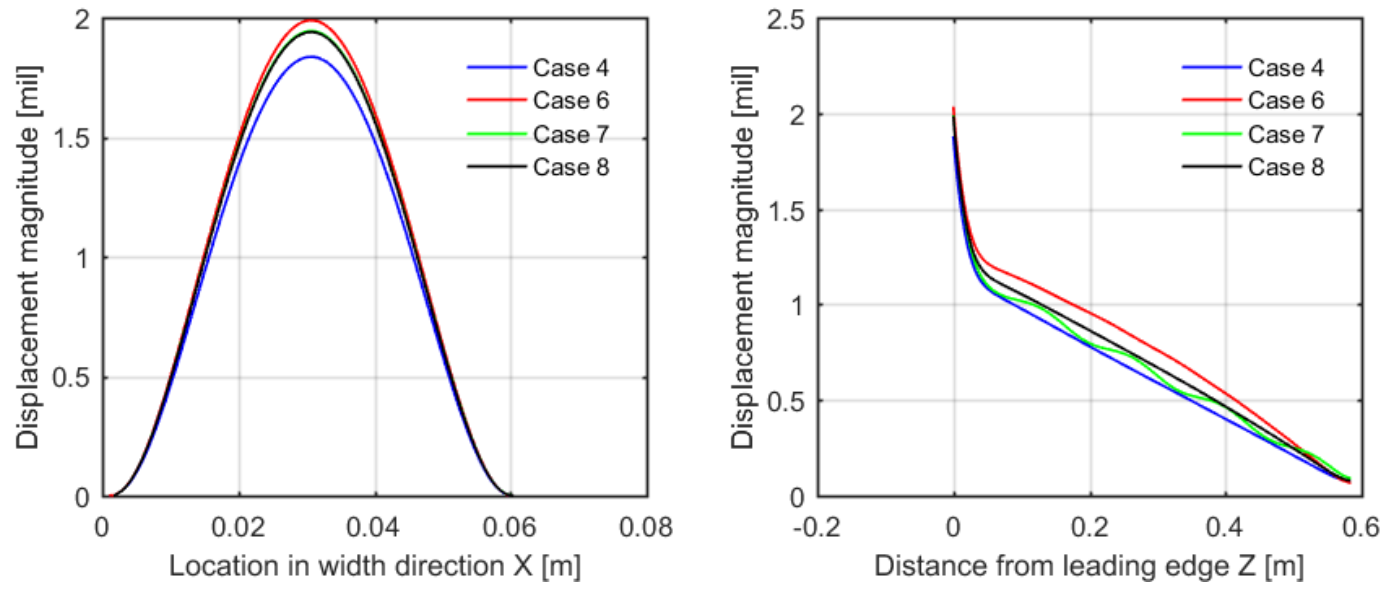

Figure 4.8. Displacement profiles for Cases 4, 6, 7, and 8

The effect of flow rate on plate displacement is presented in Figure 4.9. In this figure, the dashed lines represent the low-velocity conditions (nominal), and the solid lines with the same color represent their higher-velocity (12.35\% higher as conservative estimation) counterparts. For both the ideal and slanted-plate cases (Cases 5 and 9), a 12.35\% higher inlet mass flow rate leads to about a 26\% increase in the maximum plate displacement. Further discussion of the stripe-averaged displacement that is relevant to thermal hydraulic analyses is included in the next section.
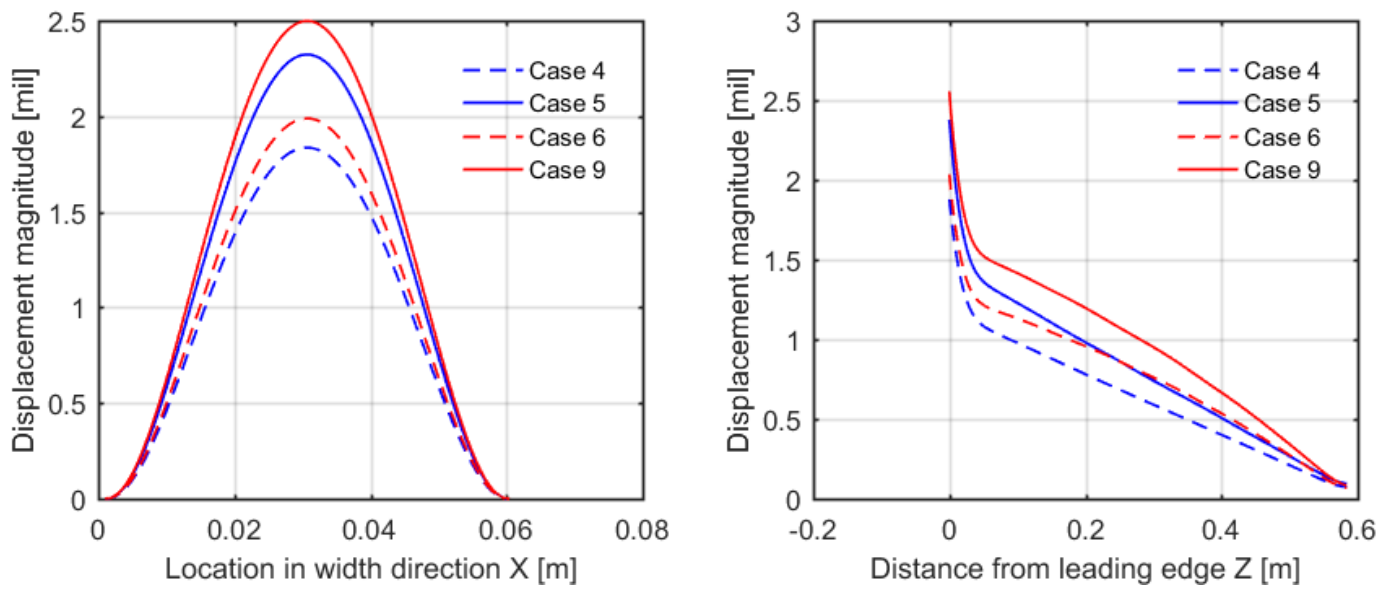

Figure 4.9. Displacement profiles for Cases 4, 5, 6, and 9

\subsection{Stripe-Averaged Plate Deflection}

In the thermal hydraulic analysis of the MITR core, the fuel plate is simulated as four axial stripes. Therefore, it is desired to obtain the averaged displacements over each stripe, and these averaged results can be used to evaluate the effects of the FSI-related plate displacements on the reactor thermal hydraulic performance. The schematics of the stripe discretization are shown in Figure 4.10 and Figure 4.11. Stripes 1 to 4 represent the fueled portion of the plate, and averaged displacements for these stripes will be evaluated. Stripes 5 and 6 represent the aluminum-only region and are not of interest (displacements in these regions are minimal because of the presence of the constrained boundary condition due to side plates). The stripe-averaged displacements for all 14 cases are shown in 
Table 4.3. The displacements for stripes 1 and 2 are almost identical to those of stripes 3 and 4 , because of the symmetry of the plate displacement. Maximum stripe-averaged displacement is calculated for Case 9, with the value of 0.819 mil ( 21 micrometers) for stripes 2 and 3 . Note that all the displacements are towards the thick channel gap. Table 4.4 presents the normalized stripeaveraged displacements using the nominal thin/internal channel gap thickness (74.6 mil). The largest change, $1.10 \%$, was calculated for Case 9. By comparing Case 4 to Cases 6, 7, and 8, additional non-uniformity imposed on the plate's shape did not contribute significantly to increasing the deflections. Various shapes of these non-uniformities, with an amplitude that stayed within the tolerances of fabrication (plate flatness) and assembly, increase the stripe-averaged deflections by up to $21 \%$.

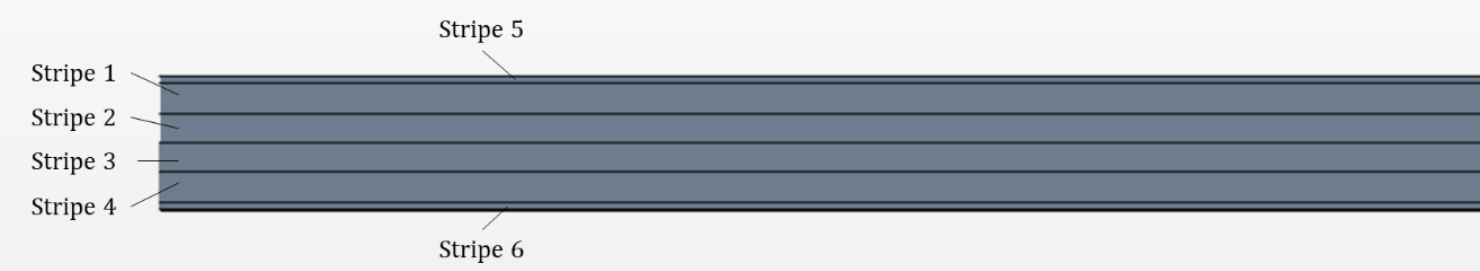

Figure 4.10. Front view of the stripes

Table 4.3. Stripe-averaged displacement

\begin{tabular}{|c|c|c|c|c|c|c|}
\hline \multirow{2}{*}{ Case\# } & \multicolumn{5}{|c|}{ Stripe-averaged displacement (mil) at stripe \# } & \multirow{2}{*}{ Note } \\
\hline & 1 & 2 & 3 & 4 & Overall & \\
\hline 1 & 0.072 & 0.209 & 0.209 & 0.072 & 0.128 & $\begin{array}{l}\text { All geometry size is } \\
\text { nominal }\end{array}$ \\
\hline 2 & 0.100 & 0.289 & 0.289 & 0.100 & 0.177 & $\begin{array}{c}\text { Nominal thick channel } \\
\text { (141 mil) }\end{array}$ \\
\hline 3 & 0.143 & 0.414 & 0.414 & 0.143 & 0.254 & $\begin{array}{l}\text { Conservative thick } \\
\text { channel (186 mil) }\end{array}$ \\
\hline 4 & 0.188 & 0.543 & 0.543 & 0.188 & 0.333 & $\begin{array}{c}\text { Conservative thick } \\
\text { channel with fuel lift } \\
\text { considered ( } 247 \text { mil) }\end{array}$ \\
\hline 5 & 0.238 & 0.692 & 0.692 & 0.238 & 0.419 & Case $4: 112.35 \%$ flow \\
\hline 6 & 0.227 & 0.655 & 0.655 & 0.226 & 0.402 & Tilt \\
\hline 7 & 0.200 & 0.577 & 0.577 & 0.199 & 0.354 & $10^{\text {th }}$ mode \\
\hline 8 & 0.208 & 0.600 & 0.599 & 0.207 & 0.368 & $2^{\text {nd }}$ mode \\
\hline 9 & 0.283 & 0.819 & 0.819 & 0.283 & 0.503 & Case $6: 112.35 \%$ flow \\
\hline 10 & 0.074 & 0.211 & 0.211 & 0.074 & 0.129 & $\mathrm{E}_{\text {fuel }}=88.4 \mathrm{GPa}$ \\
\hline 11 & 0.075 & 0.214 & 0.214 & 0.075 & 0.131 & $\mathrm{E}_{\text {fuel }}=30.6 \mathrm{GPa}$ \\
\hline 12 & 0.074 & 0.210 & 0.210 & 0.074 & 0.128 & $\mathrm{E}_{\text {fuel }}=125.5 \mathrm{GPa}$ \\
\hline 13 & 0.062 & 0.178 & 0.178 & 0.062 & 0.109 & Inner tilt plate \\
\hline 14 & 0.015 & 0.042 & 0.042 & 0.015 & 0.026 & Inner size disparity \\
\hline
\end{tabular}




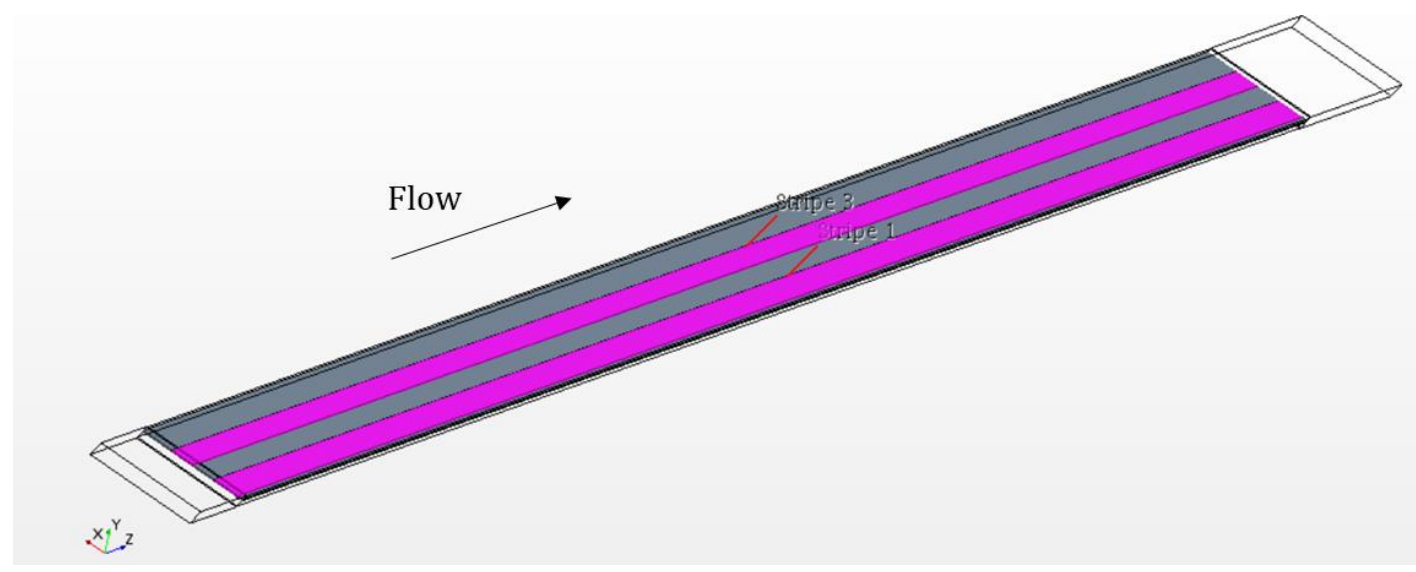

Figure 4.11. 3-D view of the stripes

Table 4.4. Stripe-averaged displacement normalized by nominal channel gap thickness $(74.6 \mathrm{mil})$

\begin{tabular}{|c|c|c|c|c|c|c|}
\hline \multirow{2}{*}{ Case\# } & \multicolumn{5}{|c|}{ Stripe-averaged displacement at stripe \# } & \multirow{2}{*}{ Note } \\
\hline & 1 & 2 & 3 & 4 & Overall & \\
\hline 1 & $0.10 \%$ & $0.28 \%$ & $0.28 \%$ & $0.10 \%$ & $0.17 \%$ & $\begin{array}{l}\text { All geometry is } \\
\text { nominal }\end{array}$ \\
\hline 2 & $0.13 \%$ & $0.39 \%$ & $0.39 \%$ & $0.13 \%$ & $0.24 \%$ & $\begin{array}{c}\text { Nominal thick channel } \\
\text { gap (141 mil) }\end{array}$ \\
\hline 3 & $0.19 \%$ & $0.55 \%$ & $0.55 \%$ & $0.19 \%$ & $0.34 \%$ & $\begin{array}{c}\text { Conservative thick } \\
\text { channel gap (186 mil) }\end{array}$ \\
\hline 4 & $0.25 \%$ & $0.73 \%$ & $0.73 \%$ & $0.25 \%$ & $0.45 \%$ & $\begin{array}{l}\text { Conservative thick } \\
\text { channel gap with fuel } \\
\text { lift considered } \\
(247 \mathrm{mil})\end{array}$ \\
\hline 5 & $0.32 \%$ & $0.93 \%$ & $0.93 \%$ & $0.32 \%$ & $0.56 \%$ & Case $4: 112.35 \%$ flow \\
\hline 6 & $0.30 \%$ & $0.88 \%$ & $0.88 \%$ & $0.30 \%$ & $0.54 \%$ & Plate tilt \\
\hline 7 & $0.27 \%$ & $0.77 \%$ & $0.77 \%$ & $0.27 \%$ & $0.47 \%$ & $10^{\text {th }}$ mode \\
\hline 8 & $0.28 \%$ & $0.80 \%$ & $0.80 \%$ & $0.28 \%$ & $0.49 \%$ & $2^{\text {nd }}$ mode \\
\hline 9 & $0.38 \%$ & $1.10 \%$ & $1.10 \%$ & $0.38 \%$ & $0.67 \%$ & Case 6: $112.35 \%$ flow \\
\hline 10 & $0.10 \%$ & $0.28 \%$ & $0.28 \%$ & $0.10 \%$ & $0.17 \%$ & $\mathrm{E}_{\text {fuel }}=88.4 \mathrm{GPa}$ \\
\hline 11 & $0.10 \%$ & $0.29 \%$ & $0.29 \%$ & $0.10 \%$ & $0.18 \%$ & $E_{\text {fuel }}=30.6 \mathrm{GPa}$ \\
\hline 12 & $0.10 \%$ & $0.28 \%$ & $0.28 \%$ & $0.10 \%$ & $0.17 \%$ & $\mathrm{E}_{\text {fuel }}=125.5 \mathrm{GPa}$ \\
\hline 13 & $0.08 \%$ & $0.24 \%$ & $0.24 \%$ & $0.08 \%$ & $0.15 \%$ & Inner tilted plate \\
\hline 14 & $0.02 \%$ & $0.06 \%$ & $0.06 \%$ & $0.02 \%$ & $0.03 \%$ & $\begin{array}{l}\text { Inner channel gap } \\
\text { thickness disparity }\end{array}$ \\
\hline
\end{tabular}




\subsection{Layered Plate Analysis}

In the previous sections, a homogenous aluminum plate was assumed to represent the whole fuel plate and its behavior due to FSI. However, the actual fuel plate consists of multiple layers of materials: the inner fuel core film made of U-10Mo, a thin (1 mil) intermediate layer of zirconium, and the outer cladding of aluminum. Thus, it is desired to quantify the deviation introduced by the used approach. Therefore, several simulations were performed with a more complex model containing separate layers of the fuel core and cladding.

\subsubsection{Simulation Setup}

Given that the intermediate zirconium layer is thin and its Young's modulus ( 93.2 GPa) [43] is not significantly different from AA6061 (66.8 GPa), its effect on FSI is negligible and hence it is modeled as part of the aluminum cladding in this work. The fuel core was modeled as 13 mil thick, following the specification of the "T" type plate [4]. A perfect bond between the layers has been assumed.

The top and front views of the domain with the separate domains for fuel and cladding are shown in Figure 4.12 and Figure 4.13.

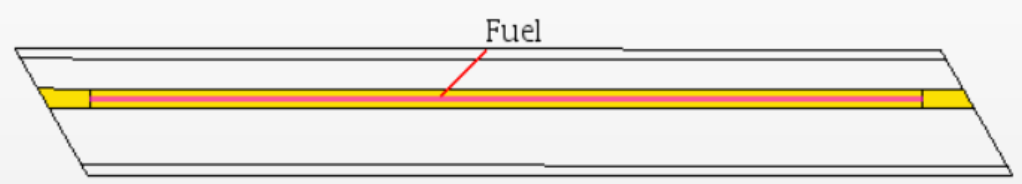

Figure 4.12. Top view of the simulation domain with fuel and cladding modeled separately

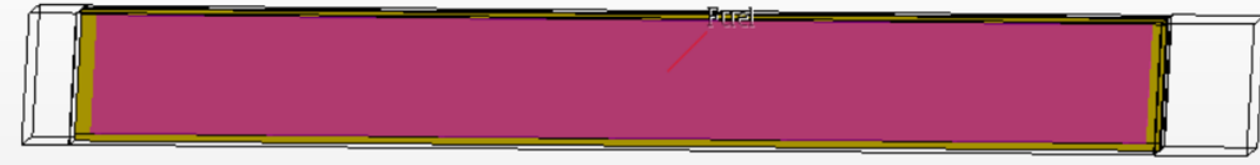

Flow

Figure 4.13. Front view of the simulation domain with fuel and cladding modeled separately

\subsubsection{Results}

Three new cases (Case 10 to 12) based on the nominal Case 1 with the separate models for fuel core and cladding were examined. The three cases differ in the Young's modulus of the fuel core. The Young's modulus of U-10Mo alloy varies with temperature, heat-treatment approach, aging, irradiation effect, etc. [43]. Therefore, three values of Young's modulus are used here to envelop the possible values of Young's modulus of U-10Mo. Case 10 with Young's modulus of 88.4 GPa represents the nominal value at $20^{\circ} \mathrm{C}$ based on Table C-13 of Reference [43], while Case 11 with $30.6 \mathrm{GPa}$ and Case 12 with $125.5 \mathrm{GPa}$ represent the lower and upper limits, respectively. The Young's modulus value of $125.5 \mathrm{GPa}$ was reported in reference [44] for gamma-quenched and aged U-10Mo alloys at $21^{\circ} \mathrm{C}$, and the value of $30.6 \mathrm{GPa}$ is for $\mathrm{U}-10 \mathrm{Mo}$ irradiated at $8.0 \times 10^{21}$ fissions $/ \mathrm{cm}^{3}$ at $20^{\circ} \mathrm{C}$ [43]. All these numbers were obtained from the Preliminary Report on U-Mo Monolithic Fuel for Research Reactors [43]. The Poisson's ratio of 0.41 from the same reference [43] is used for U-10Mo fuel. For the aluminum alloy (AA6061) cladding, Young's modulus of 66.8 GPa and Poisson's ratio of 0.33 were 
assumed. The calculated values of stripe-averaged displacements are shown in Table 4.5. For Cases 10 to 12, two kinds of stripe-averaged displacement are used. The "plate" stripe average is obtained by averaging the fuel and cladding together, so their definition is consistent with the stripe referred to in Section 4.4. The "fuel" stripe average is obtained by averaging over the fuel core only for each stripe. The maximum displacement occurs at the plate leading edge, and the fuel-core leading edge is $5 / 16$ inch downstream of the plate leading edge. Therefore, the fuel-stripe-averaged displacement is expected to be slightly lower than the plate-stripe-averaged displacement, as is observed in Table 4.5. By comparing the displacements of Cases 10,11, and 12, one observes that predicted displacement decreases with the increase in fuel-core Young's modulus, but the effect is limited. Increasing the fuel core Young's modulus from $30.6 \mathrm{GPa}$ to $125.5 \mathrm{GPa}$ results in only a $0.004 \mathrm{mil}$ $(\sim 2.0 \%)$ decrease in the maximum stripe displacement. Note that the original Case 1 result is not well aligned with the trend of Cases 10 to 12. The reason is the different meshing approach. For Case 1, the plate is meshed as a whole, but for the other three cases, the plate is meshed as several pieces because of the separate modeling of the core. Although the total cell numbers for these two approaches are close, a trivial difference could be introduced into the result. To verify this point, Case 1 was repeated using the two-layer mesh, which is the same as for Cases 10 to 12 but using aluminum properties for both core and cladding. The new Case 1 result agrees with the trends, with the maximum stripe displacement larger than Case 10 but less than Case 11.

Table 4.5. Stripe-averaged displacements for three new cases

\begin{tabular}{|c|c|c|c|c|c|c|}
\hline \multirow{2}{*}{\multicolumn{2}{|c|}{ Case }} & \multicolumn{5}{|c|}{ Area-averaged displacement (mil) at stripe \# } \\
\hline & & 1 & 2 & 3 & 4 & Overall \\
\hline \multicolumn{2}{|c|}{$1(\mathrm{E}=66.8 \mathrm{GPa})$} & 0.072 & 0.209 & 0.209 & 0.072 & 0.128 \\
\hline \multirow{2}{*}{$\begin{array}{c}10 \\
\left(\mathrm{E}_{\mathrm{fuel}}=88.4 \mathrm{GPa}\right)\end{array}$} & plate & 0.074 & 0.211 & 0.211 & 0.074 & 0.129 \\
\hline & fuel $^{*}$ & 0.074 & 0.209 & 0.209 & 0.074 & 0.141 \\
\hline \multirow{2}{*}{$\begin{array}{c}11 \\
\left(E_{\text {fuel }}=30.6 \mathrm{GPa}\right)\end{array}$} & plate & 0.075 & 0.214 & 0.214 & 0.075 & 0.131 \\
\hline & fuel $^{*}$ & 0.075 & 0.213 & 0.212 & 0.075 & 0.144 \\
\hline \multirow{2}{*}{$\begin{array}{c}12 \\
\left(E_{\text {fuel }}=125.5 \mathrm{GPa}\right)\end{array}$} & plate & 0.074 & 0.210 & 0.210 & 0.074 & 0.128 \\
\hline & fuel $^{*}$ & 0.073 & 0.208 & 0.208 & 0.073 & 0.141 \\
\hline \multirow{2}{*}{$\begin{array}{c}1 \text { Two-layer model } \\
\left(\mathrm{E}_{\text {fuel }}=66.8 \mathrm{GPa}\right)\end{array}$} & plate & 0.074 & 0.212 & 0.212 & 0.074 & 0.129 \\
\hline & fuel $^{*}$ & 0.074 & 0.210 & 0.210 & 0.074 & 0.142 \\
\hline
\end{tabular}

${ }^{*}$ The fuel core axial length is $5 / 8$ inch shorter than the whole plate with cladding, which accounts for the slightly difference of the displacement values between fuel and plate. The fuel core width is 0.225 inch less that the plate width for each side, so the fuel core region is 0.225 inch away from the constrained boundary, which accounts for the lager overall displacement for 'fuel' compared to 'plate'.

Displacements obtained in simulations for Cases 10, 11, and 12 are plotted in Figure 4.14. The difference of the displacement profiles of these three cases is small, and it is hardly noticeable that the displacement of Case 11 is larger, and the displacement of Case 12 is smaller, due to the various Young's modulus of the fuel core.

In summary, the effect of the fuel-core Young's modulus on the plate displacement is small: increasing Young's modulus from 30.6 GPa to $125.5 \mathrm{GPa}$ results in only a $2.0 \%$ decrease in the maximum stripe averaged displacement. Furthermore, the deviation introduced by the homogeneous aluminum plate assumption is insignificant. Furthermore, changes due to irradiation of the fuel core mechanical 
properties, such as modulus, have therefore a negligible effect on the overall mechanical response to recoverable deformations.
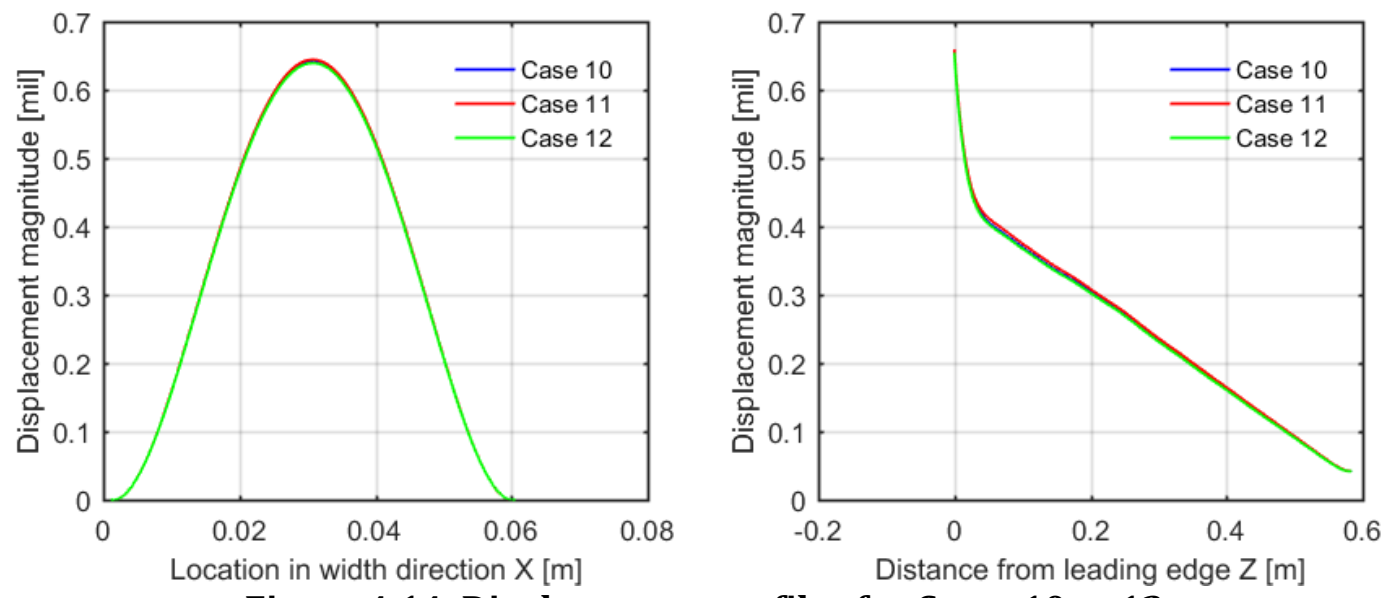

Figure 4.14. Displacement profiles for Cases 10 to 12

\subsubsection{Bending Stiffness Calculations}

The error introduced by the monolithic aluminum plate assumption can also be evaluated using simple formulas for plate flexural stiffness. The flexural stiffness for a homogeneous plate is given as [45]:

$$
D=\frac{E h^{3}}{12\left(1-v^{2}\right)}
$$

where $D$ is the flexural stiffness, $E$ is the Young's modulus, $v$ is the Poisson's ratio, and $h$ is the plate thickness. The flexural stiffness for a composite plate can be calculated as [46]:

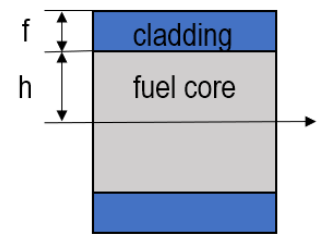

$$
D=\frac{2}{3} E^{f} f^{3}+\frac{2}{3} E^{c} h^{3}+2 E^{f} f h(f+h)
$$

where $h$ is half of the thickness of the fuel core, $E^{c}$ is the Young's modulus of the core, $f$ is the thickness of the flange (cladding), and $E^{f}$ is the corresponding Young's modulus of the cladding. The stiffness calculation result is shown in Table 4.6. Note that Eq. (4.2) does not consider Poisson's ratio. Therefore, the stiffness of the homogeneous AA6061 plate is calculated using both AA6061 Poisson's ratio and zero Poisson's ratio (neglecting this effect). For Eq. (4.2), the AA6061 cladding AA6061 core case is used to verify this equation. Three values of Young's modulus are used for the U-10Mo core. The variance of plate stiffness is less than $2 \%$ for both the upper and lower limit of the Young's modulus of U-10Mo. This stiffness-calculation result provides additional evidence that the stiffness difference between the fresh plate (E $88 \mathrm{GPa}$ for the core) and the highly degraded plate (E 30.6 GPa for the core) is minimal, and FSI analysis based on a homogenous AA6061 plate will not introduce much error. Again, as observed in the prior section, changes due to irradiation of the fuel 
core mechanical properties, such as modulus, have therefore a negligible effect on the overall mechanical response to recoverable deformations.

Table 4.6 Stiffness-calculation results

\begin{tabular}{|c|c|c|c|c|c|c|}
\hline \multirow{2}{*}{ Plate material } & \multicolumn{2}{|c|}{$\begin{array}{c}\text { Young's modulus } \\
(\mathrm{GPa})\end{array}$} & \multicolumn{2}{|c|}{ Stiffness $(\mathrm{N} \cdot \mathrm{m})$} & \multirow{2}{*}{$\begin{array}{c}\text { Compared } \\
\text { to } \\
\text { nominal }\end{array}$} & \multirow{2}{*}{$\begin{array}{l}\text { Calculated } \\
\text { via Eq. }\end{array}$} \\
\hline & Cladding & Core & $v=0.33$ & $v=0$ & & \\
\hline AA6061 Plate & \multicolumn{2}{|c|}{66.8} & 12.04 & 10.73 & - & $(4.1)$ \\
\hline $\begin{array}{l}\text { AA6061 Cladding, } \\
\text { AA6061 Core }\end{array}$ & 66.8 & 66.8 & - & 10.73 & $-0.60 \%$ & $(4.2)$ \\
\hline $\begin{array}{c}\text { AA6061 Cladding, } \\
\text { U-10Mo Core (nominal) }\end{array}$ & 66.8 & 88.4 & - & 10.80 & $0.00 \%$ & $(4.2)$ \\
\hline $\begin{array}{l}\text { AA6061 Cladding, } \\
\text { U-10Mo Core (weak) }\end{array}$ & 66.8 & 30.6 & - & 10.62 & $-1.61 \%$ & $(4.2)$ \\
\hline $\begin{array}{l}\text { AA6061 Cladding, } \\
\text { U-10Mo Core (stiff) }\end{array}$ & 68.0 & 125.5 & - & 10.91 & $1.03 \%$ & $(4.2)$ \\
\hline
\end{tabular}

\subsubsection{Effect of Fuel Swelling and Its Young's Modulus Reduction on Plate Stiffness}

During the irradiation process, the fuel core swells, and its properties change. The swelling process introduces stress in the core and the cladding. To some extent, these stresses are reduced by rheological processes (creep). Irradiation, among other factors, causes a reduction in the Young's modulus of the U-10Mo fuel. These effects are studied in detail in a separate activity under the reactor conversion project. In the current work, focus is placed on understanding the effects of volumetric change caused by swelling on the overall bending stiffness of the plate, disregarding the additional state of internal stresses caused by it.

Although data on the fission density for the first full LEU core with 22 fuel elements are not available at the moment, the irradiation levels for the cycle with that core are expected to be close to the irradiation levels of the $1^{\text {st }}$ and $2^{\text {nd }}$ cycle with Demonstration Element ML-136. Table 4.7 and Table 4.8 show the fission density in the outer plates ( 1 and 19, respectively) of the ML-136 element after its $2^{\text {nd }}$ depletion cycle. The fields in the tables are color coded with red fields having the highest and green having the lowest fission density. The highest irradiation level on the edge (where the deflection is maximum) for plate 19 is $7.86 \mathrm{E}+20 \mathrm{f} / \mathrm{cm}^{3}$. Swelling and Young's modulus reduction will be calculated for this value of fission density. 
Table 4.7 Fission density for plate 1 in Element ML-136 after its 2nd depletion cycle

\begin{tabular}{r|cccc} 
axial node & stripe 1 & stripe 2 & stripe 3 & stripe 4 \\
1 & $5.17 \mathrm{E}+20$ & $3.71 \mathrm{E}+20$ & $3.37 \mathrm{E}+20$ & $3.5 \mathrm{E}+20$ \\
2 & $4.53 \mathrm{E}+20$ & $3.29 \mathrm{E}+20$ & $2.96 \mathrm{E}+20$ & $3.05 \mathrm{E}+20$ \\
3 & $5.16 \mathrm{E}+20$ & $3.87 \mathrm{E}+20$ & $3.52 \mathrm{E}+20$ & $3.67 \mathrm{E}+20$ \\
4 & $5.78 \mathrm{E}+20$ & $4.47 \mathrm{E}+20$ & $4.13 \mathrm{E}+20$ & $4.26 \mathrm{E}+20$ \\
5 & $6.42 \mathrm{E}+20$ & $5.02 \mathrm{E}+20$ & $4.63 \mathrm{E}+20$ & $4.76 \mathrm{E}+20$ \\
6 & $6.89 \mathrm{E}+20$ & $5.47 \mathrm{E}+20$ & $5.07 \mathrm{E}+20$ & $5.25 \mathrm{E}+20$ \\
7 & $7.3 \mathrm{E}+20$ & $5.78 \mathrm{E}+20$ & $5.41 \mathrm{E}+20$ & $5.68 \mathrm{E}+20$ \\
8 & $7.29 \mathrm{E}+20$ & $6.07 \mathrm{E}+20$ & $5.65 \mathrm{E}+20$ & $5.88 \mathrm{E}+20$ \\
9 & $7.2 \mathrm{E}+20$ & $6.12 \mathrm{E}+20$ & $5.74 \mathrm{E}+20$ & $6.05 \mathrm{E}+20$ \\
10 & $7.24 \mathrm{E}+20$ & $6.06 \mathrm{E}+20$ & $5.84 \mathrm{E}+20$ & $6.16 \mathrm{E}+20$ \\
11 & $7.07 \mathrm{E}+20$ & $6.05 \mathrm{E}+20$ & $5.71 \mathrm{E}+20$ & $6 \mathrm{E}+20$ \\
12 & $6.8 \mathrm{E}+20$ & $5.72 \mathrm{E}+20$ & $5.56 \mathrm{E}+20$ & $5.81 \mathrm{E}+20$ \\
13 & $6.45 \mathrm{E}+20$ & $5.4 \mathrm{E}+20$ & $5.15 \mathrm{E}+20$ & $5.46 \mathrm{E}+20$ \\
14 & $6.02 \mathrm{E}+20$ & $4.95 \mathrm{E}+20$ & $4.7 \mathrm{E}+20$ & $4.98 \mathrm{E}+20$ \\
15 & $5.62 \mathrm{E}+20$ & $4.37 \mathrm{E}+20$ & $4.07 \mathrm{E}+20$ & $4.37 \mathrm{E}+20$ \\
16 & $6.86 \mathrm{E}+20$ & $5.18 \mathrm{E}+20$ & $4.9 \mathrm{E}+20$ & $5.39 \mathrm{E}+20$
\end{tabular}

Table 4.8 Fission density for plate 19 in Element ML-136 after its 2 nd depletion cycle

\begin{tabular}{r|cccc} 
axial node & stripe 1 & stripe 2 & stripe 3 & stripe 4 \\
1 & $4.89 \mathrm{E}+20$ & $3.97 \mathrm{E}+20$ & $3.57 \mathrm{E}+20$ & $3.58 \mathrm{E}+20$ \\
2 & $4.21 \mathrm{E}+20$ & $3.41 \mathrm{E}+20$ & $3.13 \mathrm{E}+20$ & $3.13 \mathrm{E}+20$ \\
3 & $4.84 \mathrm{E}+20$ & $4.27 \mathrm{E}+20$ & $3.99 \mathrm{E}+20$ & $4.07 \mathrm{E}+20$ \\
4 & $5.57 \mathrm{E}+20$ & $4.99 \mathrm{E}+20$ & $4.79 \mathrm{E}+20$ & $4.81 \mathrm{E}+20$ \\
5 & $6.14 \mathrm{E}+20$ & $5.57 \mathrm{E}+20$ & $5.40 \mathrm{E}+20$ & $5.50 \mathrm{E}+20$ \\
6 & $6.64 \mathrm{E}+20$ & $6.13 \mathrm{E}+20$ & $5.93 \mathrm{E}+20$ & $6.04 \mathrm{E}+20$ \\
7 & $6.93 \mathrm{E}+20$ & $6.30 \mathrm{E}+20$ & $6.21 \mathrm{E}+20$ & $6.48 \mathrm{E}+20$ \\
8 & $6.74 \mathrm{E}+20$ & $6.17 \mathrm{E}+20$ & $6.04 \mathrm{E}+20$ & $6.29 \mathrm{E}+20$ \\
9 & $6.48 \mathrm{E}+20$ & $5.88 \mathrm{E}+20$ & $5.81 \mathrm{E}+20$ & $6.05 \mathrm{E}+20$ \\
10 & $6.42 \mathrm{E}+20$ & $5.90 \mathrm{E}+20$ & $5.77 \mathrm{E}+20$ & $6.01 \mathrm{E}+20$ \\
11 & $6.29 \mathrm{E}+20$ & $5.71 \mathrm{E}+20$ & $5.65 \mathrm{E}+20$ & $5.97 \mathrm{E}+20$ \\
12 & $6.22 \mathrm{E}+20$ & $5.69 \mathrm{E}+20$ & $5.59 \mathrm{E}+20$ & $5.93 \mathrm{E}+20$ \\
13 & $6.57 \mathrm{E}+20$ & $6.32 \mathrm{E}+20$ & $6.23 \mathrm{E}+20$ & $6.65 \mathrm{E}+20$ \\
14 & $6.61 \mathrm{E}+20$ & $6.41 \mathrm{E}+20$ & $6.50 \mathrm{E}+20$ & $6.89 \mathrm{E}+20$ \\
15 & $6.33 \mathrm{E}+20$ & $6.03 \mathrm{E}+20$ & $5.94 \mathrm{E}+20$ & $6.35 \mathrm{E}+20$ \\
16 & $7.86 \mathrm{E}+20$ & $7.13 \mathrm{E}+20$ & $7.08 \mathrm{E}+20$ & $7.53 \mathrm{E}+20$
\end{tabular}

Young's modulus of unirradiated U-10Mo as a function of temperature is described using Eq. (2.35) of reference [42]:

$$
E_{U 10 M o}=90.0-0.13 T
$$


where $E$ is in $\mathrm{GPa}$ and $T$ is in ${ }^{\circ} \mathrm{C}$. For room temperature $\left(21^{\circ} \mathrm{C}\right), E$ is calculated to be $87.3 \mathrm{GPa}$. The Young's modulus reduction due to irradiation and temperature can be calculated using a set of equations, Eqs. (2.38), from [42]:

$$
E=\left\{\begin{array}{lr}
78.469-4.076 \times f_{d} & \text { at } 21^{\circ} \mathrm{C} \\
56.108-2.914 \times f_{d} & \text { at } 200^{\circ} \mathrm{C} \\
49.897-2.592 \times f_{d} & \text { at } 250^{\circ} \mathrm{C} \\
37.474-1.947 \times f_{d} & \text { at } 350^{\circ} \mathrm{C} \\
31.263-1.624 \times f_{d} & \text { at } 400^{\circ} \mathrm{C} \\
25.052-1.301 \times f_{d} & \text { at } 450^{\circ} \mathrm{C} \\
12.629-0.656 \times f_{d} & \text { at } 550^{\circ} \mathrm{C}
\end{array}\right\}
$$

where $f_{d}$ is in $10^{21} \mathrm{f} / \mathrm{cm}^{3}$.

The actual temperature distribution in the element during the first LEU cycle is not known at the moment. A typical temperature profile for a LEU core is presented in [39] and shown in Figure 4.15 for the $1^{\text {st }}$ plate. The maximum temperature in the fuel core of plate 1 is reported to be around $92^{\circ} \mathrm{C}$.

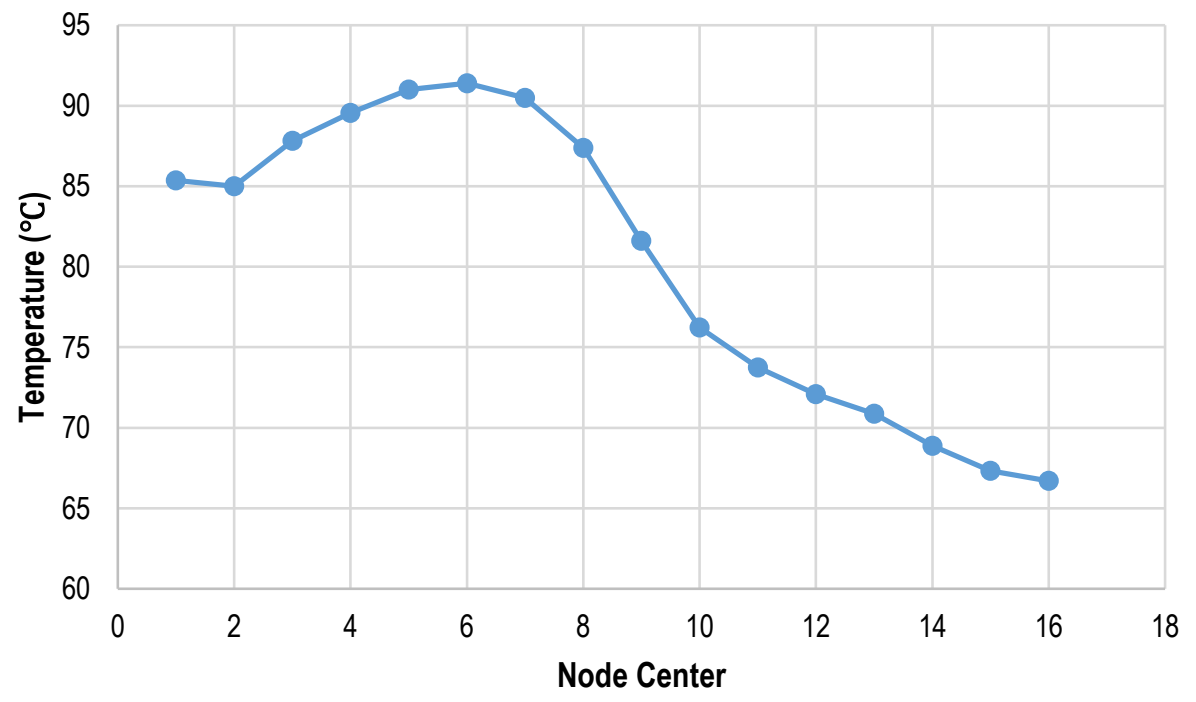

Figure 4.15. Typical temperature profile in plate 1 of ML-136

The first two equations from Eqs. (4.4) above were used to find an average fit for that temperature. On that basis, the Young's modulus reduction for $f_{d}=7.86 \mathrm{E}+20 \mathrm{f} / \mathrm{cm}^{3}$ is calculated as $66.7 \mathrm{GPa}$. This is a reduction by $24.6 \%$ from the fresh state at room temperature. An upper limit of the fit to the data on volumetric swelling of the U-10Mo is described by Eq. (78) of [43]:

$$
\Delta V=6.13 \cdot 10^{-43} \cdot f_{d}^{2}+4.0 * 10^{-21} \cdot f_{d}+14.79
$$

where $f_{d}$ is in $\mathrm{f} / \mathrm{cm}^{3}$.

The reduction of the bending stiffness, as calculated using Eq. (4.2), in the plate with the Young's modulus of the irradiated fuel core $(66.7 \mathrm{GPa})$ is only $0.6 \%$. However, to estimate the overall change in the bending stiffness of the irradiated plate, its swelling needs to be taken into account as well. 
Although Eq. (4.5) describes the volumetric swelling, for the thin plates, the swelling will predominantly cause an increase in plate thickness. The swelling in the two other directions is constrained by the proportions of the plate. Thus, it can be assumed that Eq. (4.5) describes the increase in the plate's thickness due to irradiation. Using the maximum fission density for plate 19 in cycle 2 of $7.86 \mathrm{E}+20 \mathrm{f} / \mathrm{cm}^{3}$, the increase in the core thickness is predicted to be $18.3 \%$. This value, together with Eq. (4.2) and Young's modulus of $66.7 \mathrm{GPa}$ for the irradiated fuel core, can now be used to calculate the stiffness of the swollen plate as $12.37 \mathrm{~N} \cdot \mathrm{m}$. This value, as compared to the value of the nominal stiffness of $10.80 \mathrm{~N} \cdot \mathrm{m}$ listed in Table 4.6 , is higher by $14.6 \%$. Thus, despite the reduction of the Young's modulus of the fuel core, the overall bending stiffness of the fuel plate increases as the aluminum cladding is pushed further away from the centerline of the plate. It can be concluded that the irradiation effects, if not characterized by loss of plate integrity, do not weaken the performance of the plate from the FSI perspective.

\subsection{Stresses in the Plate}

Deflection of the plate due to the pressure differential may contribute to the coolant channel gap reductions. Another aspect of the structural performance of the plates is the level of stress caused by plate's deformations. In this section the stresses in the plates are analyzed. As mentioned previously, the current study does not consider the irradiation effects, so the only analyzed stresses come from the FSI (bending caused by pressure differential). The internal stresses may locally increase significantly owing to the property change of the fuel core due to irradiation and its swelling. These effects will be analyzed under another activity associated with the USHPRR conversion.

The mesh sensitivity study reported in earlier sections focused on the convergence of the displacements in the plate. The convergence of the stresses was not reported. The conducted analysis revealed that the stresses near the supports (long edges) diverged in the models with increasing mesh density. Such stress singularity is quite common for models with elastic materials and geometries that have perfect, sharp corners. For that reason, additional analysis has been performed with the LS-DYNA structural solver as verification study only to estimate the level of stresses in the plates. LS-DYNA solver has significantly broader library of the structural elements including solid and shell type elements, some of which may overcome the issue of the stress divergence. The pressure distribution on the plate surface predicted in the STAR-CCM+ FV fluid solver has been exported and used as an input to the structural analysis in LS-DYNA. No feedback from the structural solver is then brought back to the fluid solver. Thus, this approach can be characterized as one-way coupling of these two solvers. However, since the deflections are small as compared to the size of the coolant channel gap thickness, this feedback is also expected to be insignificant.

Note that the results presented in Figure 4.16 to Figure 4.20 are calculated using fluid properties at $25^{\circ} \mathrm{C}$ for the purpose of showing distribution and convergence trends only. Figure 4.16 shows a typical von Mises stress distribution on the top of the plate. This figure presents the stresses for Case 1 with the nominal geometry and flow conditions. 

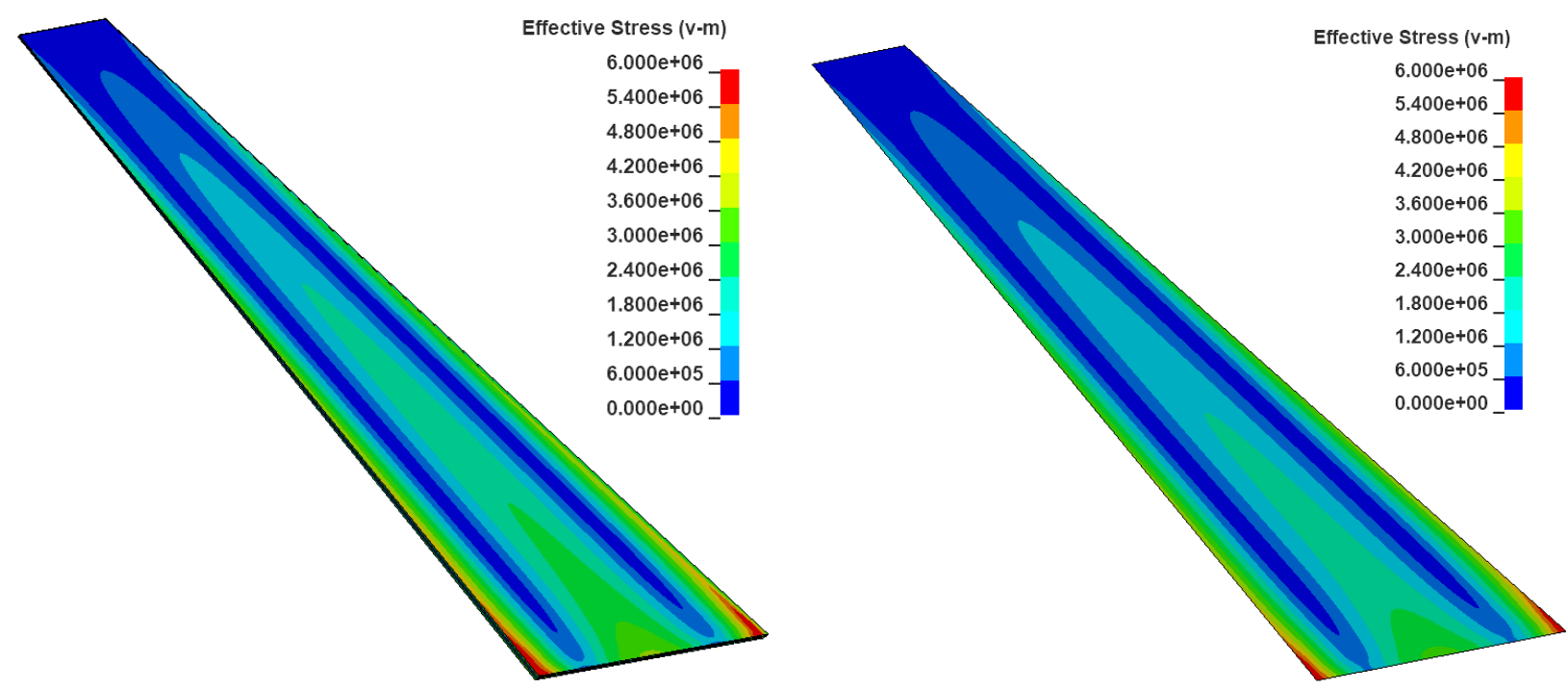

Figure 4.16. Stress (von Mises) contour of Case 1 (units in Pa) in solid (left) and shell (right) element-based models

Figure 4.17 presents the convergence of maximum displacements as a function of number of elements along the leading edge. The full convergence in the LS-DYNA solid model was not obtained. Larger-size models were not suitable for the currently available hardware. The largest deflection was predicted by the shell element-based model in LS-DYNA $(0.0185 \mathrm{~mm})$ which was only $2.2 \%$ larger than the maximum deflection predicted with STAR-CCM+ solver $(0.0181 \mathrm{~mm})$.

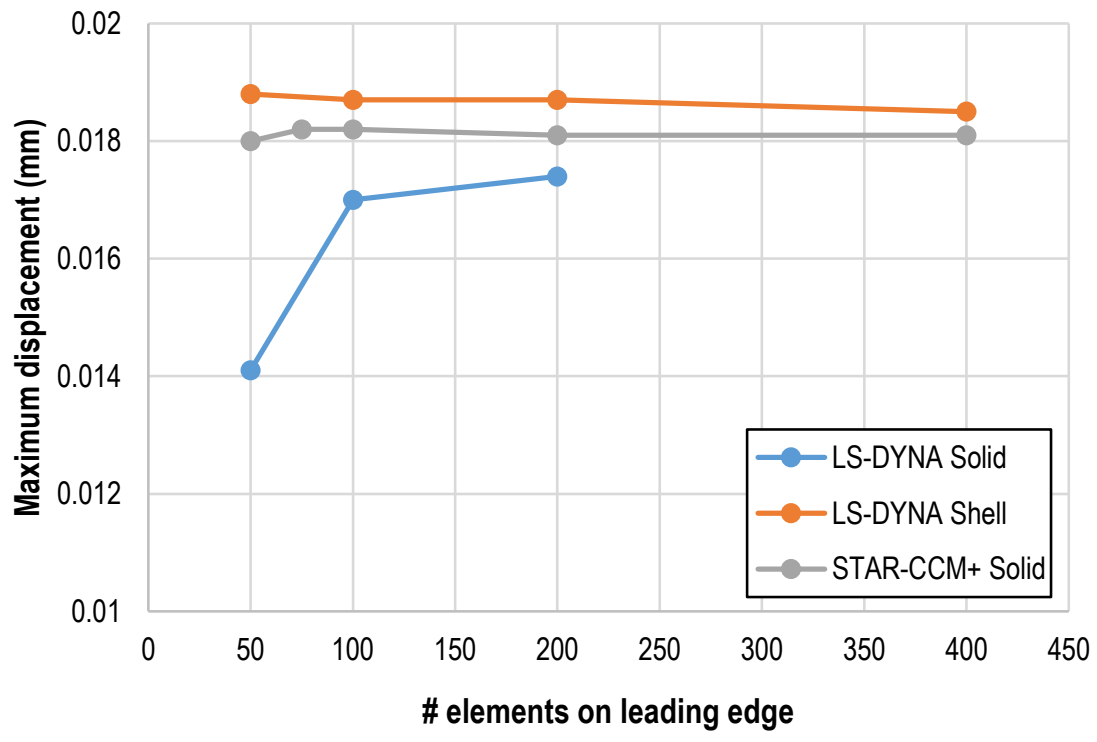

Figure 4.17. Maximum displacement as a function of elements on the leading edge

Figure 4.18 presents the convergence of the maximum stresses on the leading edge that occur in the middle of the span (in plate's width direction). Fast convergence, although to slightly different values, is obtained for all models. The stresses are bounded by the result obtained by LS-DYNA shell model at about $3.54 \mathrm{MPa}$. STAR-CCM+ model predicts these stresses in the midspan at $3.32 \mathrm{MPa}$ (or $6 \%$ lower). 


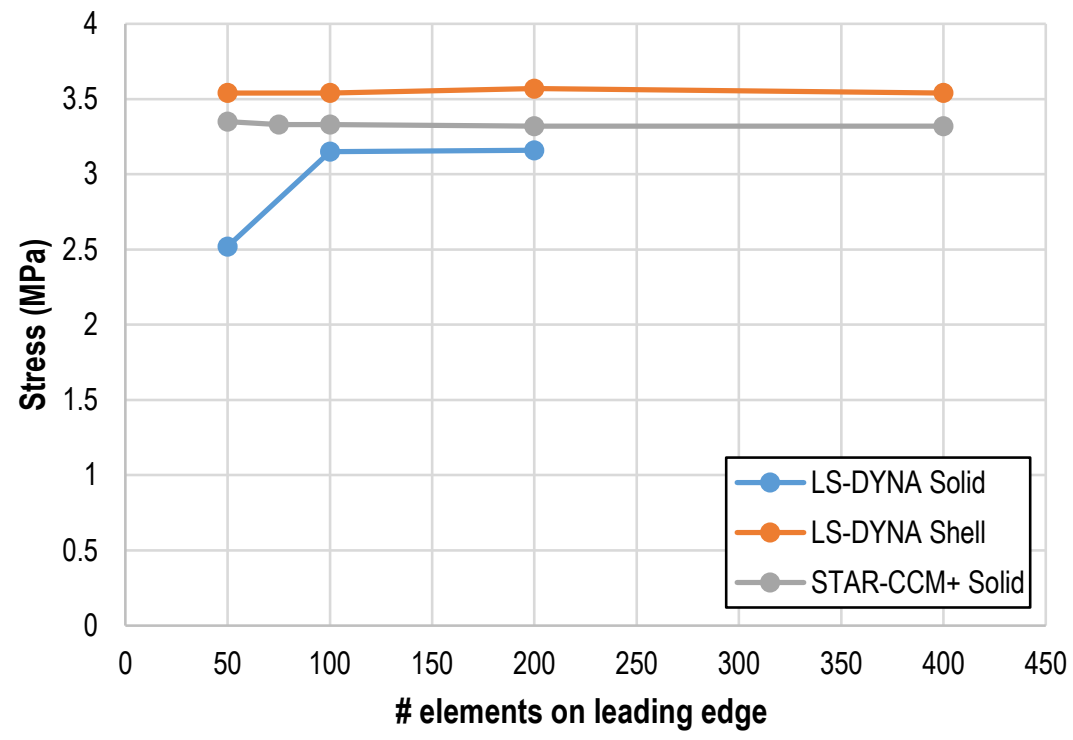

Figure 4.18. Maximum stresses in the midspan as a function of elements number on the leading edge

Figure 4.19 presents the convergence of the maximum stresses near the support edges at the leading edge of the plate. The convergence was obtained quickly for the LS-DYNA shell model. No convergence was obtained for the solid element-based models in both STAR-CCM+ and LS-DYNA. This presents the stress singularity near the boundaries.

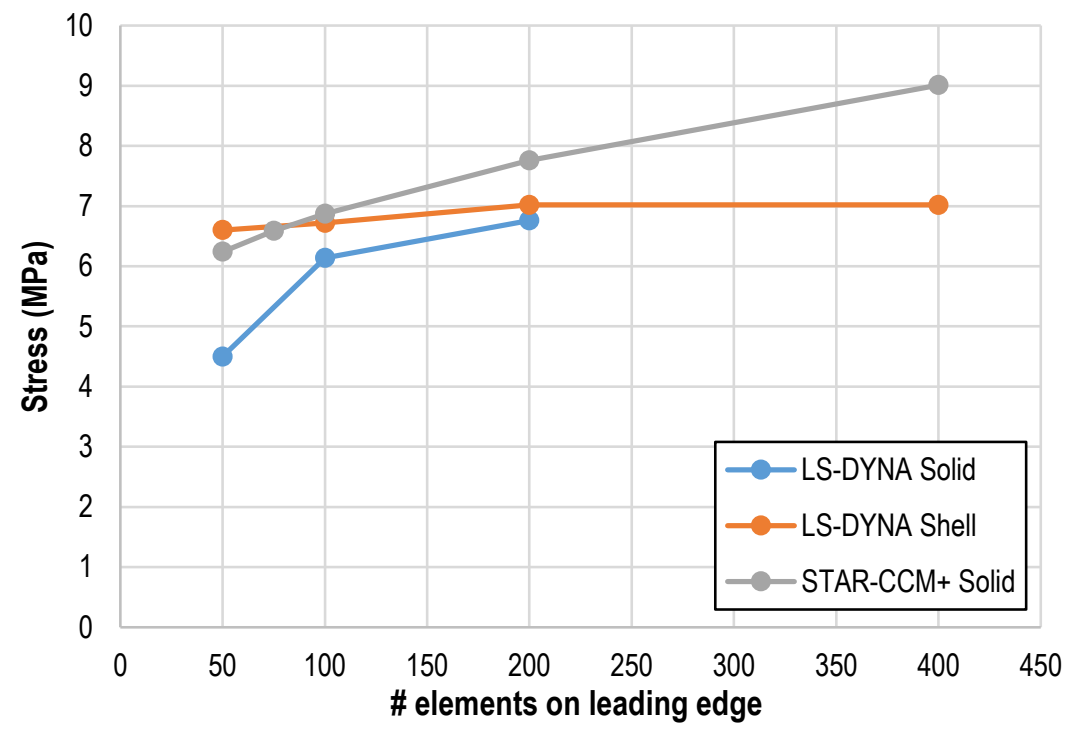

Figure 4.19. Maximum stresses near the long edges as a function of elements number on the leading edge

Figure 4.20 shows the von Mises stresses in a cross section near the leading edge in STAR-CCM+ models with 50 to 400 elements along the span of the plate. From the bending theory of beams, for a uniformly distributed load, the stresses near the edges can be expected to be about twice as high as 
the stresses in the middle of the span. They can also be expected to be a good approximation of stresses in long plates supported along the longer edges (such as the one considered here). In this case, the stresses in the middle of the span of the plate converged at $3.32 \mathrm{MPa}$ in the FE solid solver in STAR-CCM+ and 3.54 MPa in the FE shell solver in LS-DYNA (see Figure 4.18). Thus, the stresses near the boundaries are expected to be around $7 \mathrm{MPa}$. However, the stresses predicted by the solid FE model in STAR-CCM+ diverge and predict higher values that depend on the density of the mesh. As the number of elements along the leading edge grows, the stresses keep increasing. The solution obtained with shell elements in LS-DYNA converges at 7.05 MPa, near the expected theoretical value. The conclusion is that the stresses from FSI near the boundaries cannot be predicted with the models in STAR-CCM+ (and other solvers as well) that use solid elements, sharp corners, and elastic materials. Either shell elements or other methods (for example, analytical) need to be used for that purpose.
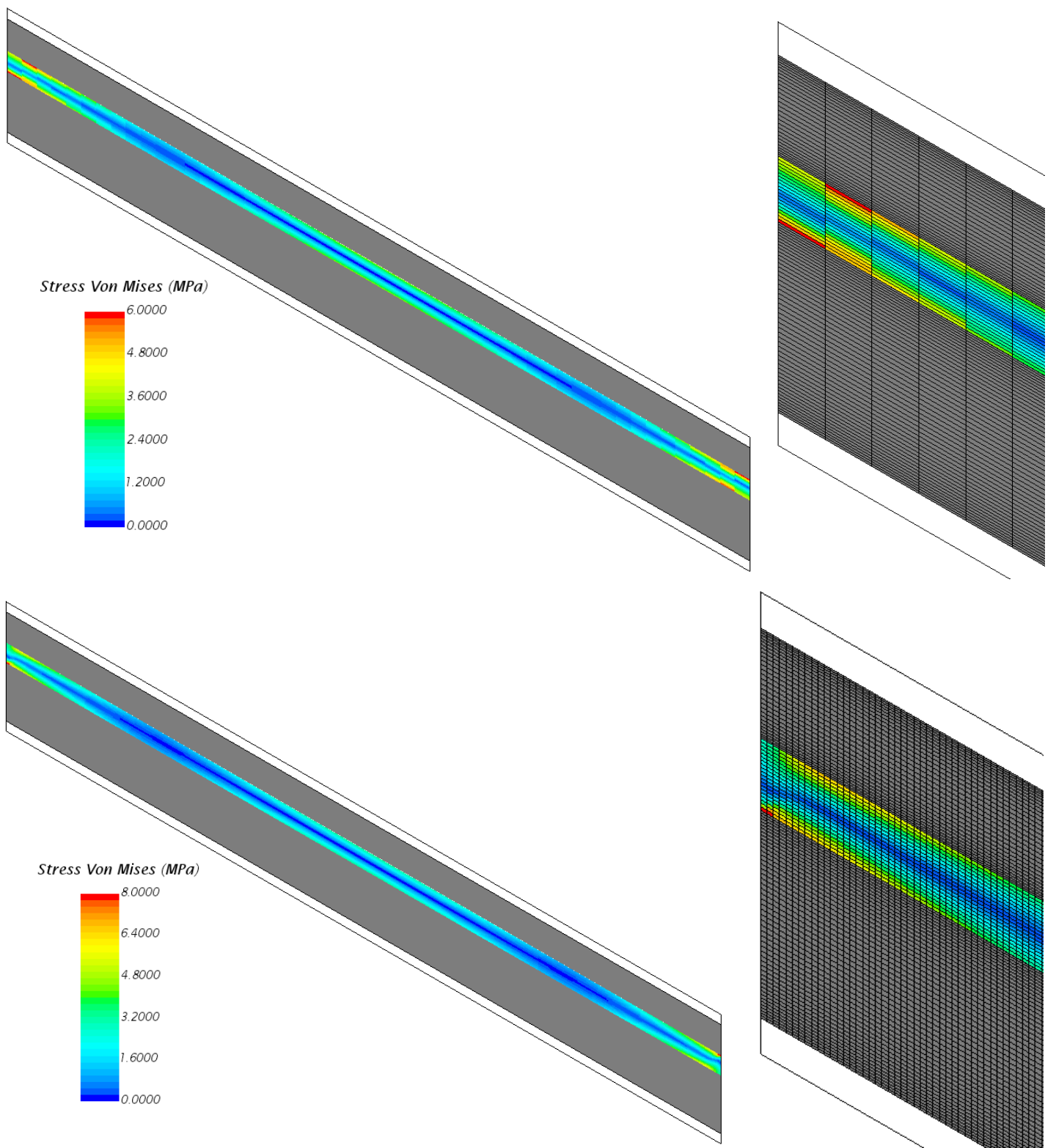

Figure 4.20. von Mises stresses in the cross section of STAR-CCM+ models with 50 (top) and 400 (bottom) elements across the span of the plate. 
Only Case 1 has been analyzed with the use of shell elements in LS-DYNA. For the other cases, the stresses near the boundaries can be estimated by doubling the stresses predicted in the middle of the span for each case. Table 4.9 presents the von Mises stresses in the middle of the span for all the analyzed cases using fluid properties at $55{ }^{\circ} \mathrm{C}$ (MITR nominal outlet temperature). The largest predicted value, $11.52 \mathrm{MPa}$, is predicted for Case 9 . Thus, the stresses near the boundary can be expected to be around 23.0MPa.

The yield strength of AA6061 cladding after a fuel plate has been processed by HIP was reported in the Preliminary U-10Mo Report [43]. Using the properties of 0-temper AA6061 is comparable in this case, which at room temperature is listed in Reference [43] as $55 \mathrm{MPa}$. This is a reasonable (and conservative) approximation for AA6061 yield strength [42]. Even without considering the irradiation-induced strengthening, the value of the highest predicted stress ( $23 \mathrm{MPa}$ in Case 9$)$ is significantly below the yield strength limit.

Table 4.9. Von Mises stress at the plate center near the leading edge

\begin{tabular}{|c|c|}
\hline Case & $\begin{array}{c}\text { von Mises } \\
\text { stress (MPa) }\end{array}$ \\
\hline 1 & 3.05 \\
\hline 2 & 4.05 \\
\hline 3 & 6.01 \\
\hline 4 & 7.99 \\
\hline 5 & 10.01 \\
\hline 6 & 8.96 \\
\hline 7 & 9.05 \\
\hline 8 & 9.16 \\
\hline 9 & 11.52 \\
\hline 10 & 3.10 \\
\hline 11 & 3.11 \\
\hline 12 & 3.10 \\
\hline 13 & 1.05 \\
\hline 14 & 0.53 \\
\hline
\end{tabular}




\section{Conclusions}

As part of the preliminary design verification for the MITR reactor conversion, the objective of this work was to quantify the LEU fuel-plate deflection expected due to FSI. Numerical simulations coupling CFD and CSM were performed using STAR-CCM+ commercial software to predict deflections of the MITR fuel plates due to channel pressure differentials. The numerical models were limited to a single plate and the two channels surrounding it. Nominal as well as conservative flow conditions were used for cases with varying channel gap thickness as well as imperfect plate shapes within the fabrication and assembly tolerances. The analysis led to the following findings:

1. Fuel elements in MITR are not fully constrained in the axial direction, and because of the upward coolant flow, they can be lifted from their resting position in the lower grid. This axial motion allows for additional separation of two elements facing each other across outer channels. Effectively, the thicker channel between them may become even bigger due to slight lifting (geometrically, separate from the FSI effect). Assuming conservatively that this channel has closed side walls (regardless of the elements being separated), the disparity of the flows around the outer plates further increases and leads to larger deflections of the plate.

2. The analysis shows that the coolant velocity in the thick channel is almost two times higher than that in the nominal size channel. These velocities are below 20\% of Miller's critical velocity, and in this flow rate regime, large-scale oscillations of the plates are not expected. Consequently, the pressure differential is expected to be the primary driver of plate deflections.

3. The deflections predicted for all cases analyzed are very small, up to $1.10 \%$ of the channel gap thickness for stripe-averaged quantities ( 0.82 mil or 21 micrometers).

4. For pressure-differential-driven deflections, the plates tend to deflect into the thicker channel, which for the outermost plates (1 and 19) is in the outward direction., The smaller (inner) channels are not reduced, and, thus, these deflections pose no threat to the cooling of the plates. For the inner plates, maximum deflections were predicted to be up to $0.24 \%$ (in stripe-averaged terms) of the channel gap thickness for the case of a slanted plate between two channels with the highest gap thickness disparity allowed by assembly tolerances.

5. Additional non-uniformity imposed on the plate's shape did not contribute significantly to increasing the deflections. Various shapes of these non-uniformities, with an amplitude that stayed within the tolerances of fabrication (plate flatness) and assembly, had a similar effect on these deflections, increasing the stripe-averaged deflections by up to $21 \%$. Flow disparities in the core as well as uncertainties in the coolant-system performance account for a flow rate possibly $12.35 \%$ higher than nominal. This may lead to a $26 \%$ increase in both stripe-averaged plate deflection and local maximum plate deflections. These sensitivities are negligible given the very small magnitude in the conclusions above $(0.82$ mil or 21 micrometers).

6. Although the plate is assumed to be homogeneous and made only of aluminum alloy (AA6061) in most cases, layered plates with different properties for the fuel core and cladding were also studied. Both the simulation and analytical results indicate that variations in Young's modulus of the fuel core do not significantly affect the plate's deflection, and the error introduced by the homogeneous all-aluminum plate assumption is minimal. The expected

MITR Low-Enriched Uranium Conversion Fluid-Structure Interaction Preliminary Design 
reduction in Young's modulus of the fuel core due to irradiation is $24.6 \%$ during the first cycle with $22 \mathrm{LEU}$ elements in the core. This reduction is found to have minimal impact on the plate's FSI performance, causing only a $0.6 \%$ decrease in the overall stiffness of the plate.

7. Also, as shown via FSI simulations and analytical solution, the changes due to irradiation of the fuel core mechanical properties, such as modulus, were found to have a negligible effect on the overall mechanical response to recoverable deformations. Swelling of the fuel core increases the overall thickness of the plate by $18.3 \%$, as a result, the bending stiffness of the plate increases by $14.6 \%$.

8. The highest stresses caused by FSI are expected near the side boundaries at the leading edge. The solid elements in STAR-CCM+ and other solvers may not be able to predict these stresses, owing to the stress singularity. However, shell elements provide converged stresses at these locations. Also, for the flat MITR plates, these stresses can be approximated by doubling the stresses predicted in the middle of the span. For all analyzed cases, the von Mises stresses are predicted to be well below the yield strength of the AA6061.

In summary, all analyzed deflections remain small compared to fabrication tolerances (6 mil of plate flatness), and for all cases analyzed, deflection occurs towards the larger channel. Thus, flow-induced plate deflection is not a factor that would be expected to reduce flows in the limiting (i.e., narrow) channels in thermal hydraulics analyses of MITR. 


\section{Acknowledgement}

The authors would like to thank Dr. Son Pham of Argonne National Laboratory for his expertise on fuel element geometries that was important to this work.

This work was sponsored by the U.S. Department of Energy, Office of Material Management and Minimization in the U.S. National Nuclear Security Administration Office of Defense Nuclear Nonproliferation under Contract DE-AC02-06CH11357. 


\section{References}

[1] E. H. Wilson, T. H. Newton Jr, A. Bergeron, N. Horelik and J. G. Stevens, "Comparison and Validation of HEU and LEU Modeling Results to HEU Experimental Benchmark Data for the Massachusetts Institute of Technology MITR Reactor," ANL/RERTR/TM-10-41, Argonne National Laboratory, Lemont, IL, 2010.

[2] A. Bergeron, E. H. Wilson, F. E. Yesilurt, F. E. Dunn, J. G. Stevens, L.-w. Hu and T. H. Newton Jr, "Low Enriched Uranium Core Design for the Massachusetts Institute of Technology Reactor (MITR) with Un-finned 12 mil-thick Clad UMo Monolithic Fuel," ANL/GTRI/TM-13/15, Argonne National Laboratory, Lemont, IL, 2013.

[3] F. E. Dunn, A. P. Olson, E. H. Wilson, K. Sun, L.-w. Hu and T. H. Newton Jr, "Preliminary Accident Analyses for Conversion of the MIT Reactor from Highly-Enriched to Low-Enriched Uranium," ANL/GTRI/TM-13/5, Argonne National Laboratory, Lemont, IL, 2013.

[4] K. Sun, L.-w. Hu, E. H. Wilson, A. Bergeron and T. A. Heltemes, "Low Enriched Uranium (LEU) Conversion Preliminary Safety Analysis Report for the MIT Research Reactor (MITR)," MITNRL-18-01 Revison 2, Massachusetts Institute of Technology, Cambridge, MA, October 2018.

[5] K. Sun, A. J. Dave, L.-w. Hu, E. H. Wilson, S. Pham, D. Jaluvka and T. Heltemes, "Transitional cores and fuel cycle analyses in support of MIT reactor low enriched uranium fuel conversion," Progress in Nuclear Energy, vol. 119, p. 103171, 2020.

[6] W. K. Stromquist and O. Sisman, "High Flux Reactor Fuel Assemblies - Vibration and Water Flow," ORNL-50, Oak Ridge National Laboratory, Oak Ridge, TN, 1948.

[7] D. R. Miller, "Critical Flow Velocities for Collapse of Reactor Parallel-Plate Fuel Assemblies," Transactions of the ASME Journal of Engineering for Power, vol. 82, no. 2, pp. 83-91, April 1960.

[8] E. B. Johansson, "Hydraulic Instability of Reactor Parallel-Plate Fuel Assemblies," Knolls Atomic Power Laboratory, Schenectady, NY, 1959.

[9] G. S. Rosenberg and C. K. Youngdahl, "A Simplified Dynamic Model for the Vibration Frequencies and Critical Coolant Flow Velocities for Reactor Parallel Plate Fuel Assemblies," Nuclear Science and Engineering, vol. 13, pp. 91-102, 1962.

[10] R. J. Scavuzzo, "Hydraulic Instability of Flat Parallel-Plate Assemblies," Nuclear Science and Engineering, vol. 21, pp. 463-472, 1965.

[11] R. D. Groninger and J. J. Kane, "Flow Induced Deflections of Parallel Flat Plates," Nuclear Science and Engineering, vol. 16, pp. 218-226, 1963.

[12] J. J. Kane, "The Effect of Inlet Spacing Deviations on the Flow-Induced Deflections of Flat Plates," Journal of Nuclear Science and Engineering, vol. 15, pp. 305-308, 1963.

[13] G. E. Smissaert, "Static and Dynamic Hydroelastic Instabilities in MTR-Type Fuel Elements: Part I. Introduction and Experimental Investigation," Nuclear Engineering and Design, vol. 7, no. 6, pp. 535-546, 1968.

[14] W. F. Swinson, R. L. Battiste, C. R. Luttrell and G. T. Yahr, "Fuel Plate Stability Experiments and Analysis for the Advanced Neutron Source," Symposium on Flow-Induced Vibration and Noise, vol. 224, pp. 133-143, 1992.

[15] W. F. Swinson, R. L. Battiste, C. R. Luttrell and G. T. Yahr, "Structural Response of Reactor Fuel Plates to Coolant Flow," in Pressure Vessels and Piping Conference, Denver CO, July 25-29, 1993.

[16] W. F. Swinson, R. L. Battiste, L. R. Luttrell and G. T. Yahr, "An Experimental Investigation of the Structural Response of Reactor Fuel Plates," Journal of Experimental Mechanics, vol. 9, pp. 212215, 1995.

MITR Low-Enriched Uranium Conversion Fluid-Structure Interaction Preliminary Design 
[17] W. F. Swinson, R. L. Battiste, R. C. Luttrell and G. T. Yahr, "Fuel Plate Stability Experiments and Analysis for the Advanced Neutron Source," ORNL/TM-12353, Oak Ridge National Laboratory, Oak Ridge, TN, 1993.

[18] M. Ho, G. Hong and A. Mack, "Experimental Investigation of Flow-Induced Vibration in Parallel Plate Reactor Fuel Assembly," in 15th Australasian Fluid Mechanics Conference, Sydney, Australia, 2004.

[19] L. Liu, D. Lu, P. Zhang and F. Niu, "Large-amplitude and narrow-band vibration phenomenon of a foursquare fix-supported flexible plate in a rigid narrow channel," Nuclear Engineering and Design, vol. 241, no. 8, pp. 2874-2880, 2011.

[20] Y. Li, D. Lu, P. Zhang and L. Liu, "Experimental investigation on fluid-structure interaction phenomenon caused by the flow through double-plate structure in a narrow-channel," Nuclear Engineering and Design, vol. 248, pp. 66-71, 2012.

[21] A. J. Castro, N. L. Scuro and D. A. Andrade, "Experimental Investigation of Critical Velocity in a Parallel Plate Research Reactor Fuel Assembly," in 2017 International Nuclear Atlantic Conference - INAC 2017, Belo Horizonte, Brazil, 2017.

[22] R. C. Gwaltney and C. R. Luttrell, "Critical Flow Velocities for Involute Parallel Fuel Plate Assemblies," Transactions of the Americal Nuclear Society, vol. 57, p. 298, 1988.

[23] W. K. Sartory, "Nonlinear Analysis of Hydraulic Bucklin Instability of AN Involute Fuel Plates," ORNL/TM-12319, Oak Ridge National Laboratory, Oak Ridge, TN, 1993.

[24] A. I. Elzawawy, J. D. Freels and F. Curtis, "Multiphysics Simulation using High Resolution FSI Modeling to Support Safety and Reliability of New Hfir Fuel at RNL," in COMSOL Conference 2015, Boston, MA, October 21, 2015.

[25] A. Tentner, C. Bojanowski, E. Feldman, E. H. Wilson, G. Solbrekken, C. Jesse, J. Kennedy, J. Rivers and G. Schnieders, "Evaluation of Thin Plate Hydrodynamic Stability through a Combined Numerical Modeling and Experimental Effort," ANL/RTR/TM-16/9, Argonne National Laboratory, Lemont, IL, 2017.

[26] J. G. Mantecon and M. M. Neto, "Numerical methodology for fluid -structure interaction analysis of nuclear fuel plates under axial flow conditions," Nuclear Engineering and Design, vol. 333, pp. 76-86, 2018.

[27] T. Howard, W. Marcum and W. Jones, "A novel approach to modeling plate deformations in fluid--structure interactions," Nuclear Engineering and Design, vol. 293, pp. 1--15, 2015.

[28] Siemens, "Simcenter STAR-CCM+ Documentation Version 14.02," 2019.

[29] R. Kmak, D. Jaluvka and E. Wilson, LEU Fuel Element, Massachusetts Institute of Technology Reactor (MITR), R4F-100-000-4, August 1, 2018.

[30] R. Kmak, D. Jaluvka and E. Wilson, Type F Fuel Plate, Massachusetts Institute of Technology Reactor (MITR), R4F-100-003-2, August 1, 2018.

[31] R. Kmak, D. Jaluvka and E. Wilson, Side Plate, Massachusetts Institute of Technology Reactor (MITR), R4F-100-001-3, August 1, 2018.

[32] W. M. Kays and A. L. London, Compact Heat Exchangers, New York, NY: McGraw-Hill, 1984.

[33] C. F. Colebrook and C. M. White, "Experiments with fluid friction in roughened pipes," Proceedings of the Royal Society of London. Series A-Mathematical and Physical Sciences, vol. 161, no. 906, pp. 367-381, 1937.

[34] D. Zigrang and N. Sylvester, "Explicit approximations to the solution of Colebrook's friction factor equation," AIChE Journal, vol. 28, no. 3, pp. 514-515, 1982. 
[35] H. Blasius, "Das Aehnlichkeitsgesetz bei Reibungsvorgangen," Z. Ver. Dtsch. Ing, vol. 56, no. 16, pp. 639--643, 1912.

[36] F. E. Dunn, L.-w. Hu and E. Wilson, "The STAT7 Code for Statistical Propagation of Uncertainties in Steady-State Thermal Hydraulics Analysis of Plate-Fueled Reactors," ANL/RTR/TM-16/7, Argonne National Laboratory, Lemont, IL, 2016.

[37] G. C. Allen, "The reactor engineering of the MITR-II construction and startup," Massachusetts Institute of Technology, Cambridge, MA, 1976.

[38] W. Jones and B. E. Launder, "The prediction of laminarization with a two-equation model of turbulence," International Journal of Heat and Mass Transfer, vol. 15, no. 2, pp. 301--314, 1972.

[39] K. Sun, A. Dave, L.-w. Hu, D. Jaluvka, S. Pham, J. Stillman and E. Wilson, "Irradiation Demonstration Element Design Parameters for MITR LEU U-Mo Fuel Conversion," MITR-NRL18-03 Revision 2, Massachusetts Institute of Technology, Cambridge, MA, 2020.

[40] A. J. Dave, K. Sun, L.-w. Hu, S. H. Pham, E. H. Wilson and D. Jaluvka, "Thermal-hydraulic analyses of MIT reactor LEU transition cycles," Progress in Nuclear Energy, vol. 118, p. 103117, 2020.

[41] C. J. Jesse, W. F. Jones and A. M. Phillips, "Final Report on the Generic Test Plate Assembly Flow Test Campaign," INL/EXT-20-57793 Revision 0, Idaho National Laboratory, Idaho Falls, ID, 2020.

[42] L. Jamison, J. Stillman, D. Jaluvka, W. Mohamed, Y. Kim and E. Wilson, "Review of the Technical Basis for Properties and Fuel Performance Data Used in HEU to LEU Conversion Analysis for U10Mo Monolithic Alloy Fuel," ANL/RTR/TM-17/19 Revision 1, Argonne National Laboratory, Lemont, IL, 2020.

[43] B. Rabin, M. Meyer, J. Cole, I. Glagolenko, W. Jones, J.-F. Jue, D. Keiser, C. Miller, G. Moore, H. Ozaltun, F. Rice, A. Robinson, J. Smith, D. Wachs, W. Williams, N. Woolstenhulme, G. Hoffman and Y. Kim, "Preliminary Report on U-Mo Monolithic Fuel for Research Reactors," INL EXT-1740975, Revision 3, Idaho National Laboratory, Idaho Falls, ID, 2020.

[44] A. R. Kaufmann, Nuclear Reactor Fuel Elements: Metallurgy and Fabrication, New York: Interscience Publishers, 1962.

[45] L. Landau and E. Lifshitz, Theory of Elasticity. Vol. 7 (3rd ed.), Oxford, UK: ButterworthHeinemann, 1986.

[46] D. Zenkert, An Introduction to Sandwich Structures, Stockholm: Engineering Materials Advisory Services, 1995.

[47] MITR, "MIT Reactor Core Housing, Lower Grid Plate drawing, 10/21/71". 


\section{APPENDIX A: Lift-Up Calculations}

Area of the rhomboid opening in the grid [47]:

$$
\begin{gathered}
a=\frac{2.146 \mathrm{in}}{\sin (60 \mathrm{deg})}=0.0629 \mathrm{~m} \\
h=2.145 \mathrm{in} \\
A=a \times h=0.00343 \mathrm{~m}^{2}
\end{gathered}
$$

Pressure drop based on STAT7 calculations:

$$
\Delta p=20.5 \mathrm{kPa}
$$

Volume of LEU element:

$$
\begin{gathered}
V_{\text {side_plate }}=150.3 \mathrm{~cm}^{3} \\
V_{\text {plates }}=886.36 \mathrm{~cm}^{3} \\
V_{\text {end_fitting }}=29.15 \mathrm{~cm}^{3} \\
V_{\text {total }}=2 V_{\text {side_plate }}+V_{\text {plates }}+2 V_{\text {end_fitting }}=1245.26 \mathrm{~cm}^{3}
\end{gathered}
$$

Mass of LEU element:

$$
m_{\text {total }}=8055 \mathrm{~g}
$$

Weight of LEU element:

$$
\begin{gathered}
g=9.81 \mathrm{~m} / \mathrm{s}^{2} \\
W_{\text {total }}=m_{\text {total }} \times g=79.02 \mathrm{~N}
\end{gathered}
$$

Submerged weight of the element:

$$
\begin{gathered}
\rho_{h 2 o}=997 \mathrm{~kg} / \mathrm{m}^{3} \\
W_{h 2 o}=V_{\text {total }} \times \rho_{h 2 o} \times g=12.179 \mathrm{~N} \\
W_{\text {sub }}=W_{\text {total }}-W_{h 2 o}=66.84 \mathrm{~N}
\end{gathered}
$$

Force balance:

$$
\begin{gathered}
F_{\text {lift }}=A \times \Delta p=70.3 \mathrm{~N} \\
F_{\text {result }}=W_{\text {sub }}-F_{\text {lift }}=-3.46 \mathrm{~N}
\end{gathered}
$$

When $F_{\text {result }}$ reaches zero or below, the element may lift up. 


\section{APPENDIX B: Results of Modal Analysis for the MITR Plate}

The modal analysis of the MITR fuel plate has been performed using LS-DYNA solver. A model based on shell elements with the grid size $40 \times 200$ fully integrated elements (8,000 total) has been used. First twelve frequencies and associated modes of vibrations are presented below.

Table B.1 Frist twelve natural frequency of the MITR plate

\begin{tabular}{|c|c|}
\hline ID & Frequency (Hz) \\
\hline 1 & 1849 \\
\hline 2 & 1851 \\
\hline 3 & 1866 \\
\hline 4 & 1889 \\
\hline 5 & 1921 \\
\hline 6 & 1964 \\
\hline 7 & 2018 \\
\hline 8 & 2086 \\
\hline 9 & 2166 \\
\hline 10 & 2261 \\
\hline 11 & 2372 \\
\hline 12 & 2499 \\
\hline
\end{tabular}
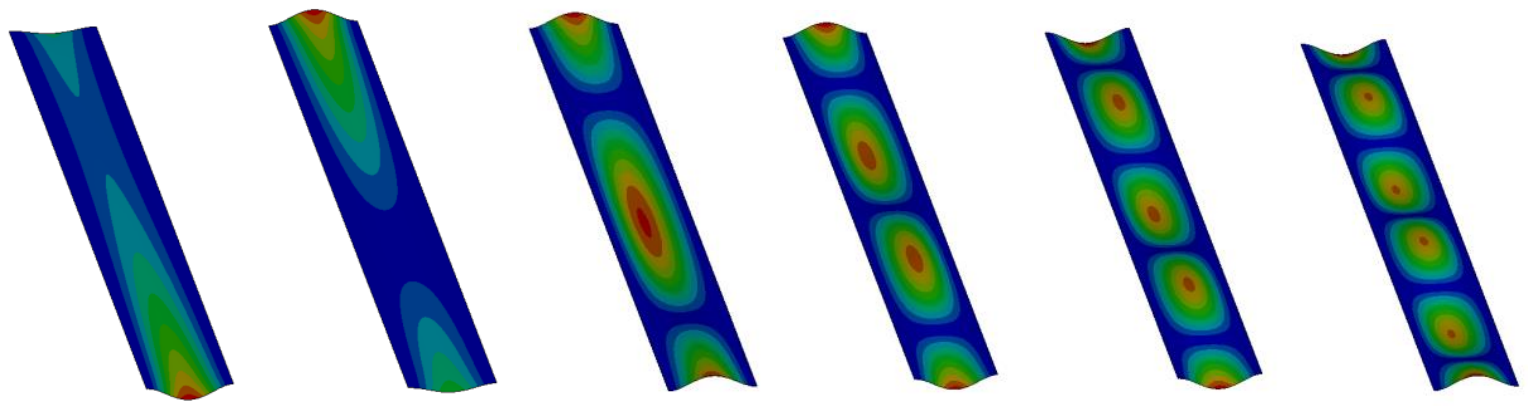

Figure B.1. Modal shapes for MITR plate associated with the first six eigenvalues
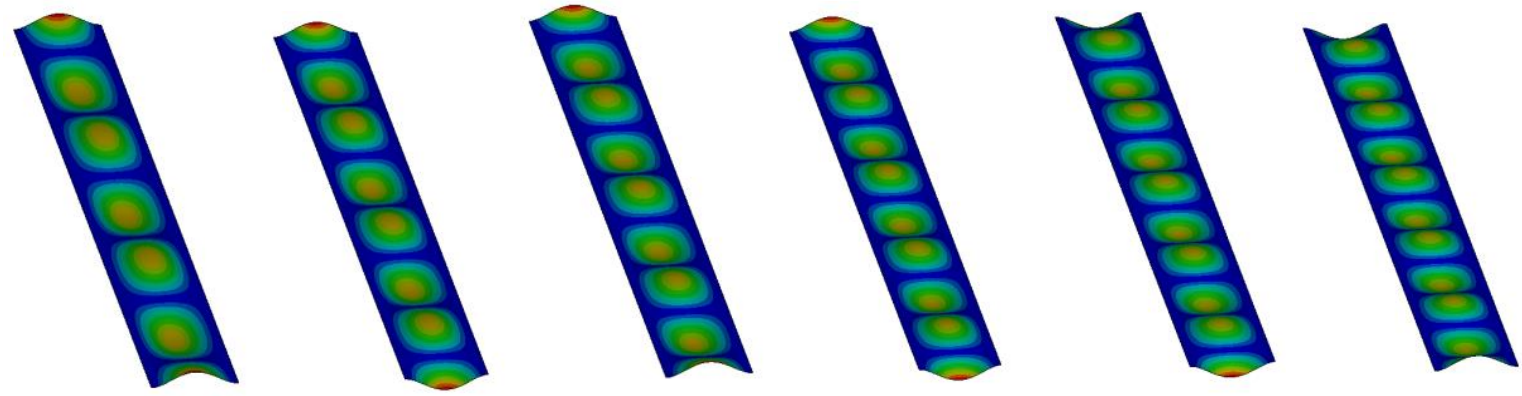

Figure B.2. Modal shapes for MITR plate associated with eigenvalues 7 to 12 


\section{Argonne $\mathbf{A}$}

\section{Nuclear Science \& Engineering Division}

Argonne National Laboratory

9700 South Cass Avenue, Bldg. 208

Argonne, IL 60439

www.anl.gov 